\title{
Critically III Older Patients Treated in Intensive Care Units : Long-Term Consequences
}

Citation for published version (APA):

Jeitziner, M. M. (2015). Critically III Older Patients Treated in Intensive Care Units : Long-Term Consequences. [Doctoral Thesis, Maastricht University]. Maastricht University. https://doi.org/10.26481/dis.20150520mj

Document status and date:

Published: 01/01/2015

DOI:

10.26481/dis.20150520mj

Document Version:

Publisher's PDF, also known as Version of record

\section{Please check the document version of this publication:}

- A submitted manuscript is the version of the article upon submission and before peer-review. There can be important differences between the submitted version and the official published version of record. People interested in the research are advised to contact the author for the final version of the publication, or visit the DOI to the publisher's website.

- The final author version and the galley proof are versions of the publication after peer review.

- The final published version features the final layout of the paper including the volume, issue and page numbers.

Link to publication

\footnotetext{
General rights rights.

- You may freely distribute the URL identifying the publication in the public portal. please follow below link for the End User Agreement:

www.umlib.nl/taverne-license

Take down policy

If you believe that this document breaches copyright please contact us at:

repository@maastrichtuniversity.nl

providing details and we will investigate your claim.
}

Copyright and moral rights for the publications made accessible in the public portal are retained by the authors and/or other copyright owners and it is a condition of accessing publications that users recognise and abide by the legal requirements associated with these

- Users may download and print one copy of any publication from the public portal for the purpose of private study or research.

- You may not further distribute the material or use it for any profit-making activity or commercial gain

If the publication is distributed under the terms of Article $25 \mathrm{fa}$ of the Dutch Copyright Act, indicated by the "Taverne" license above, 


\section{Critically Ill Older Patients Treated in Intensive Care Units \\ Long-Term Consequences}

Marie-Madlen Jeitziner 


\section{Critically Ill Older Patients Treated in Intensive Care Units Long-Term Consequences}

Design, Illustrations, Layout Tausendundeins|Simone Streit|Köniz info@tausendundeins.ch

\section{Printed by}

Ackermanndruck|Köniz

ISBN: 978-3-033-05020-4

๔ Marie-Madlen Jeitziner, 2015

\section{Dissertation}

to obtain the degree of Doctor at Maastricht University, on the authority of the Rector Magnificus,

Prof. dr. L.L.G. Soete

in accordance with the decision of the Board of Deans,

to be defended in public

on Wednesday May 20th, 2015 at 12.00 hours

by

Marie-Madlen Jeitziner 


\section{Supervisor}

Prof. dr. J.P.H. Hamers

\section{Co-Supervisors}

Dr. S.M.G. Zwakhalen

Dr. V. Hantikainen, University of Applied Sciences St. Gallen, Switzerland

\section{Assessment Committee}

Prof. dr. G.I.J.M. Kempen (chair)

Prof. dr. E.A. Capezuti, City University of New York, United States

Dr.W.J. Mulder

Prof. dr. M.L. Peters

Prof. dr. M. Simon, University of Basel, Switzerland

\section{Contents}

\section{Chapter 1 General Introduction}

Chapter 2 Pain Patterns in Critically III Older Patients During the First Days in an Intensive Care Unit

A Prospective Observational Study

Chapter 3

Long-Term Consequences of an Intensive Care Unit Stay in Older Critically III Patients

Design of a Longitudinal Study

Chapter 4

Long-Term Consequences of Pain, Anxiety, and Agitation for Critically III Older Patients after an Intensive Care Unit Stay

Chapter $5 \quad$ Changes in Health-Related Quality of Life in Critically III Older Patients One Year After an Intensive Care Unit Stay

Chapter 6 Healthcare Resource Utilization by Critically III Older Patients Following an Intensive Care Unit Stay

Chapter 7

General Discussion

Summary

Samenvatting

Acknowledgement

Curriculum vitae

Chapter $8 \quad$ Valorization 


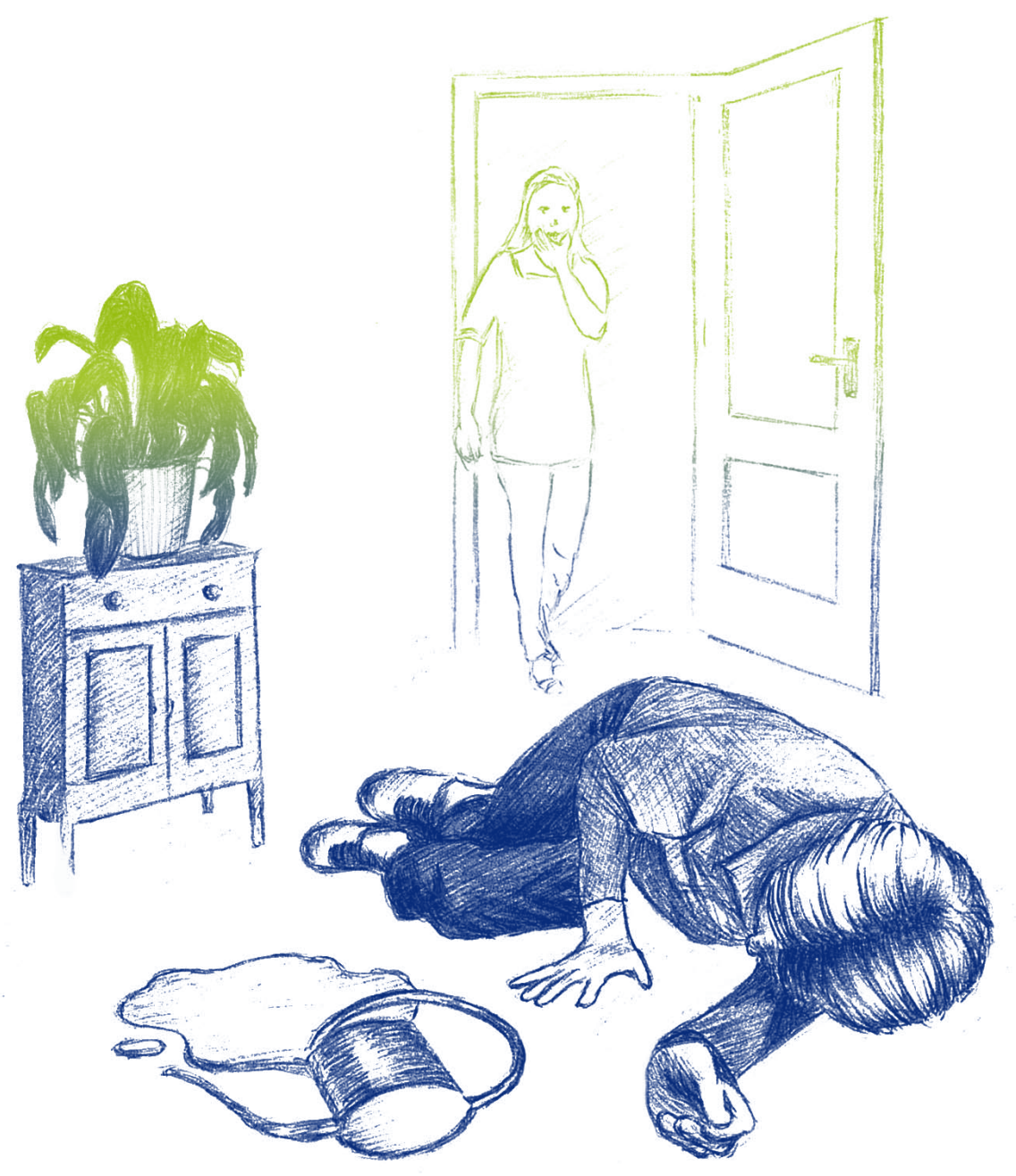


$1 / 8$

Chapter 1

General Introduction 


\section{Introduction}

«All would live long, but none would be old.»

Benjamin Franklin 1706-1790

\section{Challenges in Caring for an Aging Population in Intensive Care Units}

The demographic structure of the industrialized world is shifting towards a higher proportion of older people. Eight percent of the population was older than 60 years of age in 1950. By $2000,10 \%$ of the population was at least 60 , but by 2050 , the percentage of older people will more than double. ${ }^{1}$ Because life expectancy is increasing, the number of very old persons is also increasing. As a result of this demographic shift, the numbers of intensive care unit (ICU) hospitalizations for older patients with acute critical illnesses is also predicted to increase. ${ }^{2-7}$

About $50 \%$ of all ICU admissions are for patients over 65 years of age. ${ }^{2,8}$ Experts estimate that the growing numbers of critically ill older patients treated in ICUs will increase the need for ICU beds by $72.4 \% .{ }^{4}$ Progress in medicine, nursing, and healthcare technology allows a higher proportion of critically ill older patients to survive life-threatening illnesses. The reasons older patients are hospitalized for ICU treatment include exacerbations of chronic illnesses, new catastrophic health problems, trauma caused by homerelated accidents and injury, accidents outside the home, ${ }^{2,3,9,10}$ unplanned or planned surgical procedures, ${ }^{9,11}$ illnesses, ${ }^{3,11,12}$ and end-of-life situations. ${ }^{11,13}$

Caring for critically ill older patients who are experiencing a serious or life-threatening illness often poses significant challenges for nurses and physicians, both during and after an ICU stay. ${ }^{10,14}$ Older patients are an extremely heterogeneous group but share two key issues: limited physiological reserves due to aging, and multiple co-morbid (chronic) illnesses that often place them in a vulnerable situation. ${ }^{10} \mathrm{An}$ $\mathrm{CU}$ admission, including diagnostic or treatment procedures, can present a heavy burden for critically ill older patients resulting in distress due to pain, anxiety, and agitation. These symptoms are often unrecognized and inadequately treated, leading to longer ICU stays and increased complications. ${ }^{15-17}$ In addition to symptom distress during an ICU stay, post-ICU syndromes, such as cognitive impairment and functional decline, are a growing concern for nurses, physicians, and scientists. ${ }^{18-20}$ These problems are not unique for critically ill older patients; they are a risk for al patients experiencing a critical illness. ${ }^{18-21}$ However critically ill older patients have been found to have higher rates of cognitive impairment or functional decline, ${ }^{22,23}$ as well as a more complex recovery period.
Mortality, health-related quality of life (HROoL), and healthcare resource utilization for older patients following an ICU stay have been examined in prior research. ${ }^{24-26}$ Considerable variability in long-term consequences following an ICU stay was found for critically ill older patients. One to seven years after an ICU stay, the mortality rate was between $21 \%$ and $76 \%{ }^{3,27,28}$ Factors such as the primary diagnosis, physiological reserve, co-morbid (chronic) illness, having a fatal disease, or admission from a nursing home are highly correlated with mortality in critically ill older patients. ${ }^{411,29,30}$ In addition to mortality, HRQoL must be considered to be equally important as a long-term consequence, since HROoL takes the patient perspective into account. ${ }^{24,31}$ In general, HRQoL following an ICU stay is variable and has variously been shown to remain stable, ${ }^{3}$ improve, ${ }^{32,33}$ or worsen. ${ }^{34,35}$ Healthcare resource utilization is increasingly being discussed as an important long-term consequence of ICU stays for critically ill older patients. ${ }^{36,37}$ Continuity of care is essential but resource-intensive for these patients. ${ }^{3,36,38}$ Studies show varying discharge destinations as well as varying levels of support for older patients after an ICU stay. Possible discharge destinations are long-term acute-care hospitals, inpatient or outpatient rehabilitation programs, nursing homes, or directly to home., 31,38,39 The level of function varies from independent to totally dependent. 11,35 Most patients treated in an ICU will experience pain, anxiety, and agitation; ${ }^{40-44}$ however, the association of experiencing these symptoms with long-term consequences for critically ill older patients is not known. These symptoms have been previously examined in relation to HRQoL, ${ }^{24}$ post-traumatic stress disorder (PTSD), ${ }^{20}$ or delirium, ${ }^{15}$ but have been rarely studied as individual long-term consequences. Critically ill older patients tend to underreport their symptoms, perhaps because they accept or believe their symptoms to be normal signs of aging. ${ }^{45}$

The need for increased capacity to treat older patients in an ICU and the lack of evidence concerning the long-term benefits of intensive medical therapy means that there is a need for research in the area of long-term consequences. ${ }^{4,24,37}$ Knowledge of long-term consequences for older patients who survive a critical illness is important for older patients and their relatives, for the nurses and physicians caring for these patients, and for the community-based health service providers who plan and provide essential heathcare services. It also optimimizes the allocation of resources and confirms or invalidates the appropriateness of treatment decisions for critically ill older patients. Understanding long-term consequences after an ICU stay is becoming increasingly important in broader level clinical, social, and healthpolicy discussions. ${ }^{46}$ Consequently, research on the long-term consequences for older patients after an ICU stay is necessary as greater progress in diagnostic and therapeutic tech nologies opens up new treatment possibilities. ${ }^{47-49}$ 


\section{Consequences of an Intensive Care Unit Stay}

Pain, Anxiety, and Agitation

Pain is reported by more than $50 \%$ of the patients treated in an ICU, ${ }^{41,43,44,50}$ and recent evidence suggests that this pain may persist after ICU discharge, with half of the patients developing chronic pain. ${ }^{51-53}$ Pain is described as 'an unpleasant sensory and emotional experience associated with actual or potential tissue damage, or described in terms of such damage. ${ }^{54}$ Because many ICU patients are unable to self-report their pain due to an altered level of consciousness, mechanical ventilation or being sedated, ${ }^{15}$ pain is often under-recognized and undertreated. ${ }^{15,50}$ Critically ill older patients have additional challenges due to age-related changes in vision, hearing, and cognition. Exposure to intense pain and stress during medical and nursing procedures could be a risk factor that contributes to the transition from acute to persistent pain which is a major impairment of the neurological pain system. ${ }^{53}$ Sepsis, acute respiratory distress symptoms, and unrelieved pain are risk factors for the transition to chronicity. ${ }^{51-53}$ Insufficiently treated pain has also been recognized as a risk factor for post-ICU syndrom, which encompasses new or worsening impairment in the physical, cognitive, or mental health status after critical illness and beyond acute-care hospitalization. ${ }^{55}$ Medical and surgical ICU patients who recall pain and other traumatic situations while in the ICU have a higher incidence of persistent pain and symptoms of post-traumatic stress disorder. ${ }^{56}$ Most previous studies have examined persistent pain in the ICU patient within a certain age range or as part of HROLL. ${ }^{32,33,52}$ However, specific information on pain as a long-term consequence is scarce for critically ill older patients.

As with pain, anxiety is another symptom that causes extreme distress for patients during an ICU stay. ${ }^{42,57}$ Anxiety is a feeling of dread, fear, or lack of control; it is a normal or protective response to a perceived threat. ${ }^{42,58}$ The incidence of anxiety in ICU patients ranges from $46 \%$ to $66 \%{ }^{59,60}$ Prior research has shown that months after ICU discharge, many patients report negative emotional outcomes such as anxiety or depression, including PTSD. ${ }^{20,61,62}$ Anxiety after an ICU stay was also associated with an impairment in psychological functioning and a lower HROoL. ${ }^{63}$ Risk factors associated with anxiety after an ICU stay include duration of mechanical ventilation ${ }^{17,64}$ and the ratio of arterial oxygen tension to inspired oxygen fraction. ${ }^{64}$ However, few studies have examined anxiety as a long-term consequence in critically ill older patients.

Agitation, which often results from pain or anxiety, ${ }^{42,65}$ has been reported in $16 \%$ to $52 \%$ of ICU patients. ${ }^{16,66}$ Agitation includes physical and emotional distress. ${ }^{65}$ Severe agitation is associated with adverse events including longer ICU stays, prolonged mechanical ventilation, and self-extubation. ${ }^{66}$
Agitation is primarily evaluated in relation to delirium, ICU syndrome, or the depth of sedation ${ }^{15,16,65}$ and is considered to be a risk factor for a later development of PTSD. ${ }^{20}$ Poor recovery after delirium is common, ${ }^{67}$ but agitation as a long-term consequence in critically ill older patients has rarely been reported. These gaps in knowledge about pain, anxiety, and agitation in critically ill older patients are very important as foci for future research, because early recognition, treatment, and long-term evaluation of pain, anxiety, and agitation, can potentially reduce the likelihood of adverse consequences, such as physical restrictions or emotional changes in this vulnerable population. Nurses are integral to ensuring assessment and treatment of these three symptoms in older patients during and after their ICU stays. Better understanding of these symptoms during and after the ICU stay can inform the design of improved nursing care interventions for critically ill older patients during and following the ICU experience.

\section{Health-Related Quality of Life}

Quality of life as applied to health (HROoL) is a subjective evaluation of personal well-being and reflects only those dimensions that can be altered by disease or its treatment. ${ }^{68}$ Studies of $\mathrm{HROOL}$ in critically ill older patients following treatment in an ICU are inconclusive in that they report improvement, ${ }^{32,33}$ no change, ${ }^{3}$ or worsening HRQoL. ${ }^{34,35}$ The physical aspects of HRQoL may show improvement or no change over many years; ${ }^{24}$ the mental and emotional aspects of HROOL in critically ill older patients were found to be comparable to changes observed in the general population. ${ }^{3,24}$ Acceptance of disability is, in general, higher among critically ill older patients, and even more so for patients with strong social resources. $3,34,35$ There is growing evidence that factors other than age alone are related to changes in HROoL, such as organ or system failure. ${ }^{24}$ These mixed findings should be interpreted with caution because of the variation in study design, constant improvements in intensive care medical therapies, the tendency of older patients to be more adaptive, and because ICU triage for critically ill older patients differed in the various studies. ${ }^{24,35,69}$ Understanding HROoL for critically ill older patients is important, particularly since the benefit of treating older patients in the ICU may be debated. In addition, effective treatments and interventions during an ICU stay and in rehabilitation programs are being developed to improve the care and outcomes for critically ill older patients. Nurses will have an important role in initiating and evaluating new treatments and interventions. Further research into the HROOL of critically ill older patients is needed as a basis for enhanced interventions during and after ICU care. 


\section{Healthcare Resource Utilization}

Current financial pressure on healthcare budgets, plus the risk of long-term cognitive impairment or functional decline post-ICU stay, not only requires the analysis of resource utilization during the ICU stay, but also requires an approach to evaluating healthcare resource utilization following ICU discharge. Nurses have an essential role in facilitating a patient's ability to access appropriate resources following an ICU stay. They also have care-related responsibilities for patients following the ICU stay. Previous studies have shown that critically ill older patients need close medical follow-up and are prescribed substantial amounts of medication. ${ }^{36,70,71}$ Following an ICU stay, older patients are often transferred to other institutions such as long-term acutecare hospitals, rehabilitation centers or nursing homes, although some patients are discharged directly home. ${ }^{36,38,39}$ Recent studies report that between $72 \%$ and $97 \%$ of these patients eventually return home after an ICU stay. 3,72 Severe illnesses, such as neurological disease, neoplasia, chronic heart failure, or complications during the ICU stay, and a higher age, all reduce the probability of being able to return home. ${ }^{72}$ Results of studies conducted on healthcare resource utilization in one country are often not readily translatable to other countries due to differences in healthcare systems and variations in supportive services for older patients. Studies on healthcare resource utilization by critically ill older patients within specific healthcare systems and countries are imperative to improve the available healthcare resources. Knowledge of healthcare resource utilization is essential for service planning and resource allocation, particularly where acute care and community care intersect. ${ }^{37}$

The steadily increasing numbers of older patients who survive ICU treatment illustrate the relevance of this subject. As we learn more about long-term consequences in critically ill older patients, our understanding of their specific long-term needs wil grow. This understanding will allow nurses, physicians, and scientists to begin, even during the ICU stay, to modify factors that influence long-term consequences and to develop specifically-tailored follow-up programs for critically ill older patients.

\section{Aim and Research Questions}

The overall aim of this study was to identify how an ICU stay influences older patients' experiences later in life. A prospective non-randomized longitudinal study, with a one-year follow-up was planned to address this research aim. Data from a group of critically ill older patients and a group of age-matched participants from the general population were compared three times: at baseline (one week after discharge) and after 6 and 12 months.

The study addressed the following research questions:

- Which patterns of pain are found in critically ill older patients during their ICU stay?

- Does an ICU stay influence pain, anxiety, and agitation experienced by critically ill older patients 1 week after discharge, and at 6- and 12-months follow-up?

- Does pain, anxiety, and agitation experienced by critically ill older patients during an ICU stay affect the experiences of these symptoms 1 week after discharge, and at 6 - and 12-months follow-up?

- Does having been treated in an ICU affect the HROQL of critically ill older patients after 6 - and 12-months follow-up?

- What is the association between an ICU stay and the subsequent use of the following healthcare resources: length of stay, (re)admission to hospital or ICU, general practitioner (GP) visits, participation in rehabilitation programs, medication use, living situation and survival, in critically ill older patients 6 and 12 months after hospital discharge? 


\section{Contents of the Thesis}

Chapter 2 reports pain patterns of critically ill older patients during the ICU stay. The data were obtained through observations of older patients during both painful ICU interventions (e.g., intratracheal suctioning, turning, wound care, chest tube insertion and removal) and at rest (no procedures). Pain patterns and intensity were documented. Based on these results, specific interventions in pain management can be developed.

Chapter 3 presents the design of the main study. This was a prospective non-randomized longitudinal study of the long-term consequences of pain, anxiety, agitation, HRQoL, and healthcare resource utilization by critically ill older patients over a 12-month period. The consequences were compared to an agematched group selected from the general population. Information is provided on the recruitment of participants, the measurements, follow-up, data collection, and analyses.

Chapter 4 describes long-term pain, anxiety, and agitation, in critically ill older patients following an ICU stay. Pain, anxiety, and agitation, in critically ill older patients were compared to pain, anxiety, and agitation, in age-matched community-based participants one week post-ICU discharge|at study recruitment, and after 6 and 12 months.

Chapter 5 compares changes in HROoL over 12 months for critically ill older patients and compares these changes to the age-matched community-based participants. Measurements were taken one week post-ICU discharge at study recruitment, and after 6 and 12 months. In addition, patient-related factors and ICU-related factors associated with long-term changes in HRQoL were identified.

Chapter 6 examines healthcare resource utilization in critically ill older patients after an ICU stay, as compared to healthcare resource utilization in the age-matched community-based participants over 12 months. Data were collected on mortality, length of ICU and hospital stays, hospital or ICU (re)admission, general practitioner and medical specialist visits, rehabilitation program participation, medication use, discharge destination, home healthcare service use, and level of dependence for daytoday activities.

Chapter 7 summarizes the main findings and discusses methodological and theoretical issues. In addition, future directions for practice and research are examined and a summary of the findings of this study is presented.

\section{References}

1 Alterung der Weltbevölkerung: 1950-2050 Zusammenfassung [Internet]. 2002 "Aging of the World's population: 1950-2050 summary" [cited 2014 May 18]. Available from:

http://www.un.org/esa/population/publications/worldageing19502050/pdf/german_execsum.pdf.

2 Vosylius S, Sipylaite J, Ivaskevicius J. Determinants of outcome in elderly patients admitted to the intensive care unit. Age Ageing. 2005;34(2):157-62.

3 Kaarlola A, Tallgren M, Pettilä V. Long-term survival, quality of life, and quality-adjusted life-years among critically ill elderly patients. Crit Care Med. 2006;34(8):2120-6.

4 Bagshaw SM, Webb SA, Delaney A, George C, Pilcher D, Hart GK, Bellomo R. Very old patients ad mitted to intensive care in Australia and New Zealand: a multi-centre cohort analysis. Crit Care. 2009;13(2): R45.

5 Chelluri L, Pinsky MR, Donahoe MP, Grenvik A. Long-term outcome of critically ill elderly patients requiring intensive care. JAMA. 1993;269(24):3119-23.

6 Tabah A, Philippart F, Timsit JF, Willems V, Français A, Leplège A, Carlet J, Bruel C, Misset B, Garrouste-Orgeas M. Quality of life in patients aged 80 or over after ICU discharge. Crit Care. 2010;14(1):R2

7 Reinikainen M, Uusaro A, Niskanen M, Ruokonen E. Intensive care of the elderly in Finland. Acta Anaesthesiol Scand. 2007;51(5):522-9.

8 Brandberg $\mathrm{C}$, Blomqvist $\mathrm{H}$, Jirwe $\mathrm{M}$. What is the importance of age on treatment of the elderly in the intensive care unit? Acta Anaesthesiol Scand. 2013;57(6):698-703.

9 Saxena A, Dinh DT, Yap CH, Reid CM, Billah B, Smith JA, Shardey GC, Newcomb AE. Critical analysis of early and late outcomes after isolated coronary artery bypass surgery in elderly patients. Ann Thorac Surg. 2011;92(5):1703-11

10 Marik PE. Management of the critically ill geriatric patient. Crit Care Med. 2006;34(9 Suppl): S176-82.

11 de Rooij SE, Govers AC, Korevaar JC, Giesbers AW, Levi M, de Jonge E. Cognitive, functional, and quality-of-life outcomes of patients aged 80 and older who survived at least 1 year after planned or unplanned surgery or medical intensive care treatment. I Am Geriatr Soc. 2008:56(5):816-22

12 Daubin C, Chevalier S, Séguin A, Gaillard C, Valette X, Prévost F, Terzi N, Ramakers M, Parienti J, du Cheyron D, Charbonneau P. Predictors of mortality and short-term physical and cognitive dependence in critically ill persons 75 years and older: a prospective cohort study. Health Oual Life Outcomes. 2011;9:35.

13 Angus DC, Barnato AE, Linde-Zwirble WT, Weissfeld LA, Watson RS, Rickert T, Rubenfeld GD. Use of intensive care at the end of life in the United States: an epidemiologic study. Crit Care Med. 2004;32(3):638-43.

14 Boltz M. A system-level approach to improving the care of the older critical care patient. AACN Adv Crit Care. 2011;22(2):142-9. 
15 Barr J, Fraser GL, Puntillo K, Ely EW, Gélinas C, Dasta JF, Davidson JE, Devlin JW, Kress JP, Joffe AM, Coursin DB, Herr DL, Tung A, Robinson BR, Fontaine DK, Ramsay MA, Riker RR, Sessler CN, Pun B, Skrobik Y, Jaeschke R. Clinical practice guidelines for the management of pain, agitation, and delirium in adult patients in the intensive care unit. Crit Care Med. 2013;41(1):263-306.

16 Jaber S, Chanques G, Altairac C, Sebbane M, Vergne C, Perrigault PF, Eledjam JJ. A prospective study of agitation in a medical-surgical ICU: incidence, risk factors, and outcomes. Chest. 2005;128(4):2749-57.

17 Chlan L, Savik K. Patterns of anxiety in critically ill patients receiving mechanical ventilatory support. Nurs Res. 2011;60(3 Suppl):S50-7.

18 Cuthbertson BH, Roughton S, Jenkinson D, Maclennan G, Vale L. Quality of life in the five years after intensive care: a cohort study. Crit Care. 2010;14(1):R6.

19 Pandharipande PP, Girard TD, Jackson JC, Morandi A, Thompson JL, Pun BT, Brummel NE, Hughes CG, Vasilevskis EE, Shintani AK, Moons KG, Geevarghese SK, Canonico A, Hopkins RO, Bernard GR, Dittus RS, Ely EW. Long-term cognitive impairment after critical illness. N Engl J Med. 2013;369(14):1306-16

20 Desai SV, Law TJ, Needham DM. Long-term complications of critical care. Crit Care Med. 2011;39(2):371-9.

21 Rattray J. Life after critical illness: an overview. J Clin Nurs. 2014;23(5-6):623-33.

22 Dowdy DW, Eid MP, Sedrakyan A, Mendez-Tellez PA, Pronovost PJ, Herridge MS, Needham DM Ouality of life in adult survivors of critical illness: a systematic review of the literature. Intensive Care Med. 2005;31(5):611-20.

23 Hope AA, Morrison RS, Du Q, Wallenstein S, Nelson JE. Risk factors for long-term brain dysfunction after chronic critical illness. Ann Am Thorac Soc. 2013;10(4):315-23.

24 Oeyen SG, Vandijck DM, Benoit DD, Annemans L, Decruyenaere JM. Quality of life after intensive care: a systematic review of the literature. Crit Care Med. 2010;38(12):2386-400.

25 Wunsch H, Guerra C, Barnato AE, Angus DC, Li G, Linde-Zwirble WT. Three-year outcomes for Medicare beneficiaries who survive intensive care. JAMA. 2010;303(9):849-56.

26 Duke GJ, Barker A, Knott CI, Santamaria JD. Outcomes of older people receiving intensive care in Victoria. Med J Aust. 2014;200(6):323-6.

27 de Rooij SE, Govers A, Korevaar JC, Abu-Hanna A, Levi M, de Jonge E. Short-term and long-term mortality in very elderly patients admitted to an intensive care unit. Intensive Care Med. 2006;32(7):1039-44

28 Pavoni V, Gianesello L, Paparella L, Buoninsegni LT, Mori E, Gori G. Outcome and quality of life of elderly critically ill patients: an Italian prospective observational study. Arch Gerontol Geriatr. 2012;54(2):193-8

29 Taylor MD, Tracy JK, Meyer W, Pasquale M, Napolitano LM. Trauma in the elderly: intensive care unit resource use and outcome. J Trauma. 2002;53(3):407-14.

30 Mattison ML, Rudolph JL, Kiely DK, Marcantonio ER. Nursing home patients in the intensive care unit: Risk factors for mortality. Crit Care Med. 2006;34(10):2583-7.
31 Hofhuis JG, van Stel HF, Schrijvers AJ, Rommes JH, Bakker J, Spronk PE. Conceptual issues specifically related to health-related quality of life in critically ill patients. Crit Care. 2009;13(1):118.

32 Hofhuis JG, van Stel HF, Schrijvers AJ, Rommes JH, Spronk PE. Changes of health-related quality of life in critically ill octogenarians: a follow-up study. Chest. 2011;140(6):1473-83.

33 Vest MT, Murphy TE, Araujo KL, Pisani MA. Disability in activities of daily living, depression, and quality of life among older medical ICU survivors: a prospective cohort study. Health Qual Life Outcomes. 2011;9:9.

34 Merlani P, Chenaud C, Mariotti N, Ricou B. Long-term outcome of elderly patients requiring intensive care admission for abdominal pathologies: survival and quality of life. Acta Anaesthesio Scand. 2007;51(5):530-7.

35 Montuclard L, Garrouste-Orgeas M, Timsit JF, Misset B, De Jonghe B, Carlet J. Outcome, func tional autonomy, and quality of life of elderly patients with a long-term intensive care unit stay. Crit Care Med. 2000;28(10):3389-95.

36 Douglas SL, Daly BJ, O'Toole EE, Kelley CG, Montenegro H. Age differences in survival outcomes and resource use for chronically critically ill patients. J Crit Care. 2009;24(2):302-10

37 Lone NI, Seretny M, Wild SH, Rowan KM, Murray GD, Walsh TS. Surviving intensive care: a systematic review of healthcare resource use after hospital discharge. Crit Care Med. 2013;41(8):1832-43.

38 Szubski CR, Tellez A, Klika AK, Xu M, Kattan MW, Guzman JA, Barsoum WK. Predicting discharge to a long-term acute care hospital after admission to an intensive care unit. Am J Crit Care. 2014;23(4):e46-53.

39 Aitken LM, Burmeister E, Lang J, Chaboyer W, Richmond TS. Characteristics and outcomes of injured older adults after hospital admission. J Am Geriatr Soc. 2010;58(3):442-9.

40 Novaes MA, Aronovich A, Ferraz MB, Knobel E. Stressors in ICU: patients' evaluation. Intensive Care Med. 1997;23(12):1282-5.

41 Puntillo KA, Morris AB, Thompson CL, Stanik-Hutt J, White CA, Wild LR. Pain behaviors observed during six common procedures: results from Thunder Project II. Crit Care Med. 2004;32(2):421-7.

42 Tate JA, Devito Dabbs A, Hoffmann LA, Milbrandt E, Happ MB. Anxiety and agitation in mechanically ventilated patients. Qual Health Res. 2012;22(2):157-73.

43 Chanques G, Sebbane M, Barbotte E, Viel E, Eledjam JJ, Jaber S. A prospective study of pain at rest: incidence and characteristics of an unrecognized symptom in surgical and trauma versus medical intensive care unit patients. Anesthesiology. 2007;107(5):858-60.

44 Puntillo KA, Max A, Timsit JF, Vignoud L, Chanques G, Robleda G, Roche-Campo F, Mancebo J, Divatia JV, Soares M, Ionescu DC, Grintescu IM, Vasiliu IL, Maggiore SM, Rusinova K, Owczuk R, Egerod I, Papathanassoglou ED, Kyranou M, Joynt GM, Burghi G, Freebairn RC, Ho KM, Kaarlola A Gerritsen RT, Kesecioglu J, Sulaj MM, Norrenberg M, Benoit DD, Seha MS, Hennein A, Periera FJ, Benbenishty JS, Abroug F, Aquilina A, Monte JR, An Y, Azoulay E. Determinants of procedural pain intensity in the intensive care unit: The Europain ${ }^{\oplus}$ study. Am J Respir Crit Care Med. 2014:189(1):39-47.

45 Gagliese L. Pain and aging: the emergence of a new subfield of pain research.J Pain. 2009;10(4):343-53. 46 Ricou B, Merlani P. What limits for acute care in the elderly? Curr Opin Anaesthesiol. 2008;21(3):380-5. 
47 Mendiratta P, Tang X, Collins RT 2nd, Rycus P, Brogan TV, Prodhan P. Extracorporeal membrane oxygenation for respiratory failure in the elderly: A review of the Extracorporeal Life Support Organization Registry. ASAIO J. 2014;14.

48 Kaukonen KM, Bailey M, Suzuki S, Pilcher D, Bellomo R. Mortality related to severe sepsis and septic shock among critically ill patients in Australia and New Zealand, 2000-2012. JAMA. 2014;311(13):1308-16.

49 Eachempati SR, Hydo L, Shou J, Barie PS. Outcomes of acute respiratory distress syndrome (ARDS) in elderly patients. J Trauma. 2007;63(2):344-50.

50 Gélinas C. Management of pain in cardiac surgery ICU patients. Have we improved over time? Intensive Crit Care Nurs. 2007;23(5):298-303.

51 Dowdy DW, Eid MP, Dennison CR, Mendez-Tellez PA, Herridge MS, Guallar E, Pronovost PJ, Needham DM. Quality of life after acute respiratory distress syndrome: a meta-analysis. Intensive Care Med. 2006;32(8):1115-24.

52 Battle CE, Lovett S, Hutchings $\mathrm{H}$. Chronic pain in survivors of critical illness: a retrospective analysis of incidence and risk factors. Crit Care. 2013;17(3):R101.

53 Kyranou M, Puntillo K. The transition from acute to chronic pain: might intensive care unit patients be at risk? Ann Intensive Care. 2012;2(1):36.

54 Classification of chronic pain. Pain III: Pain terms, a current list with definitions and notes on usage, IASP Task Force on Taxonomy. In: Merskey H and Bogduk N, editors. Seattle: IASP Press, 1994: p. 209-14.

55 Davidson JE, Harvey MA, Bemis-Dougherty A, Smith JM, Hopkins RO. Implementation of the Pain, Agitation, and Delirium Clinical Practice Guidelines and promoting patient mobility to prevent post-intensive care syndrome. Crit Care Med. 2013;41(9 Suppl 1):S136-45.

56 Schelling G, Stoll C, Haller M, Briegel J, Manert W, Hummel T, Lenhart A, Heyduck M, Polasek J, Meier M, Preuss U, Bullinger M, Schüffel W, Peter K. Health-related quality of life and post traumatic stress disorder in survivors of the acute respiratory distress syndrome. Crit Care Med. 1998:26(4):651-9.

57 Moser DK. “The rust of life”: impact of anxiety on cardiac patients. Am J Crit Care. 2007;16(4):361-9.

58 Bay EJ, Algase DL. Fear and anxiety: a simultaneous concept analysis. Nurs Diagn. 1999;10(3):103-11.

59 Kress JP, Gehlbach B, Lacy M, Pliskin N, PohIman AS, Hall JB. The long-term psychological effects of daily sedative interruption on critically ill patients. Am J Respir Crit Care Med. 2003;168(12):1457-61

60 McKinley S, Stein-Parbury J, Chehelnabi A, Lovas J. Assessment of anxiety in intensive care patients by using the Faces Anxiety Scale. Am J Crit Care. 2004;13(2):146-52.

61 Wallen K, Chaboyer W, Thalib L, Creedy DK. Symptoms of acute posttraumatic stress disorder after intensive care. Am J Crit Care. 2008;17(6):534-43.

62 Granja C, Gomes E, Amaro A, Ribeiro O, Jones C, Carneiro A, Costa-Pereira A. Understanding posttraumatic stress disorder-related symptoms after critical care: the early illness amnesia hypothesis. Crit Care Med. 2008;36(10):2801-9.
63 Stevenson JE, Colantuoni E, Bienvenu OJ, Sricharoenchai T, Wozniak A, Shanholtz C, MendezTellez PA, Needham DM. General anxiety symptoms after acute lung injury: predictors and correlates. J Psychosom Res. 2013;75(3):287-93.

64 Hopkins RO, Weaver LK, Chan KJ, Orme Jr JF. Quality of life, emotional, and cognitive function following acute respiratory distress syndrome. J Int Neuropsychol Soc. 2004;10(7):1005-17.

65 Chevrolet JC, Jolliet P. Clinical review: agitation and delirium in the critically ill-significance and management. Crit Care. 2007;11(3):214.

66 Woods JC, Mion LC, Connor JT, Viray F, Jahan L, Huber C, McHugh R, Gonzales JP, Stoller JK, Arroliga AC. Severe agitation among ventilated medical intensive care unit patients: frequency, characteristics and outcomes. Intensive Care Med. 2004;30(6):1066-72.

67 Pisani MA, Kong SY, Kasl SV, Murphy TE, Araujo KL, Van Ness PH. Days of delirium are associated with 1-year mortality in an older intensive care unit population. Am J Respir Crit Care Med. 2009;180(11):1092-7.

68 Azoulay E, Kentish-Barnes N, Pochard F. Health-related quality of life: an outcome variable in critical care survivors. Chest. 2008;133(2):339-41.

69 Sprung CL, Artigas A, Kesecioglu J, Pezzi A, Wiis J, Pirracchio R, Baras M, Edbrooke DL, Pesenti A Bakker J, Hargreaves C, Gurman G, Cohen SL, Lippert A, Payen D, Corbella D, Iapichino G. The Eldicus prospective, observational study of triage decision making in European intensive care units. Part II: intensive care benefit for the elderly. Crit Care Med. 2012;40(1):132-8.

70 Sage WM, Hurst CR, Silverman JF, Bortz WM. Intensive care for the elderly: outcome of elective and nonelective admissions. J Am Geriatr Soc. 1987;35(4):312-8.

71 Williams TA, Leslie GD, Brearley L, Dobb GJ. Healthcare utilisation among patients discharged from hospital after intensive care. Anaesth Intensive Care. 2010;38(4):732-9.

72 Conti M, Friolet R, Eckert P, Merlani P. Home return 6 months after an intensive care unit admission for elderly patients. Acta Anaesthesiol Scand. 2011;55(4):387-93. 


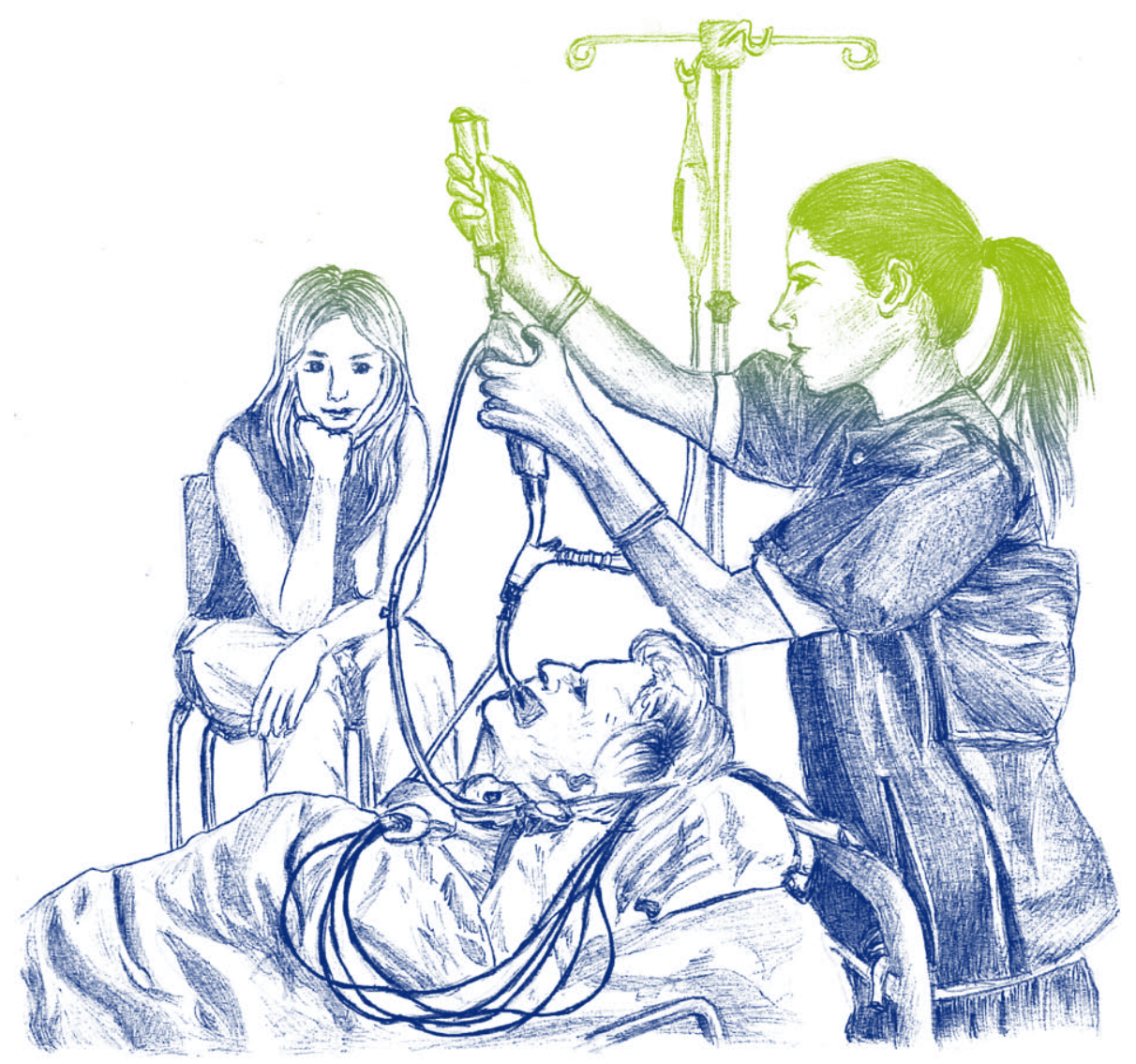




\section{Chapter 2}

Pain Patterns in Critically Ill Older Patients During the First Days in an Intensive Care Unit

A prospective observational study 


\section{Abstract}

\section{Context}

Pain is a distressing problem in intensive care units (ICUs). Effective pain assessment and management have previously been reported to be problematic in ICU settings. Existing research to identify the level and trajectory of pain patterns in ICU patients during the first days of ICU treatment is limited.

\section{Objectives}

To examine pain patterns in critically ill older patients during the first three ICU days, and to identify differences in pain patterns between severely versus moderately ill older patients.

\section{Methods}

A prospective, observational study was performed in the interdisciplinary (medicalsurgical) ICU of a university hospital. Pain was assessed every four hours during the first three ICU days. Pain intensity was measured with a numeric rating scale (NRS), verbal rating scale (VRS), and behavioral assessment scale. Descriptive analyses were performed to identify pain patterns.

\section{Results}

The sample consisted of 141 ICU patients (mean age: 68.77). The majority (55\%) were treated for heart disease. Pain levels were relatively stable and consistent at a low intensity. Mean pain scores were highest on day 1 and slowly decreased to reach the lowest levels on day 3. NRS scores: Day 1: 3.96 (SD 3.58); Day 2: 3.84 (SD 2.79); Day 3: 2.37 (SD 1.74). Pain patterns were stable in severely ill patients and variable in moderately ill patients.

\section{Conclusion}

Using multiple methods of assessment, this study demonstrated that older patients in an ICU do not experience high levels of pain. Pain is perceived as low and decreases steadily over the first three days.

\section{Introduction}

The number of critically ill older patients hospitalized in intensive care units (ICUs) is increasing. ${ }^{1}$ These older patients are confronted with pain and stressful experiences related to multiple intrinsic and extrinsic sources and standard ICU interventions. ${ }^{2,3}$ Pain, in general, is a distressing and frequent problem in an ICU. ${ }^{4-6}$ Medical and surgical critically ill patients routinely experience pain at rest and during routine care ${ }^{2,7}$ due to surgery, trauma or cancer, ${ }^{4,8,9}$ as well as due to various procedures. ${ }^{7,10,11}$

Current clinical practice guidelines document that pain assessment and management remains challenging during the ICU stay ${ }^{3,12,13}$ and can be particularly difficult in critically ill older patients. In addition to mechanical ventilation, changes in the level of consciousness and high doses of sedatives, ${ }^{3}$ older patients have complexities of age-related changes in vision, hearing, cognition, co-morbidity, reduced physiological reserve, ${ }^{14,15}$ and often have acute and chronic pain..$^{13}$ Older patients tend to report pain less frequently, possibly because pain perception may be altered with aging. ${ }^{16}$ The most fragile patients, in particular, are those who are older and severely ill, who often lack the ability or words to express their pain. To date, research on pain in this population is minimal. ${ }^{17}$

Identifying pain patterns may provide important clinical information to care for patients who are unable to self-report the presence and intensity of pain. ${ }^{18}$ Prior research reports mixed findings on the extent and patterns of pain in the ICU. Previous studies describing pain patterns have focused on specific groups of critically ill patients, ${ }^{18}$ such as younger patients or critically ill patients before and after painful interventions. , $^{6,19}$ In critically ill patients with brain injury, pain has been reported to decrease continuously over time, and in particular in the first days. ${ }^{18}$ The way in which pain is measured also affects the conclusions made about pain patterns in critically ill patients. For example, age differences identified in reported pain can be dependent on the specific pain assessment scale used. ${ }^{20}$ Verbal descriptive scales show lower pain in older patients whereas visual analogue scales suggest no differences with age. ${ }^{20}$

Given these mixed research findings and gaps in knowledge needed to guide clinical practice, research on pain during an ICU stay for critically ill older patients is neces sary. Increased knowledge about pain patterns in critically ill older patients during their ICU stay could help in the refinement of interventions for pain management at specific moments in time. Information on differences in pain patterns based on the severity of the illness is also needed. The aims of this study are:

1) to describe pain patterns in critically ill older patients during the first three days of the ICU stay; and,

2) to identify differences in pain patterns for moderately ill versus severely ill older patients. 


\section{Methods}

\section{Study Design}

This study utilized a prospective, observational design. Critically ill older patients were observed for pain at rest and during painful procedures during the first three days in the ICU.

\section{Setting and Participants}

The setting was an interdisciplinary (medical-surgical) 30-bed ICU of a university hospital. Patients hospitalized from December 2008 -April 2011 and who were 65 years of age and older were eligible for the study. Additional inclusion criteria were patients with a medical or surgical diagnosis and who remained in the ICU for at least 48 hours. Patients needed to understand German or French. Patients were excluded if they had cognitive impairment due to traumatic brain injury or severe dementia, psychotic illness, or palliative care due to a terminal illness (e.g., heart failure, respiratory failure)

\section{Measurement}

Pain was assessed using three scales: a numeric rating scale (NRS), a verbal rating scale (VRS), and a behavioral scale. .,20-22 $^{2}$

Numeric Rating Scale (NRS): Pain intensity was measured with the NRS (range 0-10). ${ }^{2,4,21}$ Anchors of the scale presented "no pain" at 0 , and "worst possible pain" at 10. The patients were asked to choose the number that best described their pain or point to the appropriate place on the scale. The scale was adapted slightly to account for any problems with reading small print and was enlarged to $18 \times 32 \mathrm{~cm}$ and presented in a vertical format. Chanques et al ${ }^{21}$ showed that the NRS is a valid and feasible method for rating pain intensity in an ICU.

Verbal Rating Scale (VRS): The VRS was chosen because of its established psychometric validation in older surgical patients, ${ }^{20,23}$ and because older patients prefer scales with verbal descriptors. ${ }^{24}$ The VRS uses the following indicators: "no pain" (0), "mild pain" (>1-4), "moderate pain" (>4-6), "severe pain" (>6-8), and "worst possible pain" (>8-10).

Behavioral Pain Scale: Pain intensity was measured using a behavioral pain scale for those patients who were unable to use the NRS or VRS. The behavioral pain scale employs three behavioral parameters; mimic, body movement and muscle tone. The behavioral assessment scale includes three behavioral parameters rated from 0-3 ( $0=$ weak or absent, $1=$ moderately severe, $2=$ severe, $3=$ very severe) resulting in a total score between $0-9$. The behavioral pain scale has good inter-rater reliability and content validity, and has been found to be comprehensible and simple to use in the clinical setting. ${ }^{22}$ The behavioral pain scale is a part of the ICU's standardized checklist that is systematically used to document pain management.

Demographic and background data included age, sex, ICU admission diagnosis and the Acute Physiology, Age and Chronic Health Evaluation II score (APACHE II), a severity of disease classification system, evaluated in the first $24 \mathrm{hrs}$ of ICU care. ${ }^{25}$ Pain and sedations medications (e.g., propofol, midazolam, and fentanyl) were obtained from the patient's medical records. Mechanical ventilation and length of ICU stay were also recorded based on the medical record. Depth of sedation during the first three ICU days was measured using the Richmond Agitation-Sedation Scale (RASS). The RASS has 10 levels ranging from -5 : unarousable (no response) to +4 : combative (danger to staff) and is valid and reliable to assess depth of sedation. ${ }^{26}$

\section{Data Collection Procedure}

Patient demographic information and clinical characteristics were obtained via the electronic Patient Data Management System. The bedside nurse caring for the patient assessed pain at rest and during painful procedures routinely every four hours throughout the ICU stay. All pain scores were immediately entered into the Patient Data Management System and an individual graphic pain pattern was generated. The study patients were observed by the critical care nurses who had had additional training in assessing and documenting pain. As soon as the critically ill older patients were able to respond, they were asked about their pain and the pain assessment instrument was ex plained. Depending on the depth of sedation (RASS between lightly sedated and lightly agitated) the NRS was first administered according to the ICU's current clinical practice guidelines. ${ }^{3,23}$ Patients who were unable to speak were instructed to nod or point to the place on the NRS scale that best described their pain. If the patients were not able to point to the pain assessment instrument, they were asked to blink their eyes or nod their heads when the number or the word reflected their pain intensity. When there was no answer to the NRS, the explanation of its use was repeated. If necessary, the nurse helped the patient use the NRS by either holding the scale for the patient or supporting arm or finger movement. If it was not possible to obtain NRS information, the VRS was administered in a similar manner. For patients who could not communicate (RASS: lightly sedated to non-responsive), an observation-based behavioral pain scale was used. The critical care nurse estimated pain intensity based on observational parameters. If the patient was agitated (RASS: agitated to combative), the NRS or the VRS were used. If a pain assessment could not be carried out, the reason was documented. 


\section{Ethical Considerations}

The Cantonal Ethics Committee of Bern, Switzerland approved the study. One week following discharge from the ICU, eligible patients were contacted, the study was explained, and the informed consent was obtained and signed. Patients gave their permission to use medical information collected via the Patient Data Management System during the ICU stay.

\section{Data Analysis}

Descriptive statistics were used for the demographic information and to characterize the sample. Quantitative data from pain measured during the first three days in the ICU stay were shown using frequency, mean and standard deviation (SD). The pain patterns during the first three days were presented as a time series. The first three days were chosen because in an earlier study the greatest changes in level of pain were observed during the first days in the ICU. ${ }^{18}$ Significant indicators of pain were defined as a score of $\geq 4$ on the numeric rating scale and moderate pain on the verbal rating scale. ${ }^{13}$ The behavioral scale does not designate cut-off points as behavior must be interpreted in the context of the clinical situation. The mean and standard deviation (SD) of the pain intensity was calculated for four six-hour periods by dividing the calendar day into six-hour blocks (6:00; 12:00; 18:00 and 24:00 hrs). Patients were considered to be severely ill if their APACHE II score was $\geq 18$. Moderately ill patients had an APACHE II score less than $18 .{ }^{25}$ All statistical analyses were performed with IBM SPSS Statistics 22.0 software.

\section{Results}

\section{Patient Characteristics}

One hundred forty-one critically ill older patients were recruited into the study Table 1 shows the characteristics of the patients. More than half of the patients were admitted to the ICU because of cardiac diseases. Patients were treated in the ICU on average for 4.6 days.

\section{Table 1 Demographic data and patient characteristics}

\begin{tabular}{|c|c|c|}
\hline \multicolumn{3}{|l|}{ Demographics and Characteristics } \\
\hline Age & & 68.61 \\
\hline Sex & & Women: $37(26 \%)$ \\
\hline $\begin{array}{l}\text { Mechanical ventilation } \\
\text { (mean number days) }\end{array}$ & & 2.5 (SD: 4.0) \\
\hline Length of ICU stay & & 4.6 (SD: 5.94) \\
\hline \multicolumn{3}{|l|}{$\begin{array}{l}\text { Admission Diagnosis, } \\
\text { number of subjects, (\%) }\end{array}$} \\
\hline & Cardiac diseases & $78(55 \%)$ \\
\hline & Pulmonary diseases & $20(14 \%)$ \\
\hline & Gastrointestinal diseases & $7(5 \%)$ \\
\hline & Neurological diseases & $13(9 \%)$ \\
\hline & $\begin{array}{l}\text { Others: Sepsis, trauma, burns, } \\
\text { drug over dose }\end{array}$ & $23(16 \%)$ \\
\hline APACHE II & & 20.53 (SD: 8.6) \\
\hline Moderately ill patients (APACHE II <18) & & RASS \\
\hline ICU day 1 & & -3 (range: -2 to -5 ) \\
\hline ICU day 2 & & -1 (range: -1 to -2 ) \\
\hline ICU day 3 & & -1 (no range) \\
\hline Severely ill patients (APACHE $\| \geq 18$ ) & & RASS \\
\hline ICU day 1 & & -3 (range: -2 to -4$)$ \\
\hline ICU day 2 & & -1 (range: -2 to 4$)$ \\
\hline ICU day 3 & & -1 (no range) \\
\hline
\end{tabular}

Note: Data expressed as mean (standard deviation (SD)), median (range) or number (\%). Abbreviations: APACHE=Acute Physiology, Age and Chronic Health Evaluation. RASS=Richmond Agitation-Sedation Score, ICU=Intensive Care Unit. 


\section{Pain Patterns During the First Three Days of the ICU Stay}

Overall, low levels of pain with relatively stable and consistent pain patterns were identified (Figure 1). Mean pain scores were highest on day 1 and slowly decreased to reach the lowest levels on day 3 (NRS mean score at 6:00 AM: day 1: 3.96, (SD 3.58); NRS mean day 2: 3.84, (SD 2.79); NRS mean day 3: 2.37, (SD 1.74)) (Figure 1).

\section{Figure 1 Pain patterns during ICU stay}

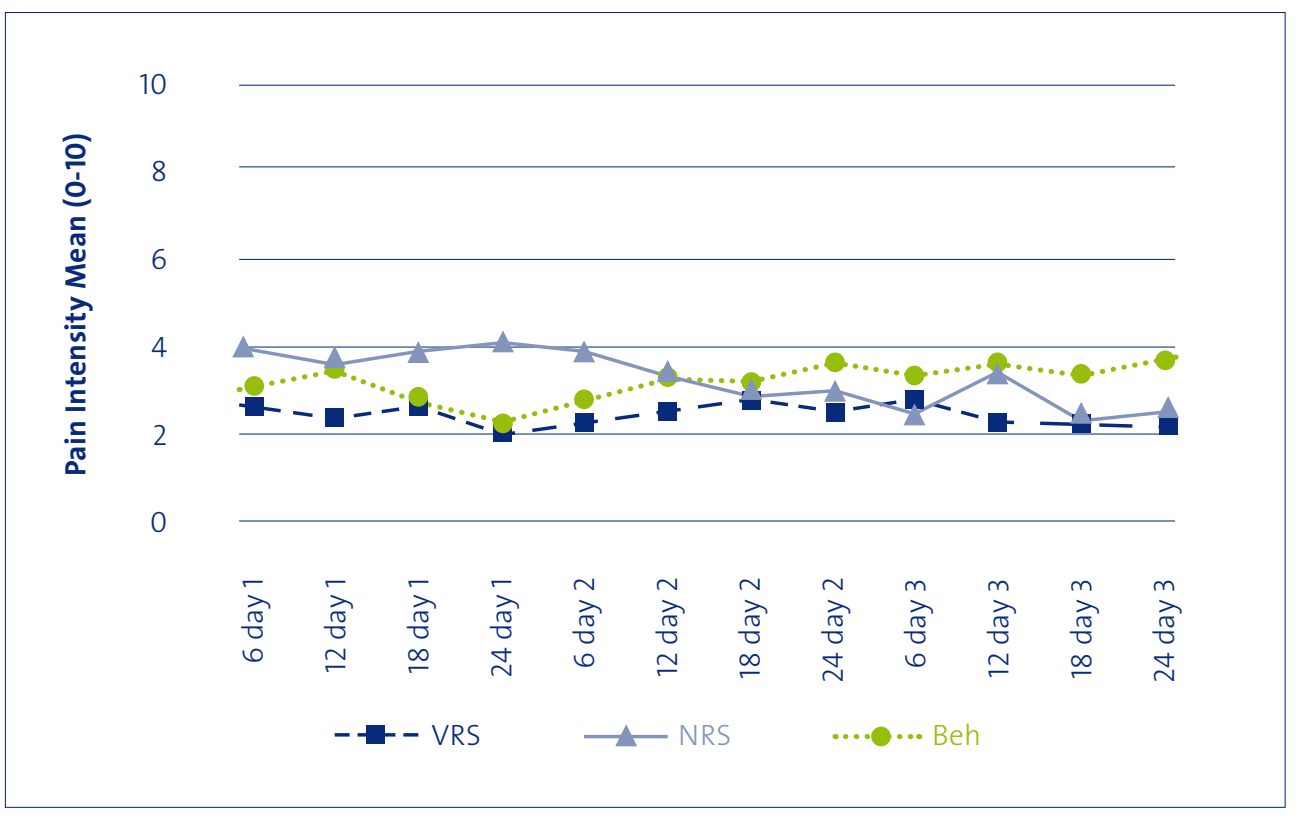

$\begin{array}{llllllllllll}6 & 12 & 18 & 24 & 6 & 12 & 18 & 24 & 6 & 12 & 18 & 24\end{array}$ day 1 day 1 day 1 day 1 day 2 day 2 day 2 day 2 day 3 day 3 day 3 day 3 NRS $n=13 \quad n=52 \quad n=57 \quad n=70 \quad n=63 \quad n=46 \quad n=22 \quad n=30 \quad n=24 \quad n=23 \quad n=11 \quad n=14$

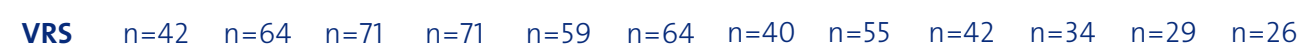

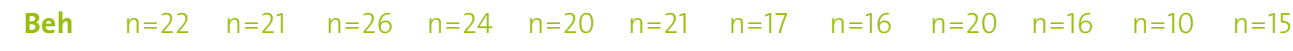

Note:Time of measurement:6:00 AM, 12:00 noon, 6:00 PM, 12:00 midnight. Abbreviations:NRS=numeric rating scale, $V R S=$ verbal rating scale, Beh=behavioral pain scale. $n=$ number of patients.
The majority of patients $(67 \%, n=94)$ demonstrated high intra-individual variability of pain during the three days (NRS: $0-10$ ) (Figure $2 a)$. One third of the patients $(43 \%, n=47)$ showed minimal fluctuation in their pain patterns over the first three days (NRS: 0-3) (Figure 2b).

\section{Figures $2 a, b$ Intra-individual variability of pain}

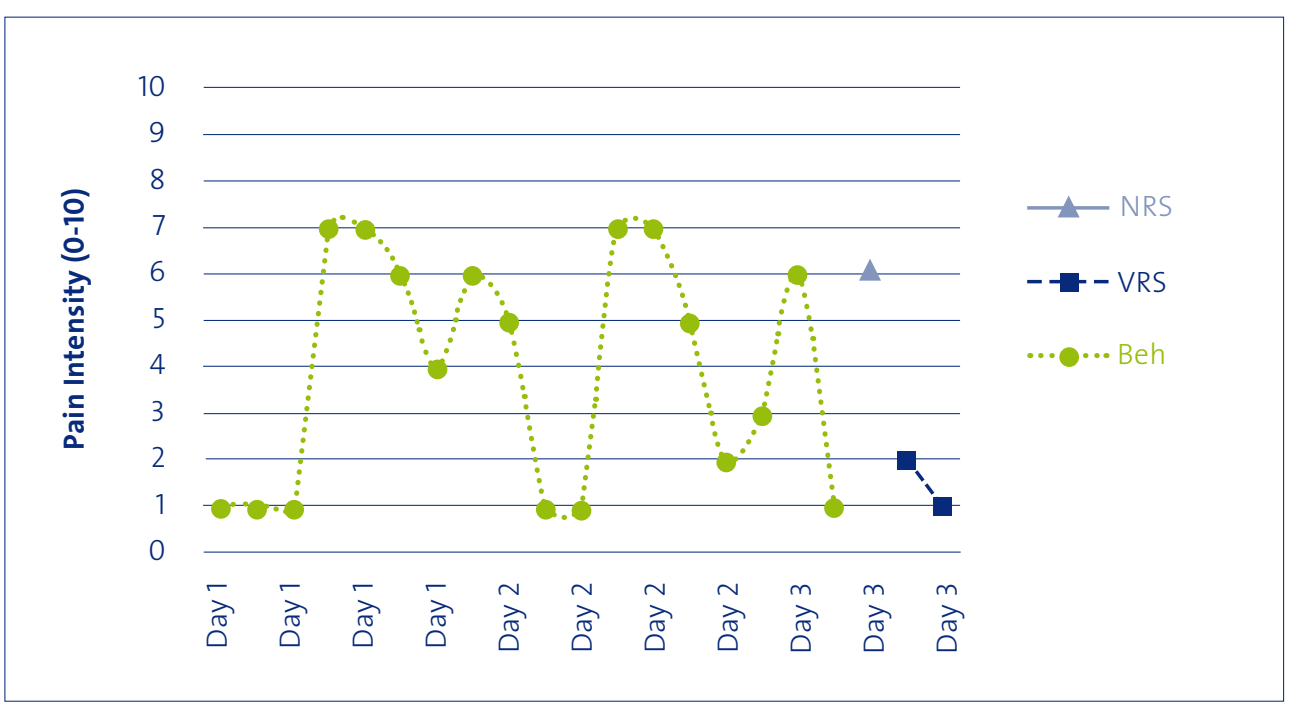

Note: 2a) Figure with increases and decreases in pain patterns. Abbreviations: NRS=numeric rating scale, VRS=verbal rating scale, Beh=behavioral pain scale.

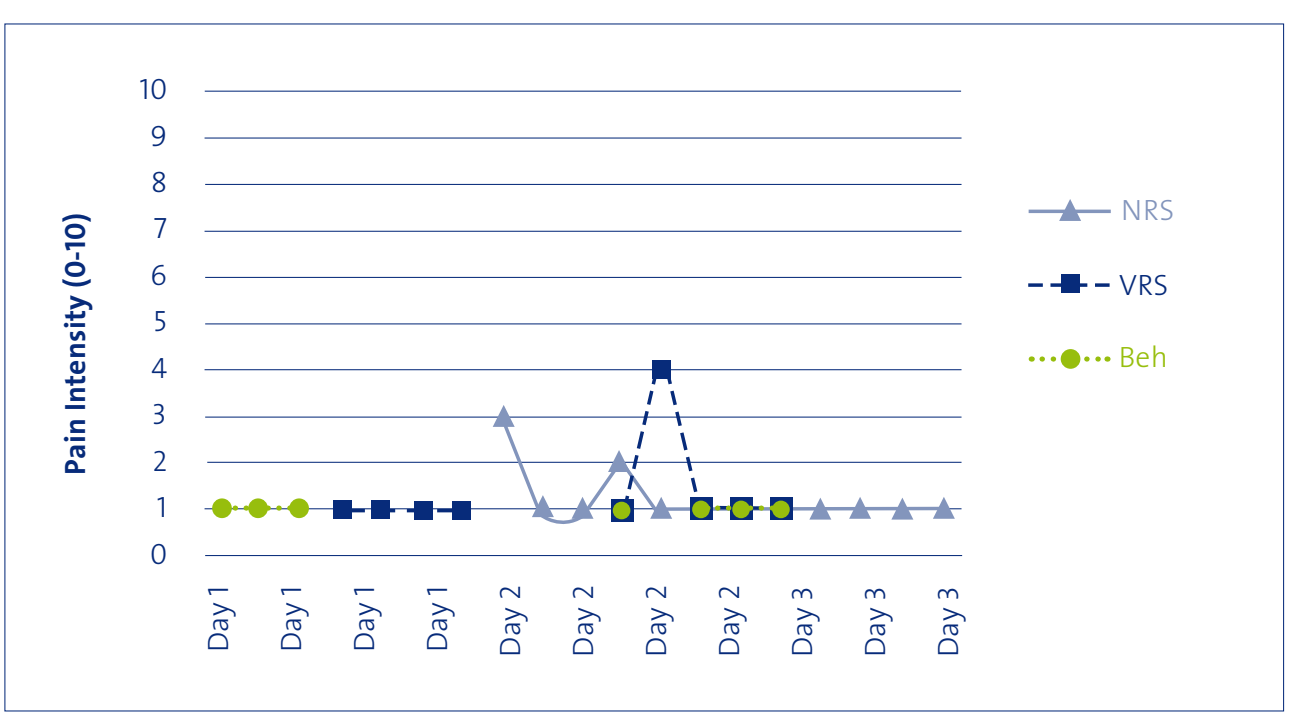

Note: 2b) Figure with minimal fluctuation. Abbreviations: NRS=numeric rating scale, VRS=verbal rating scale, Beh=behavioral pain scale. 


\section{Severity of IIIness and Pain}

Severely ill patients (APACHE II: $\geq 18$ ) showed stable and consistent pain patterns whereas the more moderately ill patients (APACHE II: $<18)$ showed slightly fluctuating patterns. Pain levels for the severely ill patients were assessed to be relatively low: NRS mean score at 6:00 AM: Day 1: 3.31 (SD 3.0); Day 2: 3.59 (SD 2.73); Day 3: 2.05 (SD 1.62). The moderately ill patients reported a moderate amount of pain on the first day: NRS mean score at 6:00 AM: Day 1: 5.7 (SD 2.99). Pain was recorded as moderate on day 2 (4.05, SD 2.7) and low on day 3, (2.69, SD 1.59) (Figures 3a, 3b and 3c).

Figures 3 a, b, c Pain patterns for severely ill patients and moderately ill patients

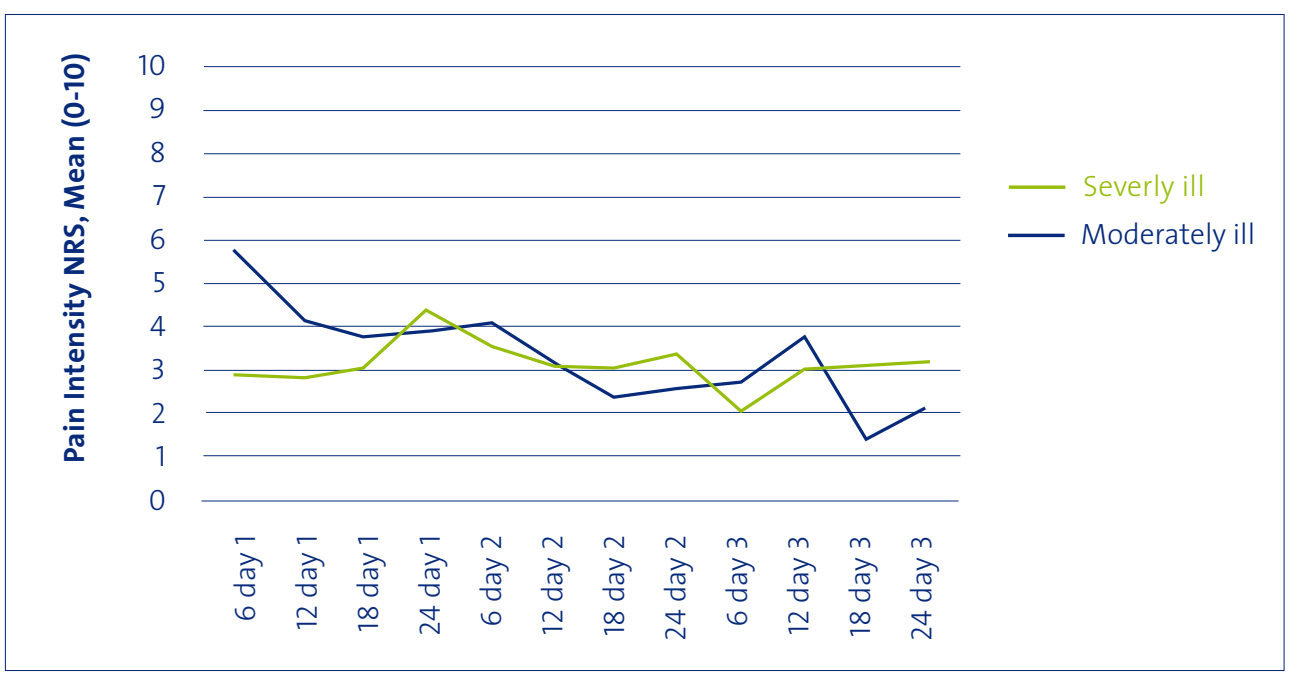

$\begin{array}{llllllllllll}6 & 12 & 18 & 24 & 6 & 12 & 18 & 24 & 6 & 12 & 18 & 24\end{array}$ day 1 day 1 day 1 day 1 day 2 day 2 day 2 day 2 day 3 day 3 day 3 day 3 Severly ill $n=8 \quad n=27 \quad n=26 \quad n=35 \quad n=28 \quad n=20 \quad n=10 \quad n=11 \quad n=11 \quad n=12 \quad n=7 \quad n=6$

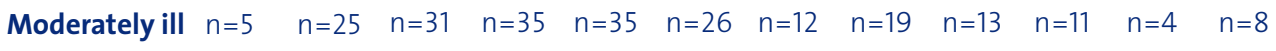

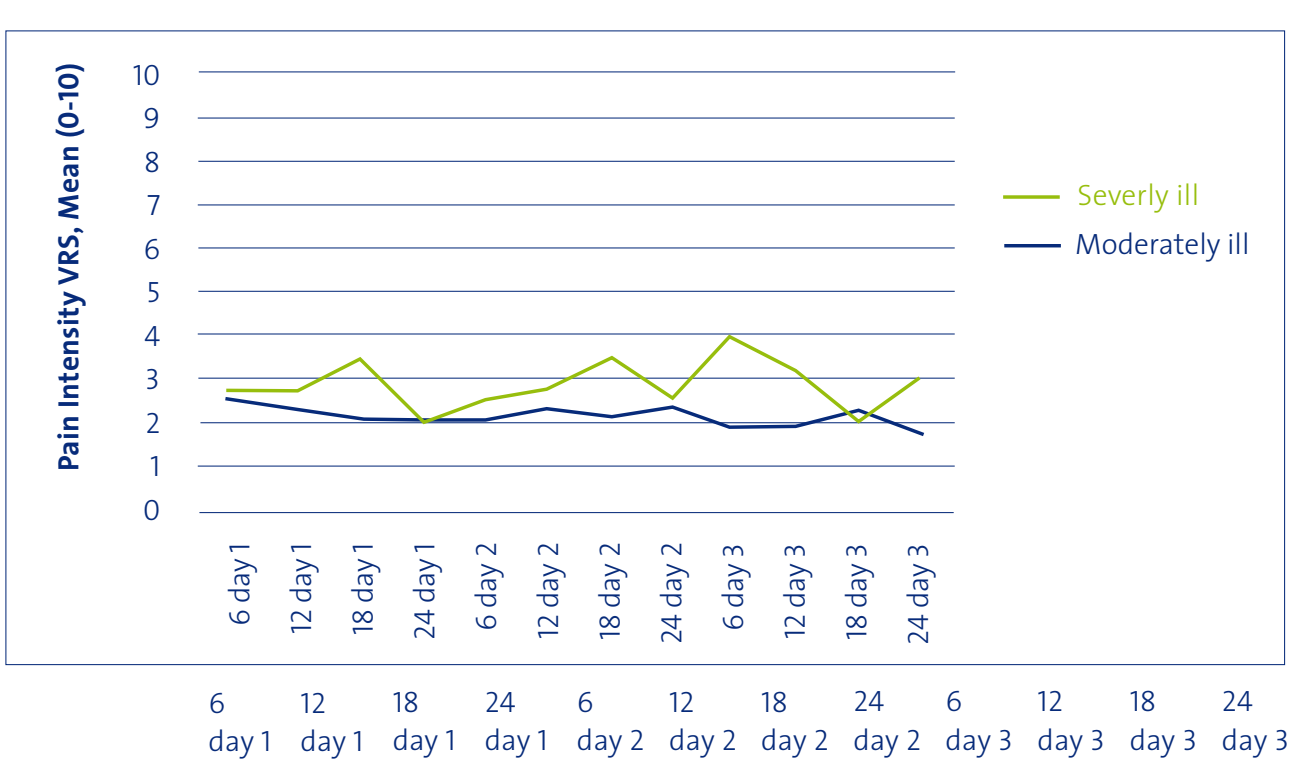

Severly ill $\quad n=27 \quad n=44 \quad n=41 \quad n=41 \quad n=31 \quad n=40 \quad n=27 \quad n=36 \quad n=25 \quad n=26 \quad n=19 \quad n=16$

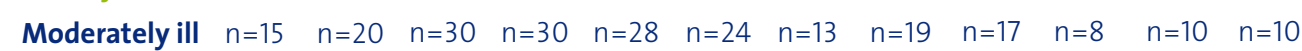

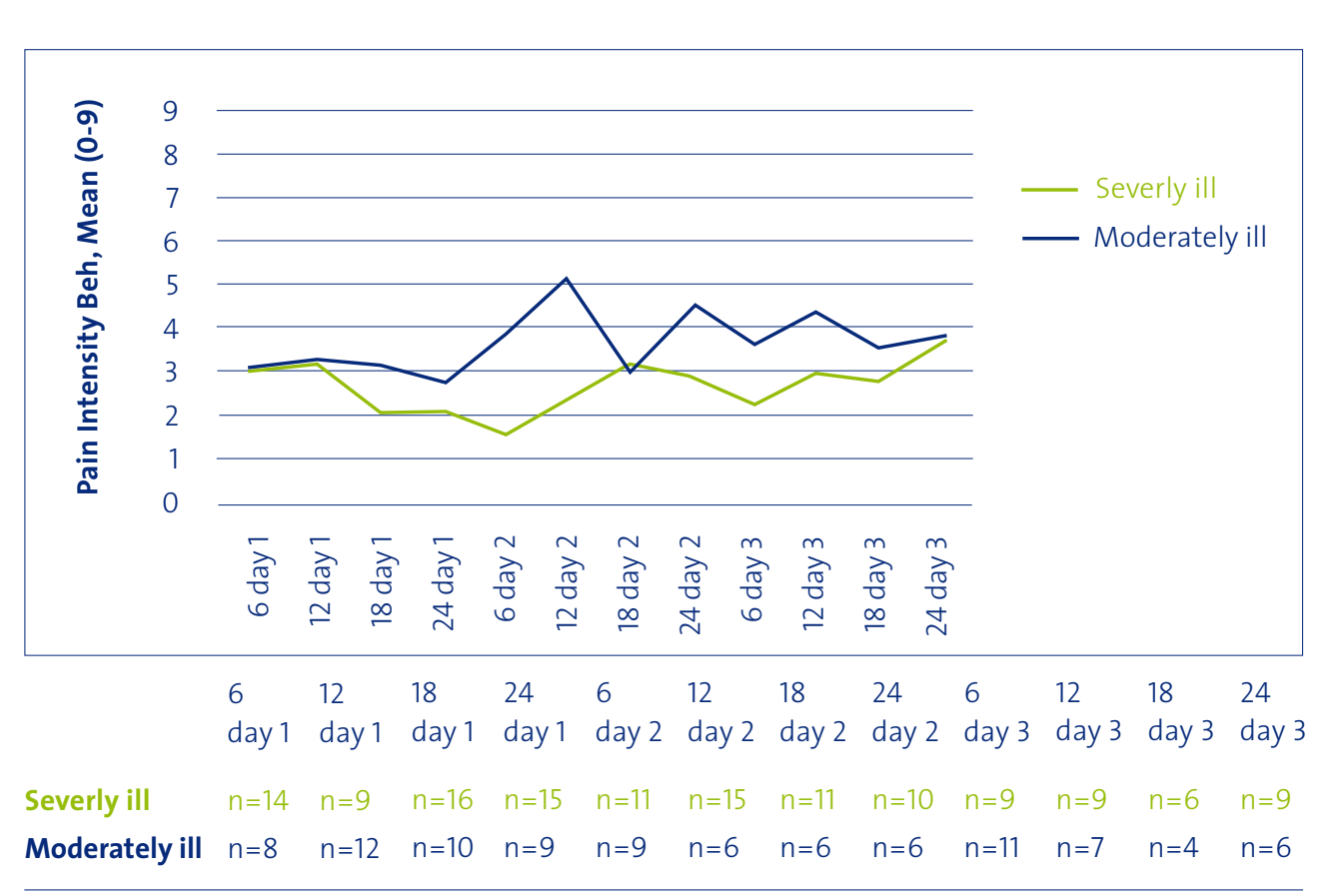

Note: Time of measurement: 6:00 AM, 12:00 noon, 6:00 PM, 12:00 midnight. Abbreviations: NRS= numeric rating scale, VRS=verbal rating scale, Beh=behavioral pain scale. $n=$ number of patients. 


\section{Pain Assessment and Analgo-Sedation}

All three instruments were used for $31 \%$ of the patients, two instruments were used for half of the patients, and in 19\% of the cases, only one instrument was used. The VRS, administered in $94 \%$ of the patients, was used most often, followed by the NRS in $77 \%$ and the behavioral pain scale in $54 \%$ of the patients. Pain medications administered in the first three days included fentanyl for $94 \%$ of the patients, propofol for $88 \%$ of the patients, and midazolam for $44 \%$ of the patients. In general, most of the patients were sleepy to lightly sedated (RASS: -1 to -2 ). The deepest sedation was found on the first ICU day. Thereafter most patients were assessed as lightly sedated. A few of the severely ill patients displayed agitated behavior on the second ICU day (RASS Range -2 to 4) (Table 1).

\section{Discussion}

This study demonstrates that an ICU stay for critically ill older patients does not necessarily result in a highly painful experience. Intensity of pain was reported to be low, pain patterns were relatively stable, and the highest pain scores were found on the first ICU day.

Because few studies have been conducted on the pattern of pain in critically ill older patients, direct comparisons between our results and those of others are difficult. However, our findings are similar to findings from one recent ICU study ${ }^{17}$ that also found low to moderate pain intensity in severely ill patients. Other studies that included critically ill patients with a broader age range and various illnesses reported moderate and intense pain levels. ${ }^{5,11,19}$ An explanation for the low pain intensity in our study could be that the patients received appropriate analgesic therapy. In addi tion, patients were only lightly sedated and thus were able to evaluate and communicate their pain.

It is interesting that pain was reported to be highest on the first day of the ICU stay. Possible reasons for these higher levels of pain on the first day could be that patients are new to the staff ${ }^{27}$ and the pain assessment and management is not yet adequate. Also, patients often receive numerous painful interventions and treatments. An earlier study of younger patients with brain injury confirmed that the highest pain scores are on day $1 .{ }^{18}$

Severely ill patients reported less pain than the moderately ill patients especially in the beginning of the ICU stay. This finding is consistent with the study by Puntillo et $\mathrm{a}^{17}$. Their study focused on the symptom experiences of 171 severely ill patients in the ICU where only $40 \%$ of the assessments found a low to moderate intensity of pain. However, it is difficult to judge the degree to which the severity of the illness influenced the experience of pain. Do severely ill patients really have less pain or is it more a phenomenon of a decreased ability to express their pain both verbally or behaviorally? ${ }^{28}$

Do they suffer from other undisclosed symptoms such as fatigue, anxiety, or thirst that may be correlated with pain ${ }^{17}$ or are they in delirium and pain can not be assessed because no validated pain scales for these situations exist? ${ }^{28}$ The influence that fatigue, thirst, anxiety or delirium had on the pain patterns in our study is not known.

A high variability in pain patterns was found in more than half of the patients in our study, displaying both increases and decreases in pain intensity. More than half of these patients were cardiac patients. There are many explanations for the high variability in pain patterns such as undergoing frequent painful interventions, ${ }^{11}$ having decreased vision and hearing abilities and having undergone surgical procedures that caused tissue damage. ${ }^{5}$ Further reasons for this high variability can be due to the ICU environment which has high noise and activity levels, the many interventions and high use of technology, as well as considering the subjective experience of pain. Further studies are needed to explore the variations in assessed pain.

The different pain scales used in our study did not show consistent patterns. Previous studies confirm that different pain scales can influence the pain intensity as pain measured on one scale is not always predictive of pain measured on anothe scale. ${ }^{20}$

Current clinical practice guidelines recommend using self-report scales, such as the NRS, with critically ill patients. ${ }^{3}$ Chanques et $a^{21}$ compared the performance of five self-report pain intensity scales in over 100 ICU patients between the ages of 48 and 69. A 0-10 visually enlarged vertical NRS was the most valid and feasible method for rating pain intensity. Gagliese et $\mathrm{al}^{23}$ also recommend using the NRS scale as first choice and a VRS as second choice for self-report instruments. Most patients in our study needed two or three scales to assess their pain, and preferred the NRS and VRS. The behavioral pain scale was less frequently used, perhaps because patients were able to assess their pain themselves due to the lighter levels of sedation.

\section{Limitations}

Some study limitations need to be acknowledged. First, our patients were a selective sample. Patients in a palliative care situation or with cognitive impairment were not included in the study and there were only a small number of patients with trauma and sepsis. These patients could suffer from intense pain which may have resulted in the low and stable pain scores. In addition, the training of the nurses may have 
influenced the results of our study. A better knowledge of analgo-sedation allowed the nurses to administer and optimize selected analgo-sedation. Secondly, we did not document symptoms such as anxiety, thirst, fatigue, or delirium, which could also influence the results. Thirdly, the data were collected in a hospital with an ICU-specific protocol for pain management, which limits the generalizability of the findings. And finally, there are missing data, for example, during the times when the patient was being examined outside of the ICU. The strengths of our study were the continuous as sessments of pain during the first three days in the ICU that allowed pain patterns to be identified and provide information for an appropriate analgo-sedation management.

\section{Conclusion}

This study shows that during an ICU stay, critically ill older patients do not have highly painful experiences. The highest pain intensity is found in the first ICU day. Adequate analgo-sedation management on the first ICU day is therefore quite meaningful for critically ill older patients. A light level of sedation allows for appropriate pain management therapy according to reported pain from the pain assessment instruments. Furthermore, it is worth it to identify the intra-individual pain patterns to facilitate adequate treatment. There is a need for further research that considers illness severity and its influence on pain. We found that the use of the NRS and VRS in critically ill older persons is appropriate to assess pain.

\section{References}

1 Bagshaw SM, Webb SA, Delaney A, George C, Pilcher D, Hart GK, Bellomo R. Very old patients admitted to intensive care in Australia and New Zealand. a multi-centre cohort analysis. Crit Care. 2009;13(2):R45

2 Puntillo KA, Morris AB, Thompson CL, Stanik-Hutt J, White CA, Wild LR. Pain behaviors observed during six common procedures: results from Thunder Project II. Crit Care Med. 2004;32(2):421-7.

3 Barr J, Fraser GL, Puntillo K, Ely EW, Gélinas C, Dasta JF, Davidson JE, Devlin JW, Kress JP, Joffe AM, Coursin DB, Herr DL, Tung A, Robinson BR, Fontaine DK, Ramsay MA, Riker RR, Sessler CN, Pun B, Skrobik Y, Jaeschke R. Clinical practice guidelines for the management of pain, agitation, and delirium in adult patients in the intensive care unit. Crit Care Med. 2013;41(1):263-306.

4 Jeitziner MM, Hamers JP, Bürgin R, Hantikainen V, Zwakhalen S. Long-term consequences of pain anxiety and agitation for critically ill older patients after an intensive care unit stay. Submitted to the Journal of Clinical Nursing.

5 Gélinas C. Management of pain in cardiac surgery ICU patients. Have we improved over time? Intensive Crit Care Nurs. 2007:23(5):298-303.

6 Arroyo-Novoa CM, Figueroa-Ramos MI, Puntillo KA, Stanik-Hutt J, Thompson CL, White C, Wild LR. Pain related to tracheal suctioning in awake acutely and critically ill adults: a descriptive study. Intensive Crit Care Nurs. 2008:24(1):20-7.

7 Payen JF, Bru O, Bosson JL, Lagrasta A, Novel E, Deschaux I, Lavagne P, Jacquot C. Assessing pain in critically ill sedated patients by using a behavioral pain scale. Crit Care Med. 2001;29(12):2258-63.

8 Nelson JE, Meier DE, Oei EJ, Nierman DM, Senzel RS, Manfredi PL,Davis SM, Morrison RS Self-reported symptom experience of critically ill cancer patients receiving intensive care. Crit Care Med. 2001;29(2):277-82.

9 Chanques G, Sebbane M, Barbotte E, Viel E, Eledjam JJ, Jaber S. A prospective study of pain at rest incidence and characteristics of an unrecognized symptom in surgical and trauma versus medica intensive care unit patients. Anesthesiology. 2007;107(59):858-60.

10 Gélinas C, Arbour C. Behavioral and physiologic indicators during a nociceptive procedure in conscious and unconscious mechanically ventilated adults: similar or different? I Crit Care. 2009;24(4):628.e7-17.

11 Puntillo KA, White C, Morris AB, Perdue ST, Stanik-Hutt J, Thompson CL, Wild LR. Patients' perceptions and responses to procedural pain: results from Thunder Project II. Am J Crit Care. 2001;10(4):238-51.

12 Herr K. Pain assessment strategies in older patients.J Pain. 2011;12(3 Suppl 1):S3-S13.

13 Deutsches Netzwerk für Qualitätsentwicklung in der Pflege. Expertenstandard Schmerzmanage ment in der Pflege bei akuten Schmerzen. "German network for quality in nursing. Expert guidelines for nursing care and management of pain in patients with acute pain." Osnabrück: Hochschule; 2011.

14 Gagliese L. Pain and aging: the emergence of a new subfield of pain research.J Pain. 2009;10(4):343-53.

15 Marik PE. Management of the critically ill geriatric patient. Crit Care Med. 2006;34(9 Suppl):S176-82. 
16 Rosenthal RA, Kavic SM. Assessment and management of the geriatric patient. Crit Care Med. 2004;32(9 Suppl):S92-S105.

17 Puntillo KA, Arai S, Cohen NH, Gropper MA, Neuhaus J, Paul SM, Miaskowski C. Symptoms experienced by intensive care unit patients at high risk of dying. Crit Care Med. 2010;38(11):2155-60.

18 Lee K, Oh H, Suh Y, Seo W. Patterns and clinical correlates of pain among brain injury patients in critical care assessed with the critical care pain observation tool. Pain Manag Nurs. 2013;14(4):259-67.

19 Stotts NA, Puntillo K, Bonham Morris A, Stanik-Hutt J, Thompson CL, White C, Reitman Wild L. Wound care pain in hospitalized adult patients. Heart Lung. 2004;33(5):321-32.

20 Gagliese L, Katz J. Age differences in postoperative pain are scale dependent: a comparison of measures of pain intensity and quality in younger and older surgical patients. Pain. 2003;103 (1-2):11-20.

21 Chanques G, Viel E, Constantin JM, Jung B, de Lattre S, Carr J, Cissé M, Lefrant JY, Jaber S. The measurement of pain in intensive care unit: comparison of 5 self-report intensity scales. Pain. 2010;151(3):711-21.

22 Jeitziner MM, Schwendimann R, Hamers JP, Rohrer O, Hantikainen V, Jakob SM. Assessment of pain in sedated and mechanically ventilated patients: an observational study. Acta Anaesthesiol Scand. 2012;56(5):645-54.

23 Gagliese L, Weizblit N, Ellis W, Chan VW. The measurement of postoperative pain: a comparison of intensity scales in younger and older surgical patients. Pain. 2005;117(3):412-20.

24 Herr KA, Spratt K, Mobily PR, Richardson G. Pain intensity assessment in older adults: use of experimental pain to compare psychometric properties and usability of selected pain scales with younger adults. Clin J Pain. 2004;20(4):207-19.

25 Knaus WA, Draper EA, Wagner DP, Zimmerman JE. APACHE II: a severity of disease classification system. Crit Care Med. 1985;13(10):818-29.

26 Ely EW, Truman B, Shintani A, Thomason JW, Wheeler AP, Gordon S, Francis J, Speroff T, Gautam S, Margolin R, Sessler CN, Dittus RS, Bernard GR. Monitoring sedation status over time in ICU patients: reliability and validity of the Richmond Agitation-Sedation Scale (RASS). JAMA. 2003;289(22):2983-91.

27 Crocker C, Scholes J. The importance of knowing the patient in weaning from mechanical ventilation. Nurs Crit Care. 2009;14(6):289-96.

28 Gélinas C, Chanques G, Puntillo K. In pursuit of pain: recent advances and future directions in pain assessment in the ICU. Intensive Care Med. 2014;40(7):1009-14. 


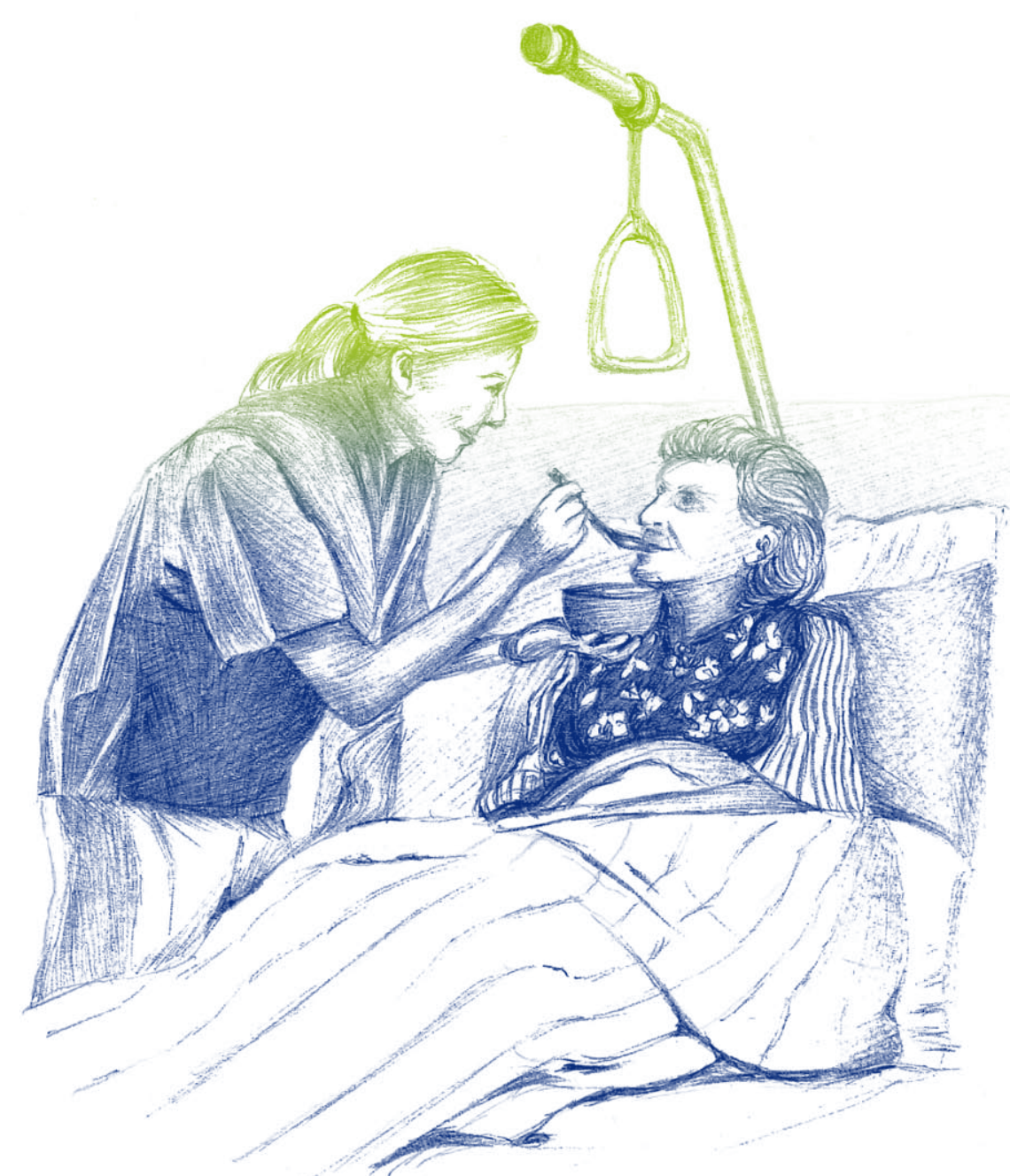


Chapter 3

Long-Term Consequences of an Intensive Care Unit Stay in Older Critically Ill Patients

Design of a Longitudinal Study 


\section{Abstract}

Background

Modern methods in intensive care medicine often enable the survival of older critically ill patients. The short-term outcomes for patients treated in intensive care units (ICUs), such as survival to hospital discharge, are well documented. However, relatively little is known about subsequent long-term outcomes. Pain, anxiety, and agitation, are important stress factors for many critically ill patients. There are very few studies concerned with pain, anxiety, agitation, and the consequences in older critically ill patients. The overall aim of this study is to identify how an ICU stay influences an older person's experiences later in life. More specifically, this study has the following objectives: (1) to explore the relationship between pain, anxiety and agitation during ICU stays and experiences of the same symptoms in later life; and (2) to explore the associations between pain, anxiety, and agitation experienced during ICU stays and their effect on subsequent health-related quality of life, use of the healthcare system (re-admissions, doctor visits, rehabilitation, medication use), living situation, and survival after discharge, and at 6- and 12-months follow-up.

Methods | Design

A prospective, longitudinal study will be used for this study. A total of 150 older critically ill patients in the ICU will participate (ICU group). Pain, anxiety, agitation, morbidity, mortality, use of the healthcare system, and health-related quality of life will be measured at 3 intervals after a baseline assessment. Baseline measurements wil be taken 48 hours after ICU admission and one week thereafter. Follow-up measurements will take place at 6 months and 12 months after discharge from the ICU. To be able to interpret trends in scores on outcome variables in the ICU group, a compari son group of 150 participants, matched by age and gender, recruited from the Swiss population, will be interviewed at the same intervals as the ICU group.

\section{Discussion}

Little research has focused on long-term consequences after ICU admission for older critically ill patients. The present study focuses specifically on long-term consequences of stress factors experienced during ICU admission.

Trial Registration

ISRCTN52754370

\section{Background}

Modern methods in intensive care medicine often enable the survival of older critically ill patients. The short-term outcomes for patients treated in intensive care units (ICUs), such as survival to hospital discharge, are well documented. However, relatively little is known about subsequent long-term outcomes. ${ }^{1}$ It is generally recognized that survival alone is not the only important outcome following an ICU stay. Various stress factors experienced in the ICU and the severity of illness or injury have long-term consequences. ${ }^{2-4}$ Over the long-term, discomfort experienced in the ICU and stressful memories of an ICU stay have been associated with the development of acute posttraumatic stress disorder-related syndromes, anxiety, depression, and impaired healthrelated quality of life (HROOL). ${ }^{5-9}$ For some patients these symptoms are chronic and cause lasting personality changes. Other studies have focused on outcomes such as functional status, ability to live at home, influence on the social network, and the burden on the family, all of which can, at times, be more important than the length of survival. ${ }^{10-12}$ Recent research has indicated that there may be significant cognitive and emotional dysfunction following critical illness. ${ }^{13-15}$ Another study showed that survivors of critical illnesses have increased healthcare system needs. Continuing hospital care, and|or rehabilitation, community support services, or other healthcare services after the ICU stay were needed. In addition, there was an increase in the use of medication and of doctor visits. ${ }^{16}$ An increasing proportion of critically ill patients are aged 65 years and older. Older patients with severe injuries are at risk of poor outcomes. ${ }^{17}$ Mortality rates are almost $22 \%$ in older surgical patients, ${ }^{18}$ and yet age alone does not appear to be a reliable predictor of outcome after ICU admission..$^{19,20}$ Older critically ill patients express preferences for longer life under compromised health conditions more frequently than healthy persons..$^{21}$ Until now, few studies have examined longterm outcomes after ICU admissions in older critically ill patients. ${ }^{17,22,23}$

Pain, anxiety, and agitation are important stress factors for many critically ill patients, yet these symptoms are difficult to distinguish from one another. Pain, anxiety and agitation can have consequences for HRQoL. ${ }^{5}$ In addition, pain, anxiety, agitation, and their consequences for long-term outcomes, have rarely been examined in older critically ill patients in the ICU. ${ }^{24-26}$ In contrast to other studies, ${ }^{22,23}$ the present study examines the relationship between the ICU stay and post-hospital pain, anxiety, and agitation in older critically ill patients, and addresses whether acute experiences in the ICU can cause more serious chronic conditions after discharge. This article describes a longitudinal study in which older critically ill patients are followed one year after their discharge from the hospital.

Under investigation were their pain experiences, levels of anxiety and agitation HROoL, and use of the healthcare system, in order to detect relationships between these main outcomes and their ICU experiences. 


\section{Study Aims}

The overall aim of this study is to identify how an ICU stay influences an older person's experiences later in life.

The study addresses the following research questions:

1) Does an ICU stay influence the pain, anxiety, and agitation experienced by older critically ill patients 1 week after discharge, and at 6- and 12-months follow-up?

2) Do the pain, anxiety and agitation experienced by older critically ill patients during an ICU stay affect their experiences of these symptoms 1 week after discharge, and at 6 - and 12 -months follow-up?

3) Does an ICU stay affect the HROoL of older critically ill patients after 6- and 12 months follow-up?

4) What is the association between an ICU stay and the subsequent use of the following healthcare resources: length of stay, (re)admission to hospital or ICU, general practitioner (GP) visits, participation in rehabilitation programs, medication use, living situation and survival, in critically ill older patients 6 and 12 months after hospital discharge?

\section{Methods|Design}

Design

A prospective longitudinal study will be conducted in older critically ill patients admitted to the ICU. Data will be collected over a period of two years at the following intervals: during ICU admission and 1 week, 6 months and 12 months after hospital discharge. A flow chart of the study is presented in Figure 1.
Figure 1 Flow chart of the study design

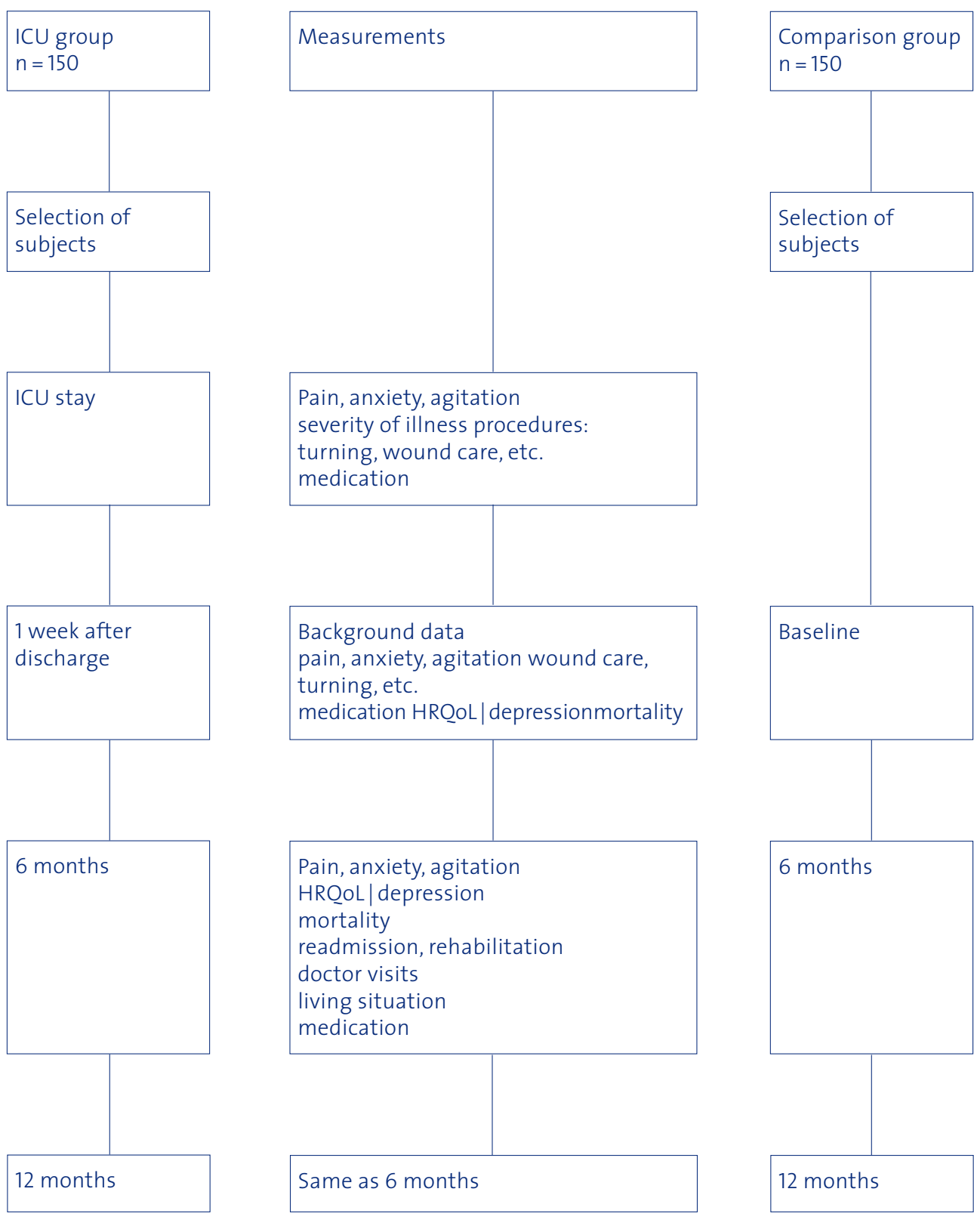

Note: Schedule of the Study and Measurements of the ICU and Comparison Groups. Abbreviations: ICU=Intensive Care Unit. HRQOL=Health-Related Quality of Life. $n=$ number of subjects. 


\section{Participants and Setting}

The study will be conducted in the interdisciplinary ICU of a Swiss university hospital, where approximately 4000 patients with surgical procedures, illnesses, and trauma are treated each year, as well as at 12 follow-up clinics. From this ICU, 150 older critically ill patients (aged 65 years and older) will be recruited, then followed up until one year after discharge from the hospital (the ICU group). A sample of 100 patients is required, based on a power analysis; with a $95 \%$ confidence interval for an estimated prevalence of pain between 0.30-0.50 and a total of 0.20 a sample size of 81-96 is needed. In order to ensure a large enough sample, and to counteract the potential loss of participants through mortality, relocation, attrition, or other problems, an additional 50 participants will be recruited (150 total). In order to be able to interpret trends in scores in the ICU group for the outcome variables pain, anxiety, agitation, HRQoL, use of the healthcare system (readmissions, GP visits, rehabilitation, length of hospital stay), medication use, living situation, and survival, we decided to collect similar data in a comparison group. Participants in the comparison group are a convenience sample of older people from the Swiss population, who have not been admitted to an ICU during the last 15 years. Through matching of age and sex, an attempt is made to increase the comparability of the groups at baseline.

\section{Inclusion and Exclusion Criteria}

To participate in this study, the participants must have a minimum age of 65 years, have had an ICU stay of at least 48 hours (ICU group), or no stay for the last 15 years (comparison group), be able to speak and read either German or French, and live in Switzerland. Participants were excluded because of temporary tracheostomies, chronic mechanical ventilation, illness-related cognitive impairment (dementia), or psychotic illnesses including delusions and changes in mental state, and potentially terminal illnesses such as lung or heart diseases and cancer.

\section{Measurements}

\section{Background Data}

Demographic data include age, sex and marital status. Furthermore, health-related data including Activities of Daily Living (ADL) and co-morbidities will be collected at baseline for all participants. The severity of the patient's condition will be determined using the Acute Physiology, Age and Chronic Health Evaluation (APACHE II), and the Simplified Acute Physiology Score (SAPS II). ${ }^{27}$

The performance of ADL will be measured using items querying the need for assistance with daily activities (home healthcare, home food delivery, residence in a retirement home or nursing home) and various quality-of-life dimensions such as physical function, physical role function, vitality, and social role function (Short Form 36 Health Survey (SF-36)). A scale developed for this study will be used to assess the need for assistance with daily activities (completely dependent; needs support by caregivers and special medical equipment; needs caregivers; independent with medical equipment; completely independent). Co-morbidities will be measured us ing the International Classification of Diseases (ICD), Version 10.28

\section{Pain, Anxiety, and Agitation During an ICU Stay}

During the ICU stay, pain, anxiety, and agitation will be measured in the ICU group. In patients unable to express pain themselves verbally, pain intensity will be measured using a behavioral pain scale employing three behavioral parameters: mimic body movement, and muscle tone. The intensity of the behavioral parameters will be assessed on the basis of a four-point Likert scale: each characteristic will be rated as weak or absent, moderately severe, severe, or very severe. The validity of the scale has been determined to be adequate, and its interrater reliability is high (kappa value 0.80) (Jeitziner MM et al. Assessment of pain in sedated and mechanically ventilated patients: an observational study, submitted). Furthermore, potentially painful procedures will be recorded. The painful procedures include: intratracheal suctioning, dressing changes, repositioning in bed, and insertion of a central venous catheter. ${ }^{29}$ Anxiety will be assessed using a numeric rating scale $(0-10)(0=$ no anxiety to $10=$ worst possible anxiety). ${ }^{30}$ Agitation during the ICU stay will be measured using the German version of the Richmond Agitation-Sedation Scale (RASS), which has 10 levels, ranging from -5 : unarousable (no response) to +4 : combative (danger to staff) This scale has proven reliable for the assessment of critically ill patients in the ICU, with strong inter-rater reliability and criterion, construct, and face validity. ${ }^{31,32}$ The Confusion Assessment Method for the ICU (CAM-ICU) will be used to assess delirium in the ICU, ${ }^{33}$ as well as general cognitive abilities, focusing on the following factors: 
a) acute onset or fluctuating course, b) inattention, c) disorganized thinking, and d) altered level of consciousness. This scale has been proven reliable and valid, with an inter-rater reliability kappa value of 0.96 . Its sensitivity was $100 \%$ and $93 \%$, with $98 \%$ and $100 \%$ specificity. ${ }^{34}$

\section{Outcome Indicators After Discharge}

In line with the study aims, the following outcome indicators will be measured in both the ICU group and the comparison group: (1) pain, anxiety, and agitation; (2) HRQoL; and (3) use of the healthcare system (readmissions, general practitioner visits, rehabilitation, length of hospital stay), medication use, living situation and survival.

Pain intensity will be measured with a numeric rating scale (NRS) $(0=$ no pain to $10=$ worst possible pain), ${ }^{29,30}$ and pain frequency with a Likert-type scale (never, seldom, occasionally, often, always). Anxiety will be assessed using a numeric rating scale (0-10) and the Hospital Anxiety and Depression Scale (HADS), which uses two subscales: an anxiety scale (HADS-A), and a depression scale (HADS-D). Internal consistency (Cronbach's alpha) is 0.80 for HADS-A and 0.81 for HADS-D. The test-retest reliability shows the correlations $r=0.81$ for HADS-A and $r=0.89$ for HADS-D. ${ }^{35}$ Agitation will be measured using the Confusion Assessment Method (CAM). The German o French Short Form of the CAM, ${ }^{36}$ including a telephone version for the 6 - and 12 month follow-ups, ${ }^{37}$ will be used for all participants. The inter-observer reliability of the CAM is high (kappa=0.81-1.0). ${ }^{38}$ Health-related quality of life will be assessed using the component scores of the Short Form 36 Health Survey (SF-36). As a comprehensive, generic, 36-item instrument, the SF-36 concentrates on the subjective evaluation of health: 1) physical function, 2) physical role function, 3) bodily pain, 4 general health perceptions, 5) vitality, 6) social role function, 7) emotional role function, and 8) mental health. The items vary from yes/no questions to those offering 6 levels of choice. All subscales have been adapted to yield assessment values between 0 and 100. The healthcare system assessment will include the number, cause, and length of hospital admissions and stays using APACHE non-operative and operative diagnoses: 1) cardiovascular, 2) respiratory, 3) gastro-intestinal, 4) neurological, 5) sepsis, 6) trauma, 7) metabolic, 8) hematological, 9) other, 10) cardiologic surgery, 11) respiratory surgery, etc., the number and the length of rehabilitation periods (location, length, ambulatory, stationary, discharge location), and the number of GP visits. Medication therapy, and mortality incidence, will be collected from all subjects in the ICU and comparison groups over the course of the study. Medication therapy includes all sedative, analgesic, antipsychotic, psychotropic, steroidal, and vasoactive medications. The cumulative amount of medication will be recorded. Mortality in cidence will be determined based on survival rates. For all instruments, French and German versions will be available. Translation of the SF-36 into German and French was done according to the Translation Protocols of the International Ouality of Life Assessment Group. ${ }^{39,40}$ The SF-36 Health Survey and the HADS have been used in a range of intensive care-related studies., ${ }^{5,41,42}$ An overview of all measurements is summarized in Tables 1 and 2 .

\section{Table 1 Measurements during ICU stay}

\begin{tabular}{|c|c|c|}
\hline Variables & Instruments & Sources \\
\hline Pain (intensity, frequency) & Behavioral scale & PDMS|O \\
\hline Agitation (intensity, frequency) & RASS, CAM-ICU) & PDMS $\mid Q$ \\
\hline $\begin{array}{l}\text { Reasons for ICU admission } \\
\text { (cause) }\end{array}$ & $\begin{array}{l}\text { APACHE: diagnosis at } \\
\text { admission) }\end{array}$ & $\mathrm{MR} \mid \mathrm{Q}$ \\
\hline Severity of illness & APACHE II, SAPS ॥ & PDMS \\
\hline
\end{tabular}

Note: RASS=Richmond Agitation-Sedation Scale. CAM-ICU=Confusion Assessment Method for the ICU. APACHE=Acute Physiology, Age and Chronic Health Evaluation. SAPS=Simplified Acute Physiology Score. PDMS=Patient Data Management System. MR=Medical record. Q_=Questionnaire.

Table 2 Measurements in the ICU group and the comparison group (follow-up)

\begin{tabular}{|c|c|c|c|c|}
\hline \multirow[t]{2}{*}{ Variables } & \multirow[t]{2}{*}{ Instruments } & \multicolumn{3}{|c|}{ Time of Measurement } \\
\hline & & $\begin{array}{l}\text { Baseline } \\
1 \text { week after } \\
\text { discharge ICU }\end{array}$ & 6 months & 12 months \\
\hline Pain (intensity, frequency) & NRS & $\mathrm{Q}$ & $\mathrm{Q}$ & Q \\
\hline Anxiety (intensity, frequency) & NRS, HADS & $\mathrm{O}$ & $\mathrm{Q}$ & $\mathrm{Q}$ \\
\hline Agitation (intensity, frequency) & CAM & $\mathrm{Q}$ & $\mathrm{Q}$ & Q \\
\hline Mortality & Survival: Yes|No & $\mathrm{O}$ & $\mathrm{O}$ & Q \\
\hline Morbidity & $\begin{array}{l}\text { International classi- } \\
\text { fication of diseases, } \\
\text { version } 10\end{array}$ & $\mathrm{MR} \mid \mathrm{Q}$ & $\mathrm{MR} \mid \mathrm{Q}$ & $M R \mid \mathrm{Q}$ \\
\hline Quality of life (HRQOL) & SF-36 & $\mathrm{Q}$ & $\mathrm{Q}$ & $\mathrm{Q}$ \\
\hline
\end{tabular}

Note: NRS=Numeric rating scale. HADS=Hospital Anxiety and Depression Scale. CAM=Confusion Assessment Method. SF-36=Short Form 36 Health Survey. HROOL=Health-related quality of life. $M R=$ Medical record. $\mathbf{Q}=$ Questionnaire 


\section{Procedure}

Background data will be gathered via medical records and questionnaires. Medical and nursing staff will gather daily routine data regarding pain, anxiety, and agitation, along with any other information relevant to usual care in the ICU. Collection of data concerning pain, anxiety and agitation will be carried out by the staff who regularly care for the patients. For this study these caregivers have received special training. Data about the outcome indicators will be collected using questionnaires 1 week, 6 months and 12 months after discharge. It should be emphasized that participants in the ICU group will be asked one week after discharge to make an assessment of both their current HROOL and their HROoL, pain, anxiety and agitation intensity, before admission to the ICU. One week after ICU discharge, patients in the ICU group will be contacted and interviewed. The interviews will be carried out only if the patients are physically and psychologically fit to be interviewed. If necessary, help will be provided in filling out the questionnaire. All data will be collected using face-to-face (baseline) and telephone (follow-up) interviews and will be collected by 4 trained interviewers. The baseline interviews with all critically ill patients will take place in the hospital. All other interviews for both groups will take place by telephone. The SF-36 and HADS will be mailed to all participants. In order for them to prepare themselves for the interview, both groups will be informed of the general nature of the questions ahead of time. Because unanswered questions would affect the evaluation of the questionnaires, an interviewer will check to ensure that all questions have been answered, and follow up in cases where information is lacking. If questionnaires are not returned, reminders will be sent to the participants.

\section{Ethical Considerations}

The study protocol was approved by the Cantonal Ethics Commission of Bern. For the patient interviews during the first week (5 to 10 days) after the ICU stay, patients will be contacted, comprehensively in-formed about the study-verbally and in writingand invited to participate. The participants in the comparison group will receive the same information. Study participants agree to participate via a written informed consent form. To ensure confidentiality, all data will be coded, and all personal data will be documented, archived, and analyzed anonymously, making it impossible to determine the identity of the individual participants.

\section{Data Analysis}

The statistical analysis will be performed using the R Project for Statistical Computing. Descriptive statistical analyses (mean, median, interquartile range) will be used to describe and characterize the data. To indicate the strength and direction of relationships between variables, Spearman's rank correlation coefficient for ordinal data and Pearson's product-moment coefficient will be conducted, depending on measurement levels and data dispersion. The Mann-Whitney U Test will be used for continuous data when comparing groups, and random effects models will be used for the longitudinal data. Attrition (i.e., missing data) during the follow-up will be reported.

\section{Discussion}

This article presents the design of a prospective longitudinal study investigating the associations between admission to the ICU and pain, anxiety, agitation, HROOL, and use of the healthcare system in later life. Previous longitudinal studies have examined ICU patients' HRQOL ${ }^{4,7-9}$ or traumatic memories of postoperative treatment. ${ }^{2,5}$ The present study specifically assesses situations involving pain, anxiety, and agitation in older patients, as well as their consequences. These symptoms can influence the long-term outcomes of older critically ill patients. The study will be conducted over a period of two years. Data on HROoL are time dependent and related to the life situation of the participant. Changes that take place during the follow-ups, such as modifications in therapy or accidents, were integrated into the analysis, based on the various measurement techniques. The instruments used for the study represent a limitation. Various studies have attempted to explain ICU stay-related variables by using identical generic instruments to compare critically ill patients'health-related quality of life with that of comparison groups from the general population. 4,9,41,42 Apparently, illness-specific influences on HROoL are not identified by these generic instruments. Various studies assessed HROoL with a variety of instruments..$^{19,43}$ In addition, the effort required for older people to fill out multiple questionnaires is not negligible. Some studies on critically ill patients have questioned the patients' families regarding their health-related quality of life. ${ }^{44,45}$ However, due to the subjective nature of quality of life, the current study uses only interview and questionnaire data provided by the patients themselves, in order to more accurately describe the patients' own perception of their ICU stay. Until now, little research has focused on the short- and long-term consequences of pain, anxiety, and agitation in older critically ill patients, including the effect on the patients' use of the healthcare system. Because inadequate pain assessment and management may needlessly increase hospital readmissions and the use of the healthcare system, this topic should be of broad interest. This study will provide the first data on the situation in Switzerland. 


\section{References}

1 Williams TA, Dobb GJ, Finn JC, Webb SA. Long-term survival from intensive care: a review. Intensive Care Med. 2005;31(10):1306-15.

2 Novaes MA, Aronovich A, Ferraz MB, Knobel E. Stressors in ICU: patients' evaluation. Intensive Care Med. 1997;23(12):1282-5.

3 Williams TA, Dobb GJ, Finn JC, Knuiman MW, Geelhoed E, Lee KY, Webb SA. Determinants of longterm survival after intensive care. Crit Care Med. 2008;36(5):1523-30.

4 Schelling G, Richter M, Roozendaal B, Rothenhäusler HB, Krauseneck T, Stoll C, Nollert G, Schmidt $M$, Kapfhammer HP. Exposure to high stress in the intensive care unit may have negative effects on health-related quality of life outcomes after cardiac surgery. Crit Care Med. 2003;31(7):1971-80.

5 Jones C, Griffiths RD, Humphris G, Skirrow PM. Memory, delusions, and the development of acute posttraumaticstressdisorder-related symptomsafterintensivecare.CritCareMed.2001;29(3):573-80.

6 Rattray JE, Johnston M, Wildsmith JA. Predictors of emotional outcomes of intensive care Anaesthesia. 2005;60(11):1085-92.

7 Granja C, Lopes A, Moreira S, Dias C, Costa-Pereira A, Carneiro A. Patients' recollections of experiences in the intensive care unit may affect their quality of life. Crit Care. 2005;9(2):R96-109.

8 Ulvik A, Kvale R, Wentzel-Larsen T, Flaatten H. Quality of life 2-7 years after major trauma. Acta Anaesthesiol Scand. 2008;52(2):195-201.

9 Hofhuis JG, Spronk PE, van Stel HF, Schrijvers GJ, Rommes JH, Bakker J. The impact of critical ill ness on perceived health-related quality of life during ICU treatment, hospital stay, and after hospital discharge: a long-term follow-up study. Chest. 2008;133(2):377-85.

10 Lee BO, Chaboyer W, Wallis M. Predictors of health-related quality of life 3 months after trau matic injury. J Nurs Scholarsh. 2008;40(1):83-90.

11 Richter JC, Pajonk FG, Waydhas C, Bregenzer T. Lebensqualität nach chirurgischer Langzeitintensiv therapie. "Ouality of life after long-term surgical intensive care treatment." Anaesthesist. 2000;49(9):822-8

12 Chaboyer W, Grace J. Following the path of ICU survivors: a quality-improvement activity. Nurs Crit Care. 2003;8(4)149-55.

13 Jackson JC, Girard TD, Gordon SM, Thompson JL, Shintani AK, Thomason JW, Pun BT, Canonico AE, Dunn JG, Bernard GR, Dittus RS, Ely EW. Long-term cognitive and psychological outcomes in the awakening and breathing controlled trial. Am J Respir Crit Care Med. 2010;182(2):183-91.

14 Jackson JC, Obremskey W, Bauer R, Greevy R, Cotton BA, Anderson V, Song Y, Ely EW. Long-term cognitive, emotional, and functional outcomes in trauma intensive care unit survivors withou intracranial hemorrhage. J Trauma. 2007;62(1):80-8.

15 Rattray J, Crocker C, Jones M, Connaghan J. Patients' perceptions of and emotional outcome after intensive care: results from a multicentre study. Nurs Crit Care. 2010;15(2):86-93.

16 Williams TA, Leslie GD, Brearley L, Dobb GJ. Healthcare utilisation among patients discharged from hospital after intensive care. Anaesth Intensive Care. 2010;38(4):732-9.
17 Aitken LM, Burmeister E, Lang J, Chaboyer W, Richmond TS. Characteristics and outcomes of injured older adults after hospital admission. J Am Geriatr Soc. 2010;58(3):442-9.

18 Arenal JJ, Bengoechea-Beeby M. Mortality associated with emergency abdominal surgery in the elderly. Can J Surg. 2003;46(2):111-6.

19 Chelluri L, Pinsky MR, Donahoe MP, Grenvik A. Long-term outcome of critically ill elderly patients requiring intensive care. JAMA. 1993;269(24):3119-23.

20 Kleinpell RM, Ferrans CE. Factors influencing intensive care unit survival for critically ill elderly patients. Heart Lung. 1998;27(5):337-43.

21 Winter L, Lawton MP, Ruckdeschel K. Preferences for prolonging life: a prospect theory approach. Int J Aging Hum Dev. 2003:56(2):155-70.

22 Rockwood K, Noseworthy TW, Gibney RT, Konopad E, Shustack A, Stollery D, Johnston R, Grace M. One-year outcome of elderly and young patients admitted to intensive care units. Crit Care Med. 1993;21(5):687-91.

23 Kaarlola A, Tallgren M, Pettilä V. Long-term survival, quality of life, and quality-adjusted life-years among critically ill elderly patients. Crit Care Med. 2006;34(8):2120-6.

24 Valdix SW, Puntillo KA. Pain, pain relief and accuracy of their recall after cardiac surgery. Prog Cardiovasc Nurs. 1995;10(3):3-11.

25 Moser DK, Dracup K, McKinley S, Yamasaki K, Kim CJ, Riegel B, Ball C, Doering LV, An K, Barnett M. An international perspective on gender differences in anxiety early after acute myocardial infarction. Psychosom Med. 2003;65(4):511-6.

26 Inouye SK. The dilemma of delirium: clinical and research controversies regarding diagnosis and evaluation of delirium in hospitalized elderly medical patients. Am J Med. 1994;97(3):278-88.

27 Janssens U, Jordan A, Graf C, Grenner H, Hanrath P. Vergleich von APACHE II, SAPS und TISS im täglichen Einsatz bei Patienten einer kardiologischen Intensivstation. "Comparison of APACHE I, SAPS and TISS in daily use for patients in a coronary care unit." Intensivmedizin und Notfallmedizin. 2000;37:31-43.

28 Bundesamt für Statistik. Normenklaturen 2011, Internationale Klassifikation der Krankenheiten (ICD-10) [Internet]. 2011 "Swiss Federal Office of Statistics, Swiss Nomenclature 2011, International Classification of Diseases (ICD-10)." [cited 2011 Feb 24]. Available from: http://www.bfs.admin.ch.

29 Puntillo KA, Morris AB, Thompson CL, Stanik-Hutt J, White CA, Wild LR. Pain behaviors observed during six common procedures: results from Thunder Project II. Crit Care Med. 2004;32(2):421-7.

30 Li DT, Puntillo K. A pilot study on coexisting symptoms in intensive care patients. Appl Nurs Res. 2006;19(4):216-9.

31 Sessler CN, Gosnell MS, Grap MJ, Brophy GM, O'Neal PV, Keane KA, Tesoro EP, Elswick RK. The Richmond Agitation-Sedation Scale: validity and reliability in adult intensive care unit patients. Am J Respir Crit Care Med. 2002;166(10):1338-44.

32 Ely EW, Truman B, Shintani A, Thomason JW, Wheeler AP, Gordon S, Francis J, Speroff T, Gautam S, Margolin R, Sessler CN, Dittus RS, Bernard GR. Monitoring sedation status over time in ICU patients: reliability and validity of the Richmond Agitation-Sedation Scale (RASS). JAMA. 2003;289(22):2983-91. 
33 Putensen C, Guenther U. Die Confusion Assessment Method (CAM) für Intensivstationen (CAM-ICU). Ubungsleitfaden. Vanderbilt Universität [Internet]. 2002 "The Confusion Assessment Method (CAM) for the Intensive Care Unit (CAM-ICU). User Handbook Vanderbilt University." [cited 2011 Feb 24] Available from: http://www.mc.vanderbilt.edu/icudelirium/docs/CAM_ICU_training_German.pdf.

34 Ely EW, Margolin R, Francis J, May L, Truman B, Dittus R, Speroff T, Gautam S, Bernard GR, Inouye SK. Evaluation of delirium in critically ill patients: validation of the Confusion Assessment Method for the Intensive Care Unit (CAM-ICU). Crit Care Med. 2001;29(7):1370-9.

35 Herrmann CH, Buss U, Snaith RP, editors. HADS-D: Ein Fragebogen zur Erfassung von Angst und Depressivität in der somatischen Medizin. Testdokumentation und Handanweisung "HADS-D: questionnaire to assess anxiety and depression in somatic medicine. Test documentation and handbook."Bern: Hans Huber, 1995.

36 Bickel H. Deutsche Version der Confusion Assessment Method (CAM) zur Diagnose des Delirs. "German version of the Confusion Assessment Method (CAM) for diagnosing Delirium." Psychosom Konsiliarpsychiatr. 2007;: :224-8.

37 Marcantonio ER, Michaels M, Resnick NM. Diagnosing delirium by telephone. J Gen Intern Med. 1998;13(9):621-3.

38 Inouye SK, van Dyck CH, Alessi CA, Balkin S, Siegal AP, Horwitz RI. Clarifying confusion: the confusion assessment method. A new method for detection of delirium. Ann Intern Med. 1990;113(12):941-8.

39 Bullinger M, Kirchberger I, Ware J. Der deutsche SF-36 Health Survey. Übersetzung und psychometrische Testung eines krankheitsübergreifenden Instruments zur Erfassung der gesundheitsbezogenen Lebensqualitat. "The German version of the SF-36 Health Survey. Iranslation and psychometric testing of a generic instrument to measure health-related quality of life." Z f Gesundheitswiss. 1995;3(1):21-36.

40 Bullinger M. Erfassung der gesundheitsbezogenen Lebensqualität mit dem SF-36-Health Survey. "Measuring health-related quality of life with the SF-36 Health Survey." Bundesgesundheitsbl - Gesundheitsforsch - Gesundheitsschutz. 2000;43:190-7.

41 Ringdal M, Plos K, Lundberg D, Johansson L, Bergbom I. Outcome after injury: memories, health-related quality of life, anxiety, and symptoms of depression after intensive care. J Trauma. 2009;66(4):1226-33.

42 Boyle M, Murgo M, Adamson H, Gill J, Elliott D, Crawford M. The effect of chronic pain on healthrelated quality of life amongst intensive care survivors. Aust Crit Care. 2004;17(3):104-6, 108-13.

43 Montuclard L, Garrouste-Orgeas M, Timsit JF, Misset B, De Jonghe B, Carlet J. Outcome, functional autonomy, and quality of life of elderly patients with a long-term intensive care unit stay. Crit Care Med. 2000;28(10):3389-95.

44 de Rooij SE, Govers AC, Korevaar JC, Giesbers AW, Levi M, de Jonge E. Cognitive, functional, and qualityof-life outcomes of patients aged 80 and older who survived at least 1 year after planned or unplanned surgery or medical intensive care treatment.J Am Geriatr Soc. 2008;56(5):816-22.

45 Hofhuis J, Hautvast JL, Schrijvers AJ, Bakker J. Quality of life on admission to the intensive care: can we query the relatives? Intensive Care Med. 2003;29(6):974-9. 


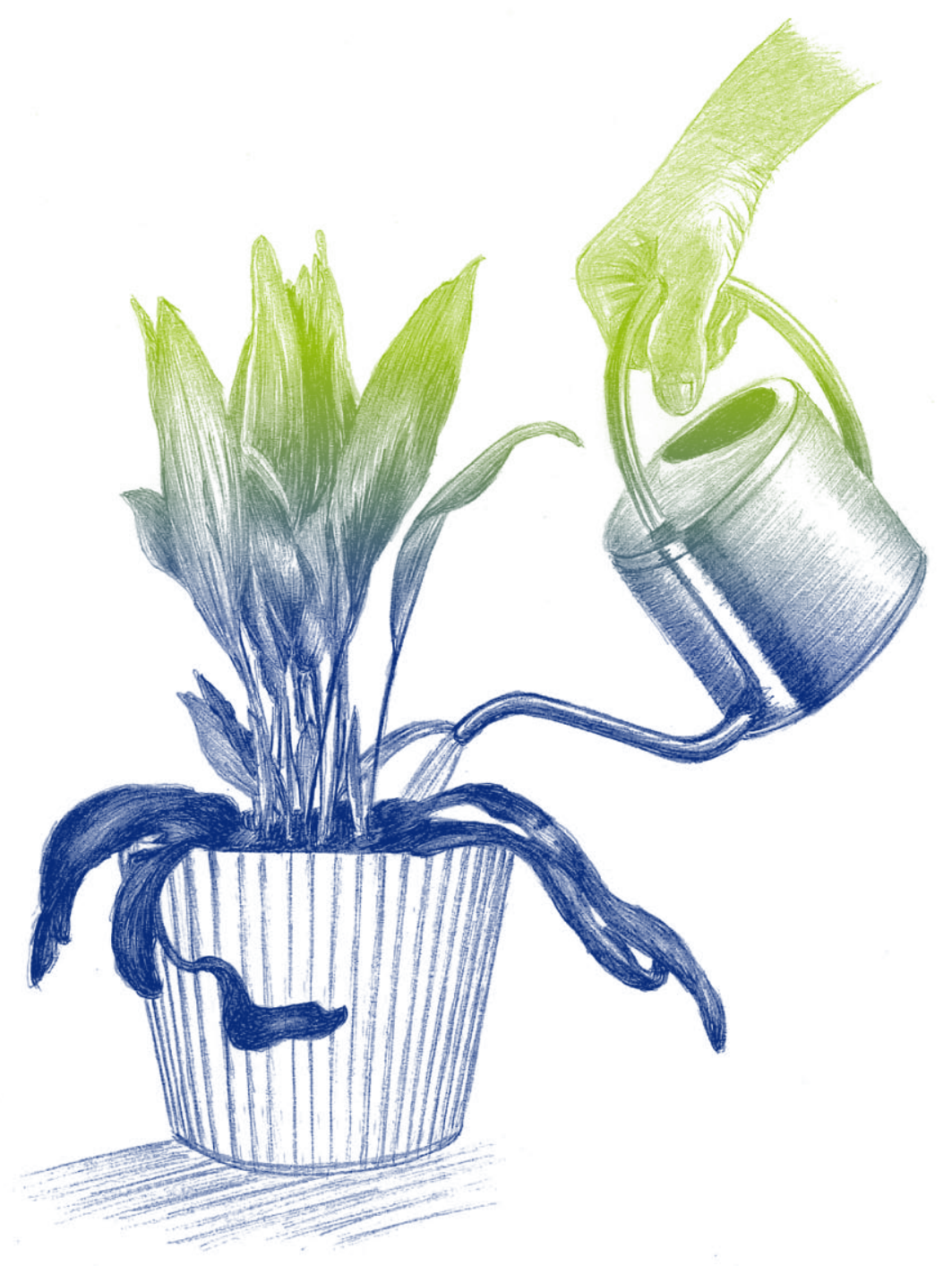



Pain, Anxiety, and Agitation for Critically Ill Older Patients after an Intensive Care Unit Stay 


\section{Abstract}

Aims and Objectives

This study investigated whether an intensive care unit (ICU) stay is associated with persistent pain, anxiety and agitation in critically ill older patients.

Background

Patients hospitalized in the ICU are at risk of experiencing pain, anxiety, and agitation, but long-term consequences for older patients have rarely been investigated.

\section{Design}

Prospective non-randomized longitudinal study.

Methods

Pain, anxiety, and agitation, measured with a numeric rating scale (0-10), were assessed in older patients ( $\geq 65$ years) hospitalized in the medical-surgical ICU of a university hospital. Agitation during the ICU stay was assessed with the Richmond Agitation-Sedation Scale. Data collection occurred in the ICU, one week after the stay, and 6 and 12 months after hospital discharge. Data were collected from an agematched community-based comparison group at recruitment and after 6 and 12 months. Study recruitment took place from December 2008 to April 2011.

Results

This study included 145 older patients (ICU group) and 146 comparison group participants. Pain was higher in the ICU group one week after discharge, although pain levels in general were low. Both groups reported no or low levels of pain after 6 and 12 months. Anxiety levels in general were low, although higher in the ICU group one week after ICU discharge. After 6 and 12 months, anxiety in both groups was comparable. Throughout the study, levels of agitation were similar in both groups.

\section{Conclusions}

Critically ill older patients did not experience increased pain, anxiety, or agitation, 12 months after an ICU stay.

Relevance to Clinical Practice

This study positively shows that an ICU stay is not associated with persistent pain anxiety, and agitation, thus providing additional information to older patients and thei families when making intensive care treatment decisions. Adequate management of pain during and after an ICU stay may minimize the suffering of older patients.

\section{Summary Box}

What does this paper contribute to the global clinical community?

- Treatment of critically ill older patients in an ICU is not necessarily associated with long-term pain, anxiety, and agitation. This information is important for helping older patients and families cope with uncertainties and fear before an ICU stay.

- Adequate management of pain during and after ICU discharge is essential and may minimize long-term suffering in critically ill older patients. 


\section{Introduction}

Worldwide, an increasing number of older patients are being treated in intensive care units (ICUs)., ${ }^{1,2}$ The combination of acute critical illness, multiple co-morbidities, age-related changes, and the ICU environment ${ }^{3}$ contributes to the vulnerability of critically ill older patients who are consequently at an in-creased risk of negative outcomes. ${ }^{4}$ Most patients hospitalized in ICUs will experience pain, and identify pain, anxiety, and agitation, as major sources of distress. ${ }^{5-7}$ Evidence shows that in general, ICU patients experience significant disability and pain for many months following ICU discharge..$^{8,9}$ Only a few studies have focused on older patients and the longterm consequences of distressing experiences, such as pain, anxiety, and agitation, during and after an ICU stay.

\section{Background}

Pain, anxiety and agitation are common symptoms in patients treated in an ICU and can be particularly distressing for older patients. ${ }^{5,10}$ Assessing and managing pain in critically ill older patients is challenging because many older patients are unable to self-report their pain. In addition, insufficient treatment of pain is frequent in spite of advances in pain therapy; $63 \%-77 \%$ of all medical and surgical ICU patients report moderate to severe pain. ${ }^{6,11}$ Even months after an ICU stay, patients continue to have traumatic memories of pain experienced during the ICU, or develop chronic pain..$^{9,12}$

Anxiety and agitation are among the most frequent mental disturbances. Between $46 \%-66 \%$ of all ICU patients experience anxiety ${ }^{13,14}$ that may persist for an extended period of time following discharge..$^{15}$ Agitation is present in $16 \%-52 \%$ of the ICU patients. ${ }^{5,16}$ Most studies on mental disturbances in an ICU and its long-term consequences have not specifically focused on agitation, but evaluated delirium or the 'ICU Syndrome.'17,18

The long-term influence of pain and anxiety experienced by older patients during an ICU stay, has been reported in relation to long-term quality of life. ${ }^{1}$ Older patients treated in ICUs have an increased risk of developing a chronic critical illness, thus exacerbating their symptom burden, including pain, anxiety, and depression. ${ }^{19}$ The association of ICU-factors such as length of stay, admission diagnosis, severity of illness, co-morbidities, response to analgo-sedation, and pre-ICU conditions with pain anxiety, and agitation, in the year following discharge is not known. Monitoring persistent pain, anxiety, and agitation, enables the development of targeted interventions to be initiated during the ICU stay and rehabilitation period.

\section{Methods}

Aims and Objectives

The primary goal of this study was to determine if an ICU stay is associated with older patients' experiences of pain, anxiety and agitation during the first year following ICU discharge. In addition we examined the relationship between the presence of long-term pain, anxiety, and agitation, and factors characterizing the ICU stay, such as length of stay, admission diagnosis, severity of illness, co-morbidities, and response to analgo-sedation.

The research questions were:

1) Is an ICU stay associated with the presence of pain, anxiety, and agitation, in critically ill older patients one week after ICU discharge and at 6-and 12-months follow-up?

2) Are pain, anxiety, agitation, length of stay, admission diagnosis, severity of illness, co-morbidities, and analgo-sedation, during an ICU stay associated with pain, anxiety and agitation 6 and 12 months after ICU discharge?

\section{Design}

This is a prospective non-randomized longitudinal design. The present study was part of a larger longitudinal study on the long-term consequences of an ICU stay for critically ill older patients. ${ }^{20}$ Data collection took place between December 2008 and April 2011. 


\section{Sample and Setting}

The study used a convenience sample of critically ill older patients hospitalized in a medical-surgical ICU of a university hospital (ICU group) and age-matched participants from the community (comparison group). The inclusion criteria for the ICU group were: able to speak and read German or French, 65 years or older, reside in Switzerland, and hospitalized in the ICU for at least 48 hours. Exclusion criteria were: inability to express themselves verbally, for example because of temporary tracheostomies, illness-related cognitive impairment (pre-existing dementia from medical records), psychotic illnesses, or palliative care due to terminal illness. The inclusion criteria for the comparison group were: able to speak and read German or French, 65 years or older, and residing in Switzerland. Exclusion criteria were: illness-related cognitive impairment and psychotic illnesses. The comparison group could have the normal illnesses of aging, but could not have had any procedures, surgeries, or hospitalizations, within two weeks prior to entry into the study. In order to avoid recall bias, the comparison group could not have been treated in an ICU within the past 15 years. The comparison group was recruited via newspaper articles, flyers, organizations, and word of mouth, and received a small financial compensation to encourage participation for the entire year of the study.

Sample Size

Based on a power analysis of the prevalence of pain in an ICU, with a 95\% confidence interval for an estimated prevalence between $0.30-0.50$ and a total of 0.20 , a sample size of 81-96 was needed for each group. ${ }^{21}$ To account for estimated loss to follow-up over one year, it was planned to recruit 150 subjects per group. Following recruitment of 20 critically ill older patients into the ICU group, 20 age-matched participants were recruited for the comparison group. This procedure enabled age-matching and recruitment at a similar point in time. This pattern continued until 150 patients and participants were recruited for their respective groups.

\section{Data Collection}

Data on pain, anxiety, agitation, and background information were collected from the ICU group during the ICU stay. Baseline measurements took place one week after ICU discharge and follow-up measurements took place after 6 and 12 months. Background data as well as baseline measurements from the comparison group were collected at study recruitment and the follow-up measurements were obtained after 6 and 12 months (Figure 1 and Table 1).

\section{Figure 1 Flow diagram of sample recruitment and attrition}

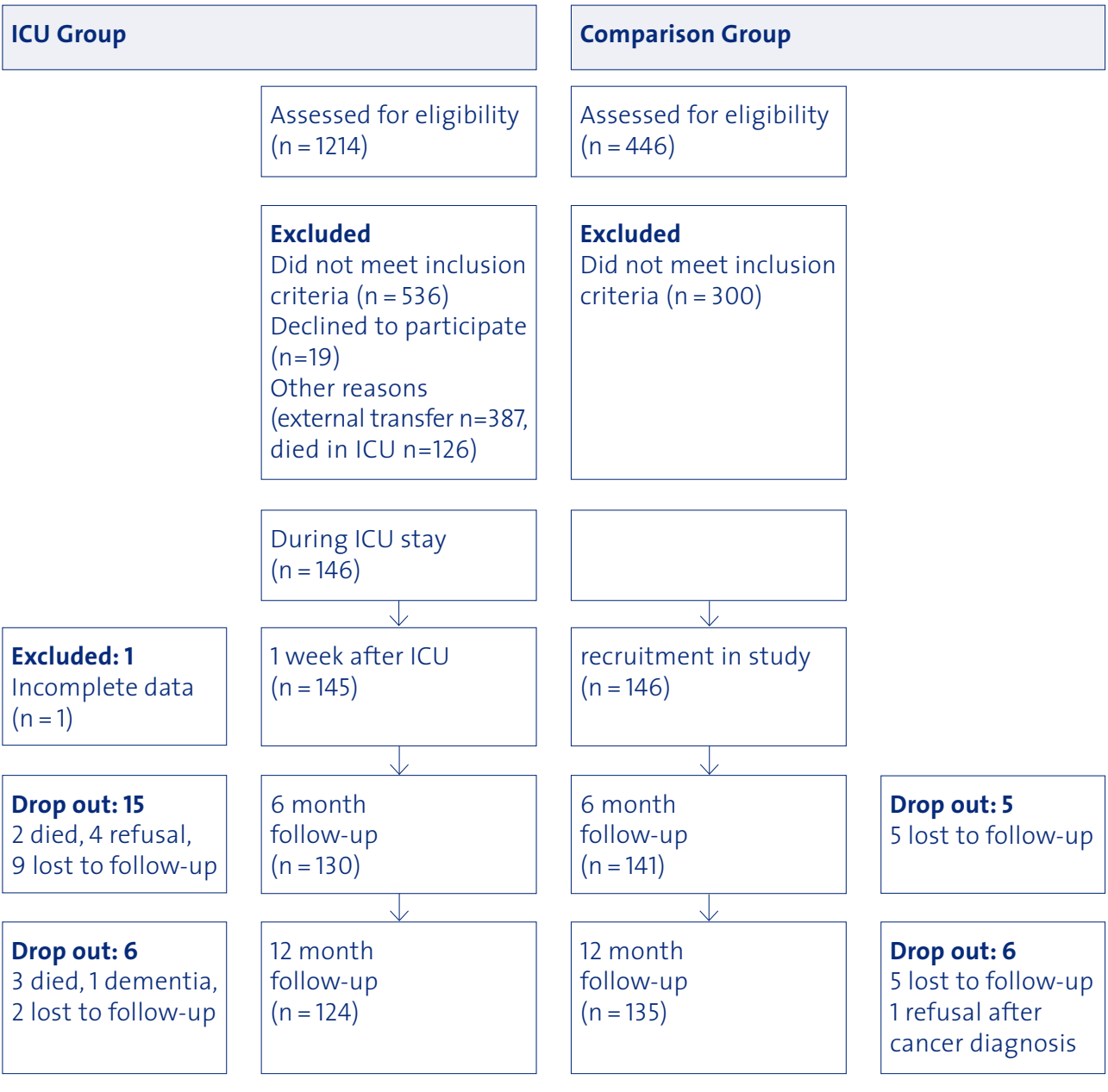

Abbreviations: ICU=Intensive Care Unit. $n=$ number of subjects. 
Background Data and Assessment Instruments

Demographics were collected from both groups (age, sex). Co-morbidities were measured using the International Classification of Diseases, Version 10. ${ }^{22}$ Additional data recorded for the ICU group were the Acute Physiology, Age and Chronic Health Evaluation Score II (APACHE II), ${ }^{23}$ ICU admission diagnosis, ICU length of stay, and the daily amount of analgesics (fentanyl), and sedatives (propofol and midazolam).

Measurements During the ICU Stay (ICU Group Only)

Patients were asked to rate their pain or anxiety using a numeric rating scale (NRS) that ranged from $0=$ no pain or anxiety to $10=$ worst possible pain|anxiety. ${ }^{24,25} \mathrm{Agita}$ tion was defined as continual movement characterized by fidgeting, moving from side to side, pulling at dressings and bed sheets, attempting to remove catheters or other tubes, and disorientation. ${ }^{26}$ Agitation was evaluated using the Richmond Agitation-Sedation Scale (RASS). ${ }^{27}$ Delirium is a disturbance of consciousness with inattention accompanied by change in cognition or perceptual disturbance that develops during a short period and fluctuates over time. Delirium was assessed using the Confusion Assessment Method for the ICU (CAM-ICU). ${ }^{28}$

Measurements at Follow-Up (After ICU Discharge/Study Recruitment

Pain, anxiety and agitation were assessed with the NRS referring to the previous seven days. Anxiety was defined as a feeling of dread, fear andlor lack of control. Agitation was defined as either motor or mental unrest. Delirium was assessed using the Short Form of the CAM including a telephone version for all interviews with the comparison group and for the 6- and 12-month follow-up calls for the ICU group Validated German and French versions of all instruments were available. Data on ICU memories were collected at one week post-ICU (ICU group only) using 4 questions from the ICU Memory Tool related to factual and delusional memories. ${ }^{29}$

\section{Procedure}

Table 1 provides an overview of the measurements and their respective time points. During the ICU stay, pain and agitation (RASS) were assessed every 2 hours and anxiety every 8 hours. The ICU's standardized sedation protocols were used. The amount of analgesics and sedatives used was recorded at all times. Four critical care nurse specialists were trained to administer the CAM-ICU and the CAM for the study. The CAM-ICU was recorded only at the time of ICU discharge.

Following ICU discharge, all eligible older patients were contacted by one of the critical care nurse specialists and invited to participate in the study. The study procedures were explained and the patients signed the informed consent form. Patients had to be cognitively alert and free from symptoms of delirium. The critical care nurse specialists initially collected the data from the ICU group using face-to-face interviews in the hospital one week after ICU discharge. The patients were asked to evaluate their pain, anxiety, and agitation, at the time of the interview. They were also instructed to recall their pain, anxiety and agitation, one week prior to ICU admission in order to establish pre-ICU baseline measurements. ${ }^{1}$ The critical care nurse specialist conducting the interview asked four questions from the ICU Memory Tool. ${ }^{29}$ The CAM was administered at the completion of the interview. The comparison group was always interviewed by telephone in addition to self-report questionnaires. The 6 - and 12-month data collection for all study participants consisted of mailed selfreport questionnaires to rate their pain, anxiety and agitation, and a telephone in terview to screen for delirium. 
Table 1 Measurements at each time point (ICU group and comparison group)

\begin{tabular}{|c|c|c|c|c|c|}
\hline \multirow[t]{2}{*}{ Variables } & \multirow[t]{2}{*}{ Tools } & \multicolumn{4}{|c|}{ Time of Measurement } \\
\hline & & $\begin{array}{l}\text { During ICU } \\
\text { Stay }^{2}\end{array}$ & $\begin{array}{l}\text { One week after } \\
\text { ICU|recruit- } \\
\text { ment }\end{array}$ & $\begin{array}{l}6 \text { month } \\
\text { follow-up }\end{array}$ & $\begin{array}{l}12 \text { month } \\
\text { follow-up }\end{array}$ \\
\hline $\begin{array}{l}\text { Background } \\
\text { Data }\end{array}$ & age, sex & & $x$ & & \\
\hline Pain & NRS & $x$ & $x^{1}$ & $x$ & $x$ \\
\hline Anxiety & NRS & $\mathrm{x}$ & $x^{1}$ & $x$ & $x$ \\
\hline Agitation & $\begin{array}{l}\text { RASS }^{2} \\
\text { NRS } \\
\text { CAM-ICU } \\
\text { CAM }\end{array}$ & $x$ & $X^{1}$ & $x$ & $x$ \\
\hline $\begin{array}{l}\text { Severity of } \\
\text { illness }\end{array}$ & APACHE $\|^{2}$ & $\mathrm{x}$ & & & \\
\hline $\begin{array}{l}\text { Diagnostic } \\
\text { categories }\end{array}$ & APACHE $\|^{2}$ & $\mathrm{x}$ & & & \\
\hline Co-morbidities & ICD 10 & $x$ & $x$ & $x$ & $x$ \\
\hline ICU Memories & $\begin{array}{l}\text { ICU Memory } \\
\text { Tool }^{2}\end{array}$ & & $x$ & & \\
\hline Medications $^{3}$ & $\begin{array}{l}\mu \mathrm{g} \mid \mathrm{mg} \text { per } \\
\text { patient per day }\end{array}$ & $x$ & $x$ & $x$ & $x$ \\
\hline
\end{tabular}

Note: Assessment pre-existing pain, anxiety, and agitation, one week before the ICU stay (retrospective assessment) at one week before the ICU (ICU group only) and present level of pain, anxiety and agitation. ${ }^{2}$ Only ICU group. ${ }^{3}$ Analgesics (opioids during ICU; after ICU tramadol, paracetamol, non-steroidal anti-inflammatory), sedatives (propofol, midazolam during ICU, after ICU all benzodiazepine and neuroleptics). Abbreviations: ICU=Intensive Care Unit. NRS=Numeric Rating Scale. RASS=Richmond Agitation-Sedation Scale. CAM ICU=Confusion Assessment Method Intensive Care Unit. CAM=Confusion Assessment Method. APACHE=Acute Physiology, Age and Chronic Health Evaluation. $I C D=$ International Classification of Diseases

\section{Ethical Considerations}

The study protocol was approved by the regional Ethics Commission (File Number: 128|08). All study participants signed informed consent forms. In addition, the ICU group gave their consent to use data from the ICU stay.

\section{Data Analysis}

The statistical analysis was conducted using the software Data R. ${ }^{30}$ Demographics were characterized by descriptive statistics. In an initial analysis, long-term differences between the ICU and the comparison group were examined for the outcome variables pain, anxiety, and agitation, in separate cumulative logit random intercept regression models. ${ }^{31}$ The scale of these outcomes (NRS 0-10) was transformed into an ordinal scale with six levels $([0,1),[1,3),[3,5),[5,7),[7,9),[9,10))$, because the NRS 0-10 is not completely metric and the data are not distributed normally. The explanatory variables of these three models included sample allocation, individual (random effect), time, and design effects (age|sex). To determine the significance of the group differences, likelihood ratio tests were used. In this analysis, a Bonferroni correction was used (significance set at $p<0.005$ ) to correct for multiple testing

In a second analysis, results from an explorative analysis on associations between explanatory variables and pain one week, 6 months and 12 months after an ICU stay were reported. In the first analysis, pain was the outcome variable showing the most significant differences between the groups. The second explorative analysis started with 36 illness-related variables (ICU admission diagnosis, severity of illness, analgo-sedation, co-morbidities, pain, anxiety and agitation during ICU, etc.), as well as structural variables (ICU length of stay). Akaike Information Criterion-based stepwise algorithms were used as a strategy in variable selection. The following explanatory variables were used: the individual (random intercept), time, sex, pain and anxiety before the ICU stay, surgery during the ICU, RASS ICU (95\% quantile: Range: -1 to +4), pain ICU (95\% quantile: range: $0-10)$, sedation (mglday), length of ICU stay, comorbidity and agitation after the ICU stay. In the second explorative analysis, $p<0.05$ was considered significant. Differences between the sexes were examined using Chi-squared tests. 


\section{Results}

\section{Patient Characteristics}

In total, 1660 persons were screened for the study; 1214 older patients for the ICU group, and 446 participants for the comparison group (Figure 1). The final sample consisted of 291 individuals: 145 patients (ICU group) and 146 participants (comparison group). Demographic information is summarized in Table 2. The comparison group had a significantly higher percentage of women ( $p<0.001)$. Eighty-three $(57 \%)$ ICU group patients had co-morbidities, 41 (28\%) had no co-morbidities, and for 2 $(15 \%)$, no information was available. In the comparison group, 55 (38\%) participants had co-morbidities, $83(57 \%)$ had no co-morbidities, and for $8(5 \%)$ participants no information was available.

At ICU discharge, 72 (50\%) patients had delirium, 59 (40\%) patients had no delirium and $14(10 \%)$ patients could not be assessed. Of the $55(38 \%)$ patients who had cardiovascular surgery, $28(51 \%)$ had symptoms of delirium. No patients or participants had symptoms of delirium at study recruitment or at any of the follow-up periods.

\section{Table 2 Characteristics of the study subjects}

\begin{tabular}{|c|c|c|}
\hline Characteristic & ICU Group & Comparison Group \\
\hline Age & $68.72(5.39)$ & $69.40(5.51)$ \\
\hline Sex, number of subjects (\%) & $\begin{array}{l}\text { Women: } 39(27 \%) \\
\text { Men: } 106(73 \%)\end{array}$ & $\begin{array}{l}\text { Women: } 75(51 \%) \\
\text { Men: } 71(49 \%)\end{array}$ \\
\hline $\begin{array}{l}\text { ICU length of stay in days, mean } \\
\text { (standard deviation) }\end{array}$ & $4.57(5.81)$ & \\
\hline APACHE II score (points) (0-71) & $20.5(8.5)$ & \\
\hline $\begin{array}{l}\text { ICU admission diagnosis, number of subjects (\%) } \\
\text { Cardiac diseases } \\
\text { - Coronary|valvular diseases }\left(\text { surg }^{1}\right) \\
\text { - Coronary|valvular diseases }\left(\text { coro }^{2}\right) \\
\text { - Diseases of aorta (surg) } \\
\text { - Cardiac arrest } \\
\text { - Cardiac failure } \\
\text { Pulmonary diseases } \\
\text { Sepsis } \\
\text { Neurological diseases } \\
\text { Trauma } \\
\text { Other (Gastrointestinal disease, burns, drug } \\
\text { overdose) }\end{array}$ & $\begin{array}{l}80(56 \%) \\
\cdot 36(45 \%) \\
\cdot 4(5 \%) \\
\cdot 19(24 \%) \\
\cdot 4(5 \%) \\
\cdot 17(21 \%) \\
20(14 \%) \\
12(8 \%) \\
13(9 \%) \\
11(7 \%) \\
9(6 \%)\end{array}$ & \\
\hline $\begin{array}{l}\text { Factual memories of the ICU stay, } \\
\text { number of subjects }(\%) \\
\text { Yes } \\
\text { No }\end{array}$ & $\begin{array}{l}118(81 \%) \\
27(19 \%)\end{array}$ & \\
\hline $\begin{array}{l}\text { Pain medication, number of subjects (\%) } \\
1 \text { week after ICU|recruitment } \\
6 \text { months after hospital discharge|recruitment } \\
12 \text { months after hospital discharge|recruitment }\end{array}$ & $\begin{array}{l}116(80 \%) \\
29(22 \%) \\
18(15 \%)\end{array}$ & $\begin{array}{l}10(7 \%) \\
6(4 \%) \\
3(2 \%)\end{array}$ \\
\hline $\begin{array}{l}\text { Sedation|Anti-anxiety medication, } \\
\text { number of subjects (\%) } \\
1 \text { week after ICU|recruitment } \\
6 \text { months after hospital discharge|recruitment } \\
12 \text { months after hospital discharge|recruitment }\end{array}$ & \begin{tabular}{|l}
$32(22 \%)$ \\
$2(2 \%)$ \\
$4(3 \%)$
\end{tabular} & $\begin{array}{l}3(2 \%) \\
0 \\
0\end{array}$ \\
\hline
\end{tabular}

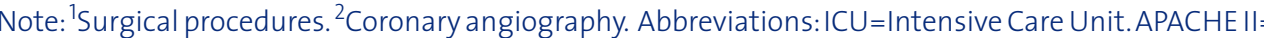
Acute Physiology, Age and Chronic Health Evaluation. 


\section{Pain, Anxiety, and Agitation over 12 Months}

Levels of pain were generally low throughout the 12 months (Figure 2). The regression analysis showed that pain scores in the ICU group were significantly higher one week after ICU discharge than those of the comparison group $(b=1.32, \mathrm{p}<0.001)$. No differences in pain scores between the groups were found at 6 or 12 months ( 6 months: $b=0.64, \mathrm{p}=0.01 ; 12$ months: $b=0.30, \mathrm{p}=0.25$ ).

\section{Figure 2 Pain over the 12 month period}

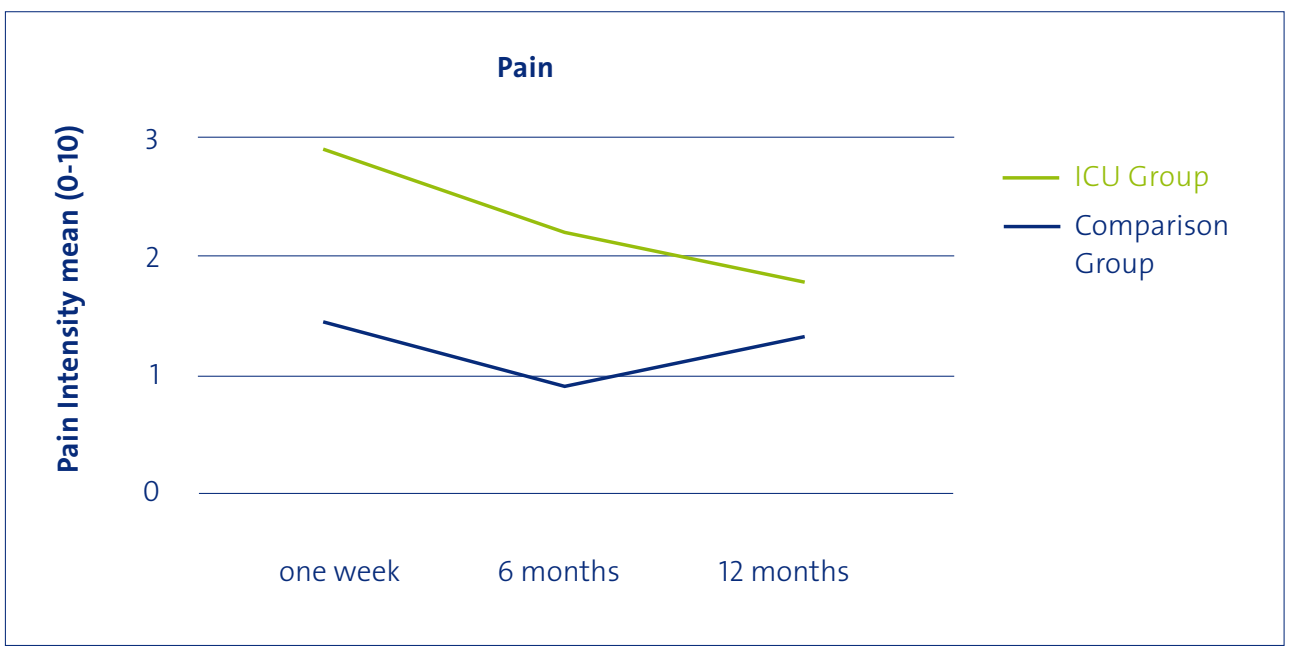

Note: ICU group: one week after ICU versus comparison group: recruitment in study: mean: 2.9 (SD: 2.8 versus mean: 1.4 (SD: 1.9), 6 months: mean: 2.2 (SD: 2.8) versus mean: 0.9 (SD: 1.9), 12 months: mean: 1.7 (SD: 2.6) versus mean: 1.3 (SD: 2.1). Abbreviations: ICU=Intensive Care Unit. SD=Standard Deviation.
Low levels of anxiety were reported by the ICU group at all times (Figure 3). The regression analysis showed that anxiety scores were higher in the ICU group than the comparison group directly after ICU discharge $(b=0.98, p=0.006)$, however differences in anxiety disappeared after 6 and 12 months ( 6 months: $b=0.98, p=0.007 ; 12$ months: $b=0.03, \mathrm{p}=0.94$ )

\section{Figure 3 Anxiety over the 12 month period}

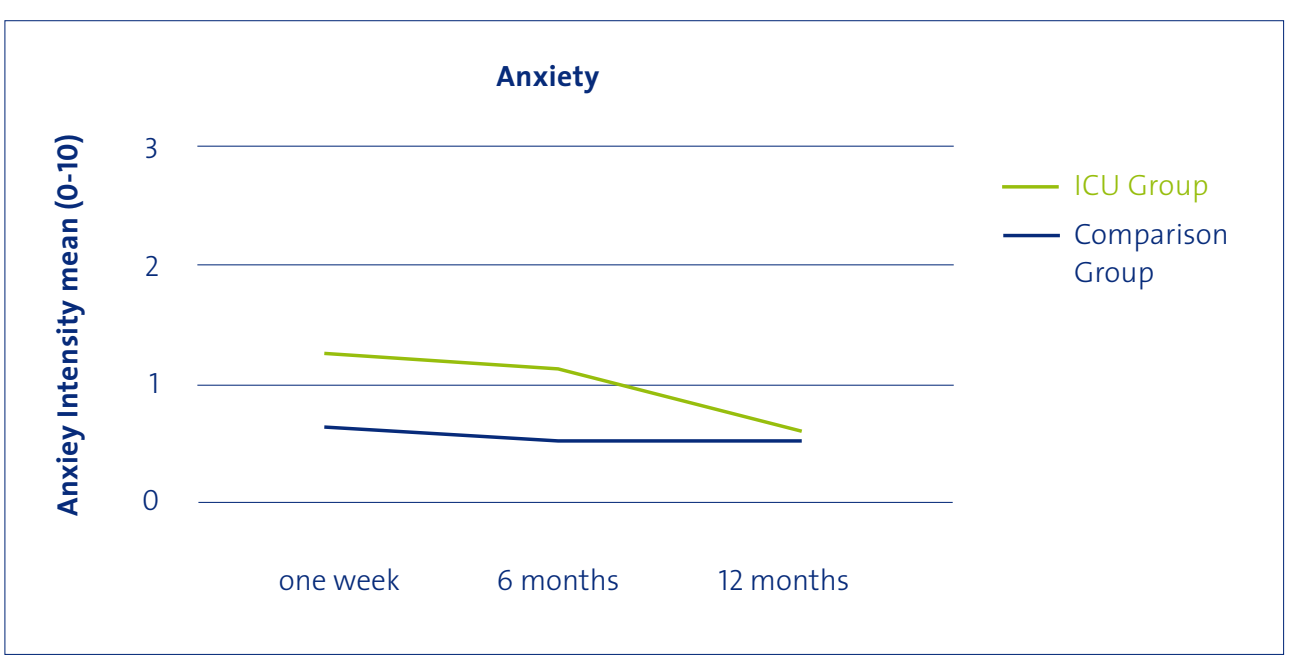

Note: ICU group: one week after ICU versus comparison group: recruitment in study: mean: 1.3 (SD: 2.7) versus mean: 0.6 (SD: 1.5), 6 months: mean: 1.1 (SD: 2.4) versus mean: 0.5 (SD: 1.4), 12 months: mean: 0.6 (SD: 1.7) versus 0.6 (SD: 1.7). Abbreviations: ICU=Intensive Care Unit. SD=Standard Deviation.

Low levels of agitation were reported by both groups throughout the 12 months (Figure 4). The regression analysis showed no significant differences between groups at any time point ( 1 week recruitment: $b=0.56, \mathrm{p}=0.04 ; 6$ months: $b=-0.72, \mathrm{p}=0.03$;

12 months: $b=-0.33, p=0.31)$. 
Figure 4 Agitation over the $\mathbf{1 2}$ month period

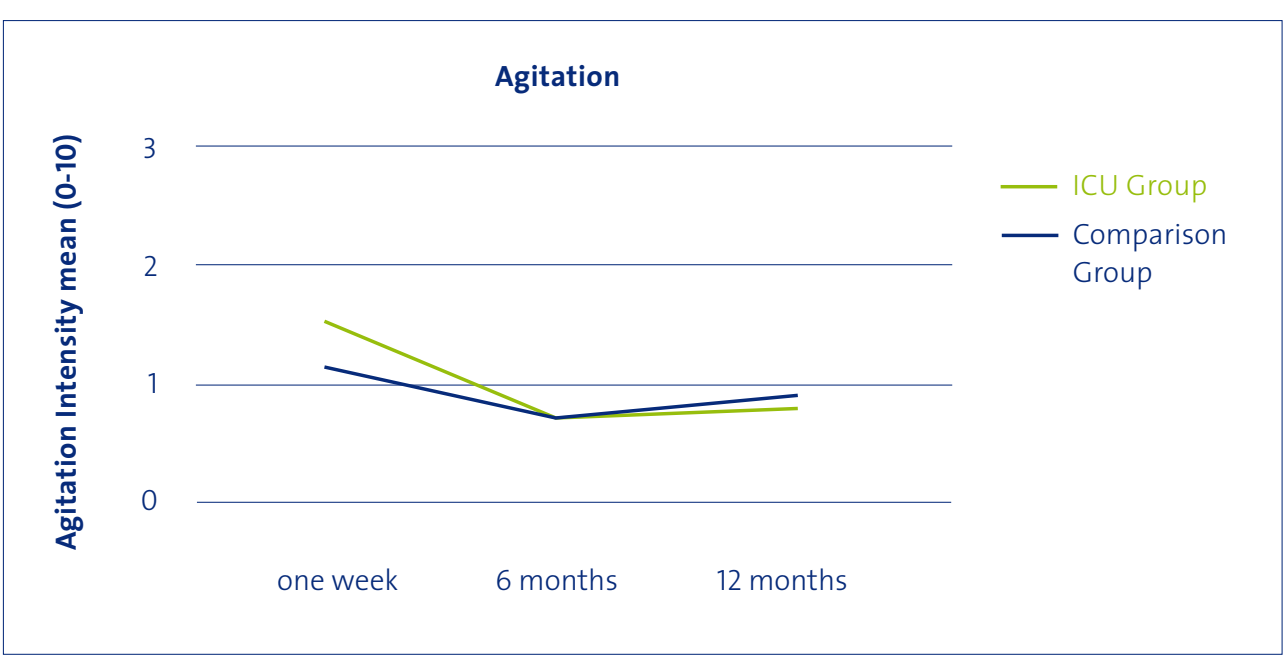

Note: ICU group: one week after ICU versus comparison group: recruitment in study: mean: 1.5 (SD: 2.7) versus mean: 1.2 (SD: 2.0), 6 months: mean: 0.8 (SD: 1.9) versus mean: 0.7 (SD: 1.8), 12 months: mean 0.8 (SD: 1.7) versus mean: 0.9 (SD: 2.0). Abbreviations: ICU=Intensive Care Unit. SD=Standard Deviation.

\section{Factors Associated with Pain in the ICU Group}

The following factors were associated with pain in the ICU group during followup: pain before ICU admission, pain during the ICU stay, surgical procedures, higher doses of sedatives, and the presence of agitation after the ICU stay. ICU group patients who had pain prior to the ICU stay had significantly more pain at 12 months $(b=0.20, p=0.007)$. ICU group patients with pain during the ICU stay reported significantly more pain directly after ICU discharge $(b=0.25, \mathrm{p}=0.01)$, after 6 months $(b=0.26$, $p=0.01)$, and at 12 months $(b=0.29, p=0.01)$. Surgical procedures during the ICU were significantly associated with more pain directly after ICU discharge $(b=1.06, p=0.02)$ ICU group patients who received high doses of sedation had significantly more pain one week after ICU discharge $(b=0.71, p=0.02)$ but not at 6 - and 12-month follow-up Agitation after the ICU stay was significantly associated with pain 6 months after ICU discharge $(b=0.27, p<0.001)$, but not at 12 months. No significant associations were found between pain and length of ICU stay or co-morbidities (Table 3).
Table 3 Factors associated with pain after intensive care unit discharge

\begin{tabular}{|c|c|c|c|}
\hline Time | Factor & $b$ & $95 \% \mathrm{Cl}$ & p-value \\
\hline \multicolumn{4}{|c|}{ One week after ICU discharge } \\
\hline \multirow{7}{*}{$\begin{array}{l}\text { Pain before ICU } \\
\text { Pain ICU } \\
\text { Anxiety before ICU } \\
\text { Surgery ICU } \\
\text { RASS ICU } \\
\text { Sedation ICU } \\
\text { Length of ICU stay }\end{array}$} & 0.04 & $-0.06,0.17$ & 0.5 \\
\hline & 0.25 & $0.16,0.51$ & 0.01 \\
\hline & 0.11 & $0.00,0.38$ & 0.2 \\
\hline & 1.06 & $0.66,2.58$ & 0.02 \\
\hline & 0.38 & $0.13,1.00$ & 0.09 \\
\hline & 0.71 & $0.48,1.56$ & 0.02 \\
\hline & -1.16 & $-2.98,-0.32$ & 0.08 \\
\hline \multicolumn{4}{|c|}{6 months after hospital discharge } \\
\hline \multirow{9}{*}{$\begin{array}{l}\text { Pain before ICU } \\
\text { Pain ICU } \\
\text { Anxiety before ICU } \\
\text { Surgery ICU } \\
\text { RASS ICU } \\
\text { Sedation ICU } \\
\text { Agitation after ICU } \\
\text { Length of ICU stay } \\
\text { Co-morbidities }\end{array}$} & 0.09 & $0.00,0.31$ & 0.13 \\
\hline & 0.26 & $0.16,0.59$ & 0.01 \\
\hline & -0.11 & $-0.44,0.07$ & 0.22 \\
\hline & -0.13 & $-1.54,0.98$ & 0.81 \\
\hline & 0.46 & $-0.05,1.17$ & 0.46 \\
\hline & 0.21 & $-0.3,0.96$ & 0.43 \\
\hline & 0.27 & $0.14,0.54$ & 0.001 \\
\hline & -0.55 & $-2.61,0.94$ & 0.42 \\
\hline & 0.80 & $-0.37,2.17$ & 0.08 \\
\hline \multicolumn{4}{|c|}{12 months after hospital discharge } \\
\hline \multirow{9}{*}{$\begin{array}{l}\text { Pain before ICU } \\
\text { Pain ICU } \\
\text { Anxiety before ICU } \\
\text { Surgery ICU } \\
\text { RASS ICU } \\
\text { Sedation ICU } \\
\text { Agitation after ICU } \\
\text { Length of ICU stay } \\
\text { Co-morbidities }\end{array}$} & 0.20 & $0.12,0.44$ & 0.007 \\
\hline & 0.29 & $0.18,0.68$ & 0.01 \\
\hline & -0.34 & $-0.82,-0.32$ & 0.004 \\
\hline & 0.41 & $-0.54,1.81$ & 0.42 \\
\hline & 0.09 & $-0.40,0.64$ & 0.72 \\
\hline & -0.03 & $-0.85,0.61$ & 0.9 \\
\hline & 0.16 & $-0.16,0.52$ & 0.19 \\
\hline & 0.73 & $-0.54,3.02$ & 0.29 \\
\hline & 0.86 & $-0.27,2.34$ & 0.07 \\
\hline
\end{tabular}

Note: Cumulative random intercept regression model for pain. Pain before the ICU=Pain one week before the ICU stay (Numeric Rating Scale (NRS): 0-10). Pain ICU=Pain during the ICU stay (95\% quantile). Anxiety before ICU=Anxiety one week before the ICU stay (NRS: 0-10). Surgery ICU=Patients had surgical procedures (no differentiation in the procedures). RASS ICU=RASS during ICU ( $95 \%$ quantile). Sedation ICU=Average sedation per day ( $\mathrm{mg} \mid 24 \mathrm{~h}$, propofol and midazolam). Not all of the coefficients in the model used in the regression analysis are shown in this table. Abbreviations: ICU=Intensive Care Unit. RASS=Richmond Agitation-Sedation Score. $b=$ Regression Coefficient. Cl=Confidence Interval. 


\section{Discussion}

Although pain and anxiety scores were higher shortly following ICU discharge, older patients treated in an ICU did not experience prolonged levels of pain, anxiety, and agitation, one year after hospital discharge. These results show that an ICU stay is not necessarily related to long-term pain, anxiety, and agitation. The reported low levels of pain confirm that these patients had received adequate pain management during follow-up and or the cause of the pain had been resolved.

In contrast to other studies reporting only pain as an outcome, ${ }^{2,9}$ our research also included anxiety and agitation as main outcomes thus providing information about the long-term presence of these distressing symptoms.

Our results are consistent with a recent study on quality of life that showed that pain or emotional wellbeing in critically ill older patients after an ICU stay is not substantially affected in the years following ICU discharge. ${ }^{2}$ Merlani et al ${ }^{1}$ found a decrease in quality of life in older patients with severe abdominal pathologies. How ever, they also reported that pain scores of those patients were close to those of the age matched population. This is in contrast with previous studies of ICU patients that found moderate to strong levels of pain and anxiety months after an ICU stay. ${ }^{9,15}$ One reason for the low level of pain and anxiety in our study may be that the patients received effective pain management and treatment for the cause of the pain and anxiety during follow-up. After one year, only $15 \%$ of the ICU group patients used pain medication and very few used medication for anxiety.

ICU patients with severe sepsis, ARDS, and with surgery, have been reported to experience persistent pain after ICU stay. ${ }^{9,32,33}$ We found that those patients who had surgery during ICU stay had significantly more pain directly after discharge from the ICU, but no other relationships between diseases and pain were shown. The higher levels of pain in our ICU group one week after the ICU stay can be explained in part by the large number of patients who had elective cardiac surgery where pain is initially difficult to control. ${ }^{11}$

Long-term anxiety has been observed in patients following an ICU stay. ${ }^{15}$ However the ICU group in our study did not report higher anxiety after one year than the comparison group. This may be explained by the fact that 118 of the ICU group retained factual memories of their ICU stay as opposed to having delusional memories which have been shown to lead to anxiety and depression after an ICU stay. ${ }^{29}$

Half of the patients in this study had symptoms of delirium at the time of ICU discharge, which is comparable to studies of delirium in an ICU showing a delirium incidence of $47 \%-54 \%{ }^{17,18}$
Previous studies have shown an association between pre-existing persistent pain and long-term pain. ${ }^{34}$ In our study, pain before ICU was also associated with pain one year after an ICU stay. However, the patients in our study had significantly more pain in the early assessment period. It is possible that other unknown factors of everyday life also contributed to later experiences of pain.

But the question remains: how is minor pain perceived by older patients? Do they consider it a "normal" part of the ageing process and therefore are they less likely to report pain or tend to rate it lower?

\section{Limitations}

Our study has some limitations. First, generalizability is limited. The results of our study are related to the treatment strategy of one university hospital ICU utilizing a selective sample (convenience sample, the exclusion of critically ill older patients receiving palliative care, inclusion of a majority of older cardiac patients). Patients with sepsis, trauma, or neurologic illnesses, have a high risk of pain, but only a few of these patients were included in the study. Secondly, recall bias may have influenced the pain, anxiety, and agitation scores for the pre-ICU period, although Jensen et al $\left.\right|^{35}$ reported that pain recall is reliable within a 14-day period. 


\section{Conclusion}

This study demonstrated that critically ill older patients do not report increased pain anxiety, and agitation one year following an ICU stay, showing an ICU stay should not result in long-term consequences. Directly following ICU discharge, the patients did experience pain and anxiety, which requires the attention of healthcare providers

\section{Relevance to Clinical Practice}

It is important that healthcare professionals assess levels of pain, anxiety, and agitation in older patients before, during, and after an ICU stay. Pain existing before admission to the ICU should be documented by nurses. Pain assessments need to include pain management strategies being used by the patient prior to the ICU admission. This information can be obtained when patients are admitted to the ICU from the patient, their medical records, emergency room staff, or family members if the patient cannot give the information themselves. Many painful interventions will be conducted during the first hours of an ICU admission including intratracheal suctioning, catheter insertions, etc. which may be experienced as more painful due to a certain level of baseline pain. Because pain experienced during the ICU stay is associated with long-term pain, a systematic documentation and treatment of pain is necessary. In addition, surgical procedures during the ICU stay demand special measures for pain management. Information on pre-hospital pain, in addition to pain during the ICU, needs to be passed on to the ICU discharge destination, whether it be a step-down unit in the hospital or a different treatment center. Older patients who are discharged from the ICU and hospital with medications for pain and anxiety should be periodically evaluated. Future research also needs to focus on pain, anxiety, and agitation in critically ill older patients receiving palliative care.

\section{References}

1 Merlani P, Chenaud C, Mariotti N, Ricou B. Long-term outcome of elderly patients requiring intensive care admission for abdominal pathologies: survival and quality of life. Acta Anaesthesio Scand. 2007;51(5):530-7.

2 Roch A, Wiramus S, Pauly V, Forel JM, Guervilly C, Gainnier M, Papazian L. Long-term outcome in medical patients aged 80 or over following admission to an intensive care unit. Crit Care. 2011;15(1):R36.

3 Menaker J, Scalea TM. Geriatric care in the surgical intensive care unit. Crit Care Med. 2010;38 (9 Suppl):S452-9.

4 Happ MB. Individualized care for frail older adults: challenges for health care reform in acute and critical care. Geriatr Nurs. 2010;31(1):63-5.

5 Jaber S, Chanques G, Altairac C, Sebbane M, Vergne C, Perrigault PF, Eledjam JJ. A prospective study of agitation in a medical-surgical ICU: incidence, risk factors, and outcomes. Chest. 2005;128(4):2749-57.

6 Chanques G, Jaber S, Barbotte E, Violet S, Sebbane M, Perrigault PF, Mann C, Lefrant JY, Eledjam JJ. Impact of systematic evaluation of pain and agitation in an intensive care unit. Crit Care Med. 2006;34(6):1691-9.

7 Breckenridge SJ, Chlan L, Savik K. Impact of tracheostomy placement on anxiety in mechanically ventilated adult ICU patients. Heart Lung. 2014;43(5):392-8.

8 Cuthbertson BH, Roughton S, Jenkinson D, Maclennan G, Vale L. Quality of life in the five years after intensive care: a cohort study. Crit Care. 2010;14(1):R6.

9 Battle CE, Lovett S, Hutchings $\mathrm{H}$. Chronic pain in survivors of critical illness: a retrospective analysis of incidence and risk factors. Crit Care 2013:17(3):R101.

10 Barr J, Fraser GL, Puntillo K, Ely EW, Gélinas C, Dasta JF, Davidson JE, Devlin JW, Kress JP, Joffe AM, Coursin DB, Herr DL, Tung A, Robinson BR, Fontaine DK, Ramsay MA, Riker RR, Sessler CN, Pun B, Skrobik Y, Jaeschke R. Clinical practice guidelines for the management of pain, agitation, and delirium in adult patients in the intensive care unit. Crit Care Med. 2013;41(1):263-306.

11 Gélinas C. Management of pain in cardiac surgery ICU patients. Have we improved over time? Intensive Crit Care Nurs. 2007:23(5):298-303.

12 Granja C, Lopes A, Moreira S, Dias C, Costa-Pereira A, Carneiro A. Patients' recollections of experiences in the intensive care unit may affect their quality of life. Crit Care. 2005;9(2):R96-109.

13 Kress JP, Gehlbach B, Lacy M, Pliskin N, PohIman AS, Hall JB. The long-term psychological effects of daily sedative interruption on critically ill patients. Am J Respir Crit Care Med. 2003;168(12):1457-61.

14 McKinley S, Stein-Parbury J, Chehelnabi A, Lovas J. Assessment of anxiety in intensive care patients by using the Faces Anxiety Scale. Am J Crit Care. 2004;13(2):146-52.

15 Stevenson JE, Colantuoni E, Bienvenu OJ, Sricharoenchai T, Wozniak A, Shanholtz C, Mendez-Tellez PA, Needham DM. General anxiety symptoms after acute lung injury: predictors and correlates. Psychosom Res. 2013;75(3):287-93. 
16 Woods JC, Mion LC, Connor JT, Viray F, Jahan L, Huber C, McHugh R, Gonzales JP, Stoller JK, Arroliga AC. Severe agitation among ventilated medical intensive care unit patients: frequency, characteristics and outcomes. Intensive Care Med. 2004;30(6):1066-72.

17 Smulter N, Lingehall HC, Gustafson Y, Olofsson B, Engström KG. Delirium after cardiac surgery: incidence and risk factors. Interact Cardiovasc Thorac Surg. 2013;17(5):790-6.

18 Bryczkowski SB, Lopreiato MC, Yonclas PP, Sacca JJ, Mosenthal AC. Delirium prevention program in the surgical intensive care unit improved the outcomes of older adults. J Surg Res. 2014;190(1):280-8

9 Nelson JE, Cox CE, Hope AA, Carson SS. Chronic critical illness. Am J Respir Crit Care Med. 2010;182(4):446-54

20 Jeitziner MM, Hantikainen V, Conca A, Hamers JP. Long-term consequences of an intensive care unit stay in older critically ill patients: design of a longitudinal study. BMC Geriatr. 2011;11:52.

21 Hulley SB, Cummings SR, Browner WS, Grady D, Hearst N, Newman TB. Designing Clinical Research: an epidemiologic approach. Philadelphia: Lippincott Williams \& Wilkins; 2001.

22 DIMDI. Deutsches Institut für Medizinische Dokumentation und Information, Internationale Klassifikation der Krankheiten (ICD-10) [Internet]. 2012 "German Institute for Medical Documentation and Information, International Classification of Diseases (ICD-10)." [cited 2012 May 10] Available from: http://www.dimdi.de/static/de/klassi/diagnosen/icd1o/index.htm.

23 Knaus WA, Draper EA, Wagner DP, Zimmerman JE. APACHE II: a severity of disease classification system. Crit Care Med. 1985:13(10):818-29.

24 Benotsch EG, Lutgendorf SK, Watson D, Fick LJ, Lang EV. Rapid anxiety assessment in medica patients: evidence for the validity of verbal anxiety ratings. Ann Behav Med. 2000;22(3): 199-203.

25 Li DT, Puntillo K. A pilot study on coexisting symptoms in intensive care patients. Appl Nurs Res. 2006;19(4):216-9.

26 Management of the agitated intensive care unit patient. Crit Care Med. 2002;30(1 2):S97-S123.

27 Ely EW, Truman B, Shintani A, Thomason JW, Wheeler AP, Gordon S, Francis J, Speroff T, Gautam S,Margolin R, Sessler CN, Dittus RS, Bernard GR. Monitoring sedation status over time in ICU patients: reliability and validity of the Richmond Agitation-Sedation Scale (RASS). JAMA. 2003;289(22):2983-91.

28 Ely EW, Margolin R, Francis J, May L, Truman B, Dittus R, Speroff T, Gautam S, Bernard GR, Inouye SK. Evaluation of delirium in critically ill patients: validation of the Confusion Assessment Method for the Intensive Care Unit (CAM-ICU). Crit Care Med. 2001;29(7):1370-9.

29 Jones C, Griffiths RD, Humphris G, Skirrow PM. Memory, delusions, and the development of acute posttraumatic stress disorder-related symptoms after intensive care. Crit Care Med. 2001;29(3):573-80

30 Christensen R. Ordinal-regression models for ordinal data R package version 2013.9-30 [Internet] [cited 2014 Mar 10]. Available from: http://www.cran.r-project.org/package=ordinal.

31 Agresti A. Analysis of ordinal categorical data. 2nd ed. New Jersey: John Wiley \& Sons Inc; 2010
32 Dowdy DW, Eid MP, Dennison CR, Mendez-Tellez PA, Herridge MS, Guallar E, Pronovost PJ, Needham DM. Ouality of life after acute respiratory distress syndrome: a meta-analysis. Intensive Care Med. 2006;32(8):1115-24.

33 Gjeilo KH, Klepstad P, Wahba A, Lydersen S, Stenseth R. Chronic pain after cardiac surgery: a prospective study. Acta Anaesthesiol Scand. 2010;54(1):70-8.

34 Althaus A, Hinrichs-Rocker A, Chapman R, Arránz Becker O, Lefering R, Simanski C, Weber F, Moser KH, Joppich R, Trojan S, Gutzeit N, Neugebauer E. Development of a risk index for the prediction of chronic post-surgical pain. Eur J Pain. 2012;16(6):901-10.

35 Jensen MP, Turner LR, Turner JA, Romano JM. The use of multiple-item scales for pain intensity measurement in chronic pain patients. Pain. 1996;67(1):35-40. 


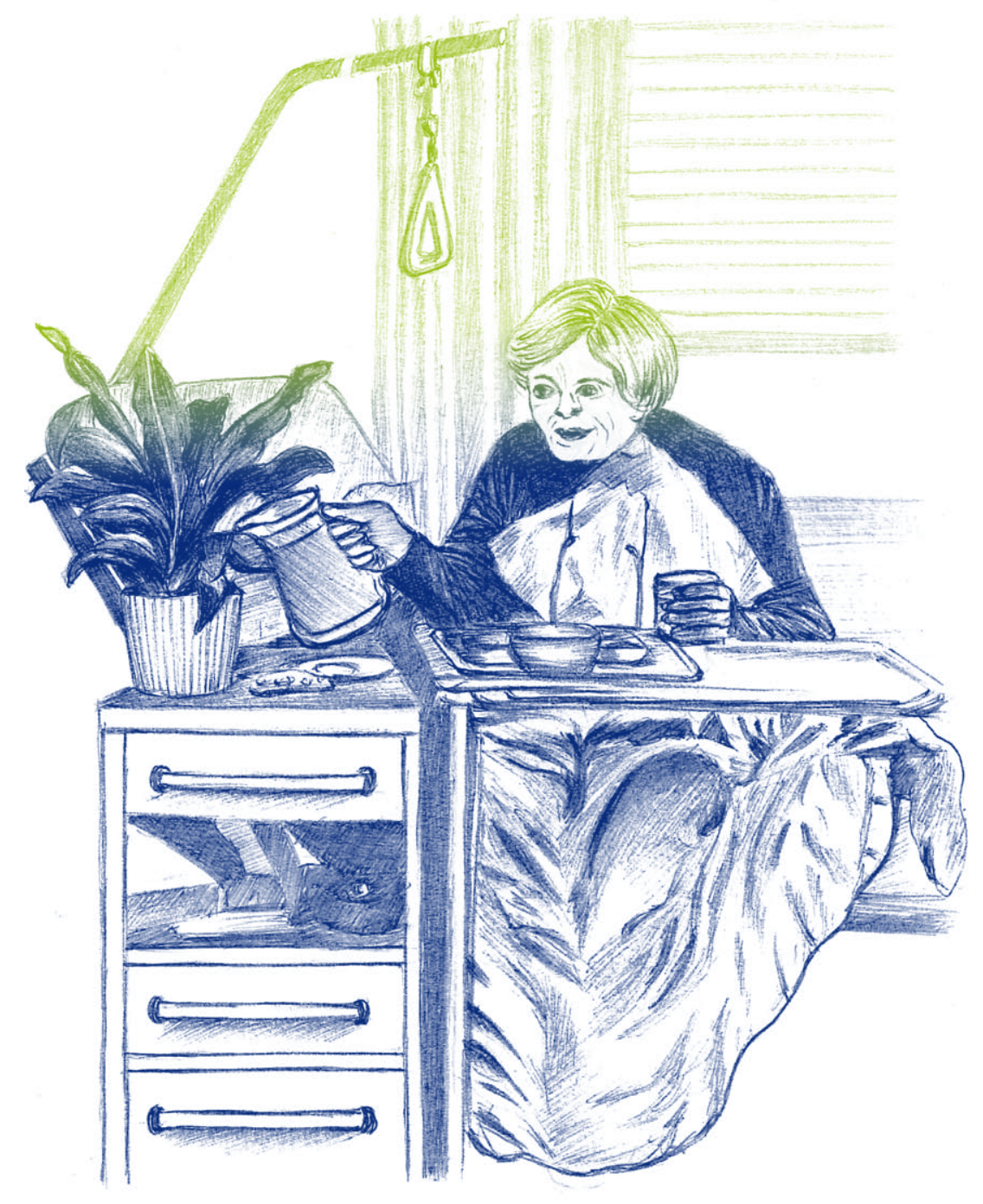


Chapter 5

Changes in Health-Related Ouality of Life in Critically Ill Older Patients One Year After an Intensive Care Unit Stay 


\section{Abstract}

Aims and Objectives

This study investigates the health-related quality of life in older patients, over one year following an intensive care unit (ICU) stay.

\section{Background}

Health-related quality of life is an important outcome when assessing long-term effectiveness of ICU treatment, and assists patients, their relatives and healthcare professionals in making treatment decisions.

\section{Design}

Prospective non-randomized longitudinal study.

\section{Methods}

The Short Form Health Survey 36 was administered 1 week after an ICU stay (retrospective baseline), and after 6 months and 12 months to the study population and to an age-matched comparison group at recruitment (baseline), and after 6 months and 12 months. Demographic data, admission diagnosis, length of stay, severity of illness, pain, anxiety, agitation, intratracheal suctioning, turning and, intubation were recorded. Recruitment period: December 2008 to April 2011

\section{Results}

Health-related quality of life of the older patients was significantly lower than the comparison group, both before and after the intensive care unit stay, and showed great individual variability. Within group scores, however, they were stable over the year. Both physical and mental health scores were lower for the older patients. Renal failure, cardiac surgery, and illness severity were associated with lower physica health scores. Cardiovascular illness, intratracheal suctioning and turning were as sociated with lower mental health scores.

\section{Conclusions}

Health-related quality of life was lower in older patients than in the age-matched group but remained stable over one year.
Relevance to Clinical Practice

Older patients with severe illnesses, acute renal failure or who have had cardiac surgery, need additional support after hospital discharge due to functional restrictions. Discharge planning should ensure that this support will be provided. Special attention should be given to develop and utilize methods to reduce distress during routine ICU interventions such as intratracheal suctioning or turning.

\section{Summary Box}

What does this paper contribute to the global clinical community?

- The current study shows that over the one-year follow-up period, health-related quality of life was consistently lower in critically ill older patients following an intensive care unit stay than in the age-matched comparison group. Differences between groups were already present at baseline and remained stable over one year.

- Older patients with severe illnesses, acute renal failure or who have had cardiac surgery need additional support after hospital discharge due to functional restric tions. Discharge planning should ensure that this support is provided.

- Special attention should be given to develop and utilize methods to reduce distress during routine ICU interventions such as intratracheal suctioning or turning 


\section{Introduction}

Critically ill older patients account for $13 \%$ to $51 \%$ of all admissions to intensive care units (ICUs). ${ }^{1-3}$ Progress in medicine, nursing and technology has made it possible for older patients to survive life-threatening illnesses. Health-related quality of life $(\mathrm{HROOL})$ is considered a significant long-term outcome following treatment in an $I_{C U}{ }^{4,5}$ Evaluating HROOL in older patients after an ICU stay involves various factors such as the environment, psychological and physiological consequences of ICU treatment, and ethical considerations. ${ }^{6}$ Indeed, older patients base their preferences for life-sustaining therapies according to the potential distress caused by ICU treatments and the risk of negative outcomes. ${ }^{7}$ Information on HROoL in older patients following an ICU stay provides patients, relatives and healthcare professionals with important data upon which to base their treatment decisions.

\section{Background}

Health-related quality of life is a dynamic phenomenon and includes an estimation of social, psychological, physical, and everyday aspects of well-being and functioning. 6,8 HROoL is most relevant when judged by the patients themselves; appropriate as sessment tools for this purpose have been described within the framework of comparative studies. ${ }^{2,9}$ Health-related quality of life has been reported as an important outcome for older patients following ICU treatment, 9,10 however studies show con flicting results ranging from improvement ${ }^{5,11}$ to stability ${ }^{2}$ and even to worsening HROoL. ${ }^{9,12}$ These dissimilarities may be due to methodological differences relating to study design, measurement tools, follow-up period, availability of baseline measurements or differences in terminology., ${ }^{5,13}$ The HROoL of ICU patients, in general, is dependent on diagnostic categories, with acute respiratory distress syndrome, sepsis, and trauma known to result in a long-term reduction in HROoL. ${ }^{4}$ Interestingly, factors like age, severity of illness, ${ }^{4,14}$ extended ICU or hospital stay, and prolonged mechanical ventilation ${ }^{4,12}$ have not been found to be indicators of a reduced HROOL after an ICU stay. However, Schelling et $\mathrm{al}^{15}$ found that former ICU patients who recalled pain and other traumatic situations experienced while in the ICU had a lower HROOL.

Understanding long-term HROOL for older patients is important, particularly because the overall benefit of an ICU stay for older patients is often questioned. ${ }^{16,17}$ For the older patients, little is known regarding the association between HROoL and the severity of illness, length of ICU stay, admission diagnosis, or other potentially traumatic situations such as pain, anxiety, agitation or experiencing painful interventions such as intratracheal suctioning, removal of chest tubes, wound care, central venous catheter insertion, and turning. ${ }^{18,19}$
There is a need for HRQoL studies of older patients to investigate the changes they may experience in HROOL and obtain insight into the associations between HROoL and factors associated with an ICU stay.

\section{Methods}

Aims and Objectives

The overall aim of this study is to identify changes in HROoL in older patients one year following an ICU stay, and to identify those patient- and ICU-related factors associated with the long-term changes. The following research questions were addressed:

1) Is an ICU stay associated with changes in the HROoL of older patients 6 and 12 months after ICU discharge?

2) Are patient characteristics and the ICU-related characteristics: severity of illness, length of ICU stay, admission diagnosis, pain, anxiety, agitation, and ICU interventions, associated with HROLL 6 and 12 months after ICU discharge?

Design

This study is one part of a larger longitudinal study on the long-term consequences of an ICU stay in older patients. This prospective non-randomized longitudinal study used an ICU group and an age-matched comparison group. A description of the design has previously been published. ${ }^{20}$

Sample and Setting

Health-related quality of life was compared over one year in a convenience sample of ICU patients and community-based participants as a reference group. By comparing the two groups, trends in HROoL could be interpreted. Between December 2008 and April 2011, all newly admitted ICU patients were screened for study eligibility (Figure 1). The ICU group consisted of patients who were aged 65 years and older and who had been treated in the interdisciplinary ICU of a university hospital. The ICU is a 30-bed unit that treats both medical and surgical adult patients. Inclusion criteria for the ICU group were the ability to speak and read German or French, age 65 or older, ICU stay longer than 48 hours and residing in Switzerland. Exclusion criteria were an inability to communicate verbally (e.g., due to a temporary tracheostomy or chronic mechanical ventilation), cognitive impairment (e.g., head trauma or pre-existing dementia as noted in medical records), psychotic illness or palliative care due to a terminal illness (e.g., heart failure or respiratory failure). 
All patients were hospitalized in the university hospital at the time of recruitment. The comparison group consisted of age-matched individuals recruited from the community. Participants in the comparison group were 65 years or older, could speak and read German or French and lived in Switzerland. Exclusion criteria for the comparison group were cognitive impairment, psychotic illness or those who had had medical or surgical procedures within 2 weeks of entry in the study. In order to prevent recall bias, the comparison group could not have had an ICU stay within the past 15 years. The comparison group was recruited via newspaper articles, leaflets, organizations, and word-of-mouth, and received small financial compensation.

\section{Figure 1 Flow diagram of sample recruitment}

\begin{tabular}{|c|c|}
\hline $\begin{array}{l}\text { ICU Group } \\
\text { Assessed for eligibility } \\
(n=1214)\end{array}$ & $\begin{array}{l}\text { Comparison Group } \\
\text { Assessed for eligibility } \\
(\mathrm{n}=446)\end{array}$ \\
\hline $\begin{array}{l}\text { Excluded } \\
\text { Did not meet inclusion criteria }(n=536)^{*} \\
\text { Declined to participate }(n=19) \\
\text { Other reasons (external transfer } \\
n=387 \text {, died in ICU } n=126)\end{array}$ & $\begin{array}{l}\text { Excluded } \\
\text { Did not meet inclusion criteria }(n=300)\end{array}$ \\
\hline $\begin{array}{l}\text { Met inclusion criteria while in ICU } \\
(n=146)\end{array}$ & \\
\hline $\begin{array}{l}\text { One week after ICU } \\
(n=145) \\
\text { Incomplete data }(n=1)\end{array}$ & $\begin{array}{l}\text { Recruitment in study } \\
(n=146)\end{array}$ \\
\hline $\begin{array}{l}6 \text { month follow-up } \\
(\mathrm{n}=130) \\
2 \text { died, } 4 \text { refusals, } 9 \text { lost to follow-up }\end{array}$ & $\begin{array}{l}6 \text { month follow-up } \\
(n=141) \\
5 \text { lost to follow-up }\end{array}$ \\
\hline $\begin{array}{l}12 \text { month follow-up } \\
(\mathrm{n}=124) \\
3 \text { died, } 1 \text { new diagnosis of dementia, } \\
2 \text { lost to follow-up }\end{array}$ & $\begin{array}{l}12 \text { month follow-up } \\
(\mathrm{n}=135) \\
1 \text { refusal after cancer diagnosis, } \\
5 \text { lost to follow-up }\end{array}$ \\
\hline
\end{tabular}

Note: *Most patients were excluded because of cognitive impairment. Abbreviations: ICU=Intensive Care Unit. n=number of subjects.

\section{Sample Size}

The present study was part of a larger longitudinal study. ${ }^{20}$ No power analysis was done for this part of the study. The power analysis for the main longitudinal study was based on pain prevalence. Using a 95\% confidence interval for an estimated prevalence of pain between $0.30-0.50$ and a total of 0.20, a sample size of 81-96 was needed. ${ }^{21}$ In anticipation of a certain loss during follow-up, we aimed to include a total of 150 patients in each group. Both groups were recruited using the following pattern: once 20 patients were recruited for the ICU group, 20 participants were recruited for the comparison group. This pattern was followed until both groups had 150 participants.

\section{Data Collection}

Background data for the ICU group were collected during the ICU stay. HROoL was measured in the ICU group one week following ICU discharge (retrospective baseline), and 6 months and 12 months after hospital discharge (follow-up). Data collection for the comparison group took place at recruitment into the study (baseline HROoL and background data), and after 6 and 12 months (follow-up). Table 1 provides an overview of the measurements. 


\section{Table 1 Variables and measurements}

\begin{tabular}{|c|c|c|c|c|c|}
\hline \multirow[t]{2}{*}{ Variables } & \multirow[t]{2}{*}{ Tools } & \multicolumn{4}{|c|}{ Time of Measurement } \\
\hline & & $\begin{array}{l}\text { During ICU } \\
\text { Stay }\end{array}$ & $\begin{array}{l}\text { One week after } \\
\text { ICU stay| } \\
\text { recruitment } \\
\text { (baseline) }\end{array}$ & $\begin{array}{l}6 \text { month } \\
\text { follow-up }\end{array}$ & $\begin{array}{l}12 \text { month } \\
\text { follow-up }\end{array}$ \\
\hline $\begin{array}{l}\text { Background } \\
\text { Data }\end{array}$ & age, sex & $x$ & $X^{1,4}$ & & \\
\hline HRQDoL & SF-36 & & $x^{2}$ & $x$ & $x$ \\
\hline Pain & $\begin{array}{l}\text { NRS } \\
\text { behavioral } \\
\text { parameter }\end{array}$ & $x$ & $x^{2,4}$ & $x$ & $x$ \\
\hline Anxiety & NRS & $x$ & $x^{2}$ & $x$ & $x$ \\
\hline $\begin{array}{l}\text { Agitation } \\
\text { (and level of } \\
\text { sedation) }\end{array}$ & RASS $^{4}$ & $x$ & $x^{2}$ & $x$ & $x$ \\
\hline $\begin{array}{l}\text { Severity of } \\
\text { illness }\end{array}$ & APACHE $I^{4}$ & $x$ & & & \\
\hline $\begin{array}{l}\text { Admission } \\
\text { diagnosis }\end{array}$ & APACHE $I^{4}$ & $x$ & & & \\
\hline $\begin{array}{l}\text { ICU-Inter- } \\
\text { ventions }\end{array}$ & $\begin{array}{l}\text { Intratracheal } \\
\text { suctioning, }{ }^{4} \\
\text { wound care, } \\
\text { turning, }{ }^{4} \text { phys- } \\
\text { ical restraints, } \\
\text { chest tube } \\
\text { removal, } \\
\text { insertion of } \\
\text { central venous } \\
\text { catheter }^{4}\end{array}$ & $x$ & & & \\
\hline $\begin{array}{l}\text { Visual and } \\
\text { auditory } \\
\text { impairment }\end{array}$ & $\begin{array}{l}\text { Need for } \\
\text { glasses and } \\
\text { hearing aids }\end{array}$ & & $x$ & & \\
\hline
\end{tabular}

Note: ${ }^{1} \mathrm{Age}$ and sex: comparison group. ${ }^{2}$ Retrospective assessment pre-ICU of HROOL, pain, anxiety, and agitation (baseline). ${ }^{3}$ Scale with three behavioral parameters. ${ }^{4} \mathrm{ICU}$ group only. Abbreviations ICU=Intensive Care Unit. HROoL=Health-Related Quality of Life. SF-36=Short Form Health Survey 36. NRS=Numeric Rating Scale. RASS=Richmond Agitation-Sedation Scale. APACHE=Acute Physiology, Age and Chronic Health Evaluation.
Measurements During Follow-Up

Health-related quality of life was assessed using validated German and French translations of the Short Form Health Survey 36 (SF-36), with the standard time frame of 1 week. ${ }^{22-24}$ The SF-36 is a valid and reliable instrument for assessing general health status ${ }^{11,25}$ and consists of 8 dimensions: physical functioning (10 items), role limitation based on physical problems ( 4 items), bodily pain ( 2 items), general health (5 items), vitality ( 4 items), social functioning ( 2 items), role limitation due to emotional problems ( 3 items) and mental health ( 5 items). The items require yes|no answers or the use of a 3 or 6 -level numeric rating scale. The total scores range from 0-100. A higher score indicates a better HROoL. The 8 dimensions are consolidated into two overall dimensions: Physical Health Summary Scale (PCS) and Mental Health Sum mary Scale (MCS).

Demographic data (i.e., age, sex) were also collected from all study participants. HROOL was assessed from the perspective of the patient. A numeric rating scale (NRS) was used for data on pain, anxiety, and agitation. ${ }^{18,26}$

\section{Measurements Related to the ICU Sta}

ICU-related data included length of ICU stay, severity of illness, ICU admission diagnoses, and ICU interventions. Severity of illness was measured with the Acute Physiology, Age and Chronic Health Evaluation II (APACHE II). ${ }^{27}$ The following ICU interventions were recorded: intratracheal suctioning, wound care, turning, physical restraints, chest tube removal procedures, and the insertion of a central venous catheter, as well as the use of visual and hearing aids.

The presence and intensity of pain and anxiety were measured using NRS from $0=$ no pain|anxiety to $10=$ worst possible pain|anxiety. ${ }^{18,26}$ For patients unable to verbally express their level of pain, an observational scale employing three behavioral parameters: mimic, body movement, and muscle tone, was used to measure pain intensity. The validity of this instrument has been determined to be adequate, and its interrater reliability is high (weighted kappa coefficient of 0.80). ${ }^{28}$ The Richmond AgitationSedation Scale (RASS) was used to assess agitation and level of sedation. ${ }^{29}$ All data relating to the ICU stay were available in the electronic Patient Data Management System records. Once a patient signed the informed consent form, which included giving permission to access and collect data recorded during the ICU stay, the data were transferred to the study forms. 


\section{Procedure}

During the ICU Stay (ICU Group Only)

Four critical care nurse specialists trained the ICU-bedside nurses in using the assessment instruments to measure pain, anxiety and agitation. The bedside nurses regularly assessed pain, anxiety and agitation in all patients throughout the entire ICU stay, and also recorded all ICU interventions, for example, intratracheal suctioning. A standardized analgo-sedation protocol with daily sedation interruption is routinely used in this ICU. ${ }^{30}$ Patient characteristics (age, sex), ICU-related characteristics and background data were extracted from the electronic Patient Data Management System by four critical care nurse specialists.

Baseline ICU Group and Comparison Group (Both Groups)

The critical care nurse specialists contacted eligible patients one week after ICU discharge while the patients were still hospitalized on another hospital ward. The study was explained and informed consent forms were signed. When necessary, instructions and an explanation of the SF-36 were given. The ICU group was asked to use the SF-36 to estimate their HROoL one week prior to the ICU stay, which served as the baseline measurement and no HROOL measurements were recorded for the time period one week after the ICU stay. One week after ICU discharge, data on pain, anxiety, and agitation from one week prior to ICU admission were retrospectively collected. The comparison group was contacted by telephone at recruitment into the study and the study was explained. Following agreement to participate, the participant was sent the informed consent form and a copy of the SF-36 (baseline) along with a pre-addressed and stamped envelope in which to return the forms. In addition, pain and anxiety before the ICU stay (ICU group) or at recruitment into the study (comparison group) were assessed using the numeric rating scale. ${ }^{26}$ Demographic data (age, sex) from the comparison group were collected at this time.

The 6 and 12 Months Follow-Up (Both Groups)

A critical care nurse specialist with additional training in interview techniques contacted both groups by telephone. All study participants were told that they would receive the SF-36 by mail, and were informed of its contents. An overview of this process is given in Figure 2.
Figure 1 Flow diagram of measurements

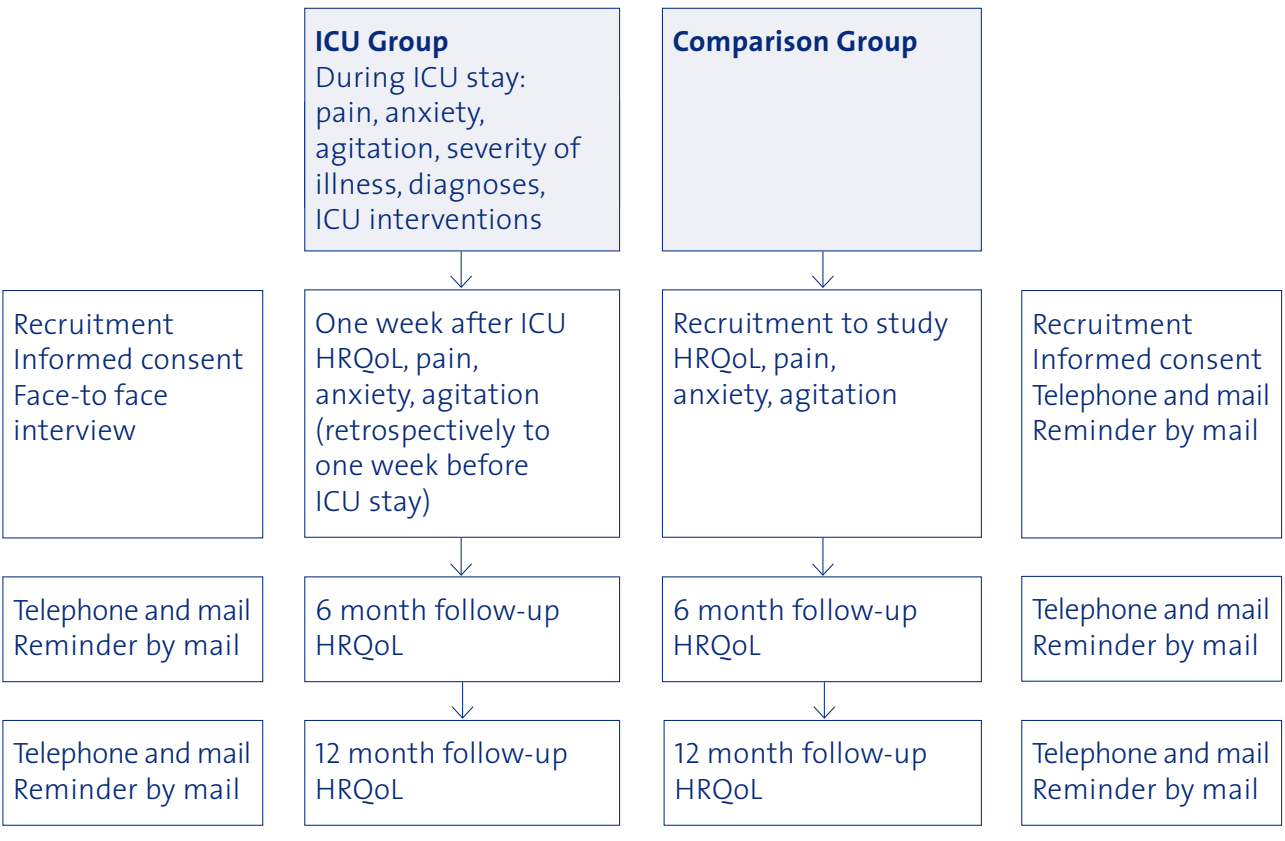

Note: ICU=Intensive Care Unit. HRQDoL=Health-Related Quality of Life.

\section{Ethical Considerations}

The regional Ethics Committee approved the study protocol (File Number: 128|08). After all participants were informed of the study, a signed informed consent document was obtained. The ICU group gave additional permission to use data obtained during their ICU stay.

\section{Data Analysis}

The analysis was performed with the software package "R." ${ }^{11}$ Descriptive statistics (means, medians, standard deviations or interquartile ranges) were used. The first step was to examine the association between ICU stay and HROoL over a 12-month period using a random intercept model for physical health score and mental health score. The original response scales from the SF-36 were transformed with the arcus sinus square root transformation as a first aid transformation to "normalize" the data. ${ }^{32}$ 
Explanatory variables at all time points were the individual (random effects), indicators for the ICU group one week after the ICU stay (retrospective baseline) and at 6 and 12 months after hospital discharge (follow-up), sex and age. In addition, the relationship between the ICU stay, the physical health score and the mental health score was examined with random intercept models. We began with a model that included all available patient and ICU-related variables (ICU admission diagnosis, severity of illness, admission diagnosis, length of ICU stay, pain, anxiety, agitation before and during ICU stay, ICU interventions, and visual and hearing aids) based on the current literature. ${ }^{4,18}$ Selected ICU-related characteristics and structural variables were regressed for physical health score and mental health score. Explanatory variables used for physical health score were visual aids, renal failure, cardiovascular surgery, severity of illness, number of turnings, pain and anxiety before the ICU stay, and interactions between variables. Explanatory variables for mental health score were cardiovascular illnesses, severity of illness, turnings, intratracheal suctioning and interactions between variables. All models included an individual specific intercept. Physical health score and mental health score were transformed by the arcus sinus square root transformation. In the first analysis a Bonferroni correction was used $(p<0.008)$; in the second explorative analysis, $p<0.05$ was considered significant. HRQoL dimensions were analyzed with descriptive statistics.

\section{Results}

\section{Sample Characteristics}

A total of 1214 older ICU patients and 446 older participants were screened for inclusion in the study (Figure 1). Definitive inclusion in the study took place 1 week after the ICU stay. The majority of the patients who were excluded from recruitment in the study had cognitive impairments. The final sample consisted of 291 older persons: 145 ICU patients (ICU group) and 146 participants (comparison group). Data from one patient in the ICU group was incomplete, and therefore this patient was ineligible for the study. Five ICU group patients died, and 4 patients withdrew their consent and stopped participation primarily because they did not want to remember the ICU stay. Eleven patients could not be located because they had moved and one patient was diagnosed with dementia. Ten comparison group participants could not be located because they had moved and one was diagnosed with a malignant disease. Sample characteristics and interventions during the ICU stay are presented in Table2. The comparison group had a greater number of women than the ICU group. Most patients ( $n=116,77 \%)$ were admitted directly to the ICU; the other patients $(n=34$ 23\%) were admitted from other hospitals or transferred from other wards of the university hospital.

\section{Table 2 Demographic data and intensive care interventions}

\begin{tabular}{|c|c|}
\hline \multicolumn{2}{|l|}{ Group characteristics and intensive care interventions } \\
\hline $\begin{array}{l}\text { Age } \\
\text { ICU group } \\
\text { Comparison group }\end{array}$ & $\begin{array}{l}68.72(5.39) \\
69.40(5.51)\end{array}$ \\
\hline $\begin{array}{l}\text { Women, number of patients (\%) } \\
\text { ICU group } \\
\text { Comparison group }\end{array}$ & $\begin{array}{l}39(27 \%) \\
75(51 \%)\end{array}$ \\
\hline \multicolumn{2}{|l|}{ Data from ICU Group only } \\
\hline Severity of illness (APACHE II Score points [0-71]) & $20.5(8.5)$ \\
\hline $\begin{array}{l}\text { Admission diagnosis, number of patients (\%) } \\
\text { Cardiac disease } \\
\text { Pulmonary disease } \\
\text { Sepsis } \\
\text { Neurological disease } \\
\text { Trauma } \\
\text { Other: Gastrointestinal disease, burns, drug overdose }\end{array}$ & $\begin{array}{l}80(55 \%) \\
20(14 \%) \\
12(8 \%) \\
13(9 \%) \\
11(8 \%) \\
9(6 \%)\end{array}$ \\
\hline Length of ICU stay (days) & $4.57(5.81)$ \\
\hline $\begin{array}{l}\text { Intratracheal suctioning per patient, median (range), } \\
\text { number of patients (\%) }\end{array}$ & $\begin{array}{l}6(0-403) \\
129(89 \%)\end{array}$ \\
\hline Wound care (complex dressings, VAC therapy), number of patients (\%) & $6(4 \%)$ \\
\hline $\begin{array}{l}\text { Turning, (lateral recumbent and supine position), per patient median } \\
\text { (range), number of patients (\%) }\end{array}$ & $\begin{array}{l}43(5-786) \\
52(36 \%)\end{array}$ \\
\hline Chest tube insertion and removal (number of procedures) & 21 insertions $\mid 15$ removals \\
\hline Physical restraints, number of patients (\%) & $42(28 \%)$ \\
\hline Intubation, number of patients (\%) & $135(91 \%)$ \\
\hline $\begin{array}{l}\text { Central venous catheter insertion (central venous catheters, } \\
\text { Swan-Ganz catheters, etc.), median (range), number of patients (\%) }\end{array}$ & $\begin{array}{l}3(0-9) \\
136(94 \%)\end{array}$ \\
\hline Mechanical ventilation, number of patients (\%) & $131(90 \%)$ \\
\hline Visual impairment: wears glasses, number of patients (\%) & $111(77 \%)$ \\
\hline Auditory impairment: wears a hearing aid, number of patients (\%) & $26(18 \%)$ \\
\hline
\end{tabular}

Note: Data expressed as mean (SD) or number (\%) unless otherwise indicated. Abbreviations:ICU=Inten sive Care Unit. APACHE=Acute Physiology, Age and Chronic Health Evaluation. SD=Standard Deviation 


\section{Association Between ICU Stay and HROOL}

The ICU group had lower physical and mental health scores than the comparison group during the 12-month study period (Figure 3, Table 3). The regression analysis showed that the HROoL scores for the ICU group were significantly lower than those of the comparison group at all time periods of the study (physical health score: before ICU: $b=-0.19, \mathrm{p}<0.001 ; 6$ months: $b=-0.27, \mathrm{p}<0.001 ; 12$ months: $b=-0.21, \mathrm{p}<0.001$; menta health score: before ICU: $b=-0.14, p<0.001 ; 6$ months: $b=-0.16, p<0.001 ; 12$ months: $b=$ $-0.14, p<0.001)$. Within each group, however, HROOL scores remained relatively stable over the year (Figure 3)

\section{Figure 3 Changes in physical and mental health scores}
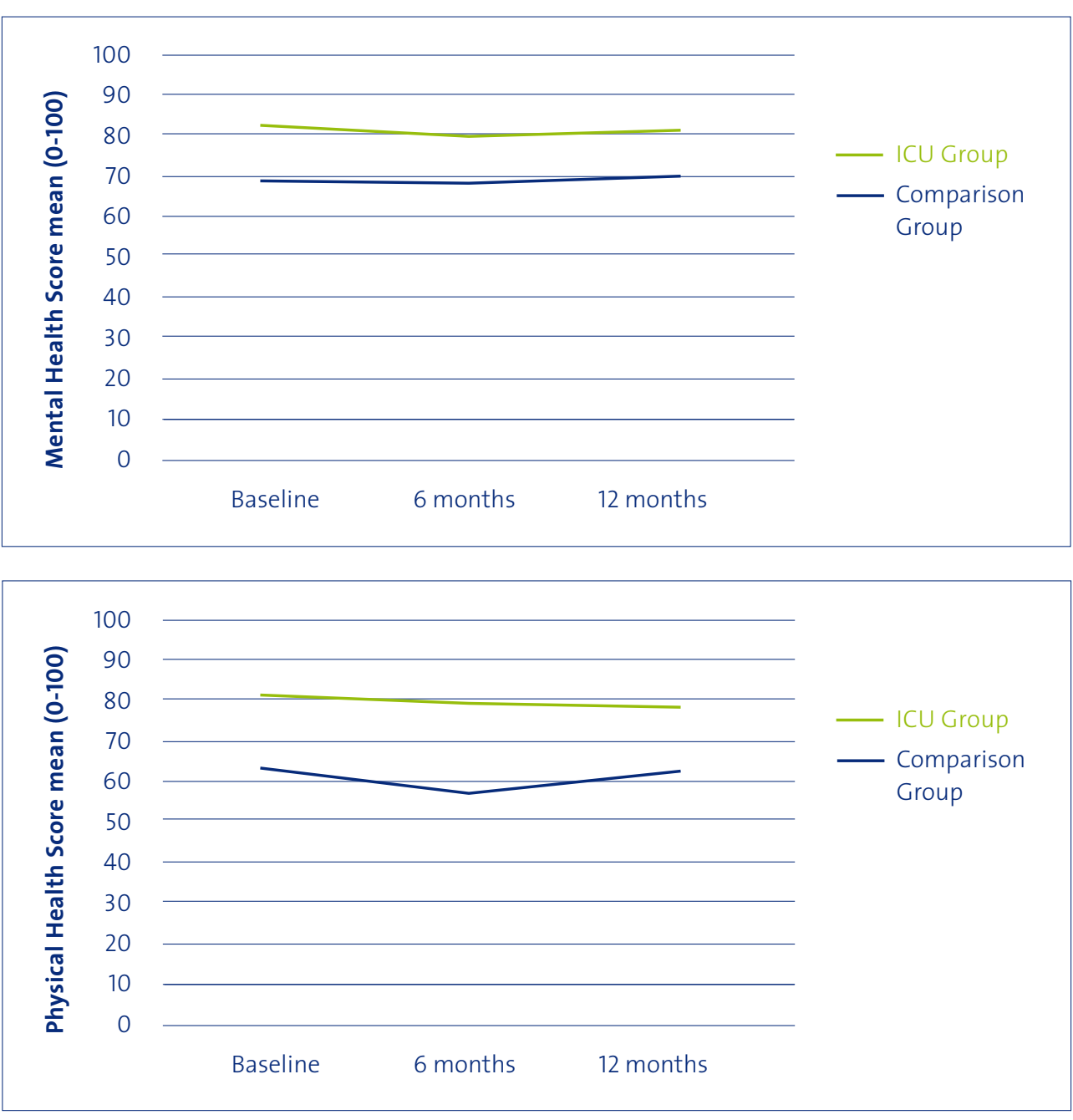

Note: Baseline: retrospective measurement of one week before ICU stay for ICU group (baseline) recruitment in study for comparison group (baseline), after 6 month follow-up and after 12 month follow-up. Abbreviations: ICU=Intensive Care Unit.

The ICU group had lower HROOL scores in all dimensions throughout the study, including the period before the ICU stay. Physical functioning and role physical displayed the greatest between-group differences. Minor differences were seen in bodily pain and mental health (Table 3). 
Table 3 HROoL during one year

\begin{tabular}{|c|c|c|}
\hline \multirow[b]{2}{*}{ SF-36 Dimension } & \multicolumn{2}{|c|}{ One week after ICU stay (retrospective baseline)|recruitment (baseline } \\
\hline & ICU Group & Comparison Group \\
\hline Physical functioning (PF) & $61.13(37.87)$ & $87.99(18.30)$ \\
\hline Role physical (RP) & $58.21(48.23)$ & $89.12(26.35)$ \\
\hline Bodily pain (BP) & $75.51(35.65)$ & $81.04(21.26)$ \\
\hline General health $(\mathrm{GH})$ & $66.41(24.69)$ & $76.05(16.58)$ \\
\hline Vitality (VT) & $56.90(30.65)$ & $68.15(17.57)$ \\
\hline Social functioning (SF) & $76.55(34.78)$ & $89.73(16.65)$ \\
\hline Role emotional (RE) & $74.45(43.77)$ & $94.98(18.91)$ \\
\hline Mental health (MH) & $70.80(22.45)$ & $81.20(14.28)$ \\
\hline Physical health score (PCS) & $63.63(27.15)$ & $80.67(15.45)$ \\
\hline \multirow[t]{2}{*}{ Mental health score (MCS) } & $69.02(23.07)$ & $82.13(12.50)$ \\
\hline & \multicolumn{2}{|c|}{6 month follow-up } \\
\hline SF-36 Dimension & ICU Group & Comparison Group \\
\hline Physical functioning (PF) & $54.00(34.33)$ & $85.73(20.58)$ \\
\hline Role physical (RP) & $47.80(46.12)$ & $84.63(32.75)$ \\
\hline Bodily pain (BP) & $71.54(30.64)$ & $81.03(22.93)$ \\
\hline General health $(\mathrm{GH})$ & $56.59(24.25)$ & $74.91(18.80)$ \\
\hline Vitality (VT) & $55.88(23.27)$ & $66.36(20.68)$ \\
\hline Social functioning (SF) & $74.90(31.41)$ & 88.15 (19.09) \\
\hline Role emotional (RE) & $78.93(38.69)$ & $88.89(28.80)$ \\
\hline Mental health $(\mathrm{MH})$ & $73.31(20.65)$ & $77.88(16.60)$ \\
\hline Physical health score (PCS) & $57.16(26.29)$ & $78.67(18.97)$ \\
\hline \multirow[t]{2}{*}{ Mental health score (MCS) } & $67.92(22.79)$ & $79.34(16.80)$ \\
\hline & \multicolumn{2}{|c|}{12 month follow-up } \\
\hline SF-36 Dimension & ICU Group & Comparison Group \\
\hline Physical functioning (PF) & $55.49(35.34)$ & $83.72(22.06)$ \\
\hline Role physical (RP) & $65.85(42.84)$ & $84.66(30.05)$ \\
\hline Bodily pain (BP) & $74.21(29.76)$ & $78.55(24.45)$ \\
\hline General health $(\mathrm{GH})$ & $58.88(28.11)$ & $74.80(18.56)$ \\
\hline Vitality (VT) & $59.42(23.77)$ & $66.02(19.58)$ \\
\hline Social functioning (SF) & 73.45 (31.12) & $88.91(19.56)$ \\
\hline Role emotional (RE) & $82.01(36.74)$ & $90.91(26.40)$ \\
\hline Mental health $(\mathrm{MH})$ & 75.29 (18.81) & 80.09 (16.54) \\
\hline Physical health score (PCS) & $62.71(26.75)$ & $77.91(18.25)$ \\
\hline Mental health score (MCS) & $69.72(23.03)$ & $80.37(15.68)$ \\
\hline
\end{tabular}

Note: ICU group (numbers)|comparison group (numbers): after one week 145|146; after 6 months 130|141 and after 12 months 124|135. Data expressed as mean (SD). Abbreviations: ICU=Intensive Care Unit. SD=Standard Deviation.
HROoL, Pain, Anxiety, Agitation, and ICU-Related Characteristics

The regression analysis showed significantly lower physical health scores in patients with acute renal failure $(b=-0.30, p=0.005)$, cardiac surgery $(b=-0.68, p=0.01)$, and high severity of illness $(b=-0.03, p=0.04)$. However, patients who had both cardiac surgery and a high severity of illness had significantly higher physical health scores $(b=0.02, p=0.04)$

Significantly lower mental health scores were found in patients with cardiovascular illnesses $(b=-1.21, p=0.002)$, frequent turnings $(b=-0.07, p=0.004)$, and frequent intratracheal suctioning $(b=-0.10, p=0.005)$. No significant associations with HROoL after the ICU stay were found with length of ICU stay, or between pain, anxiety, or agitation during the ICU stay.

\section{Discussion}

This study showed that the HROoL of the ICU group was lower throughout the study period than that of the aged-matched comparison group; moreover, the differences between groups were already present at baseline. We also found that a lower physical health score was associated with higher severity of illness and cardiac surgery. Intensive care interventions and cardiovascular illnesses were associated with a lower mental health score. Noteworthy is the high variation in HROOL scores found within the ICU group but not in the comparison group. In addition, a relatively stable HROoL was seen within each group during the year following the ICU stay|recruitment to the study. The reduced HROoL in the older patients after one year has been described in other studies, particularly in the physical domains. ${ }^{2,9}$ Some publications have reported a lower HRQoL prior to ICU admission, which is similar to our findings..$^{33,34}$ But in contrast to our findings, Merlani et al ${ }^{9}$ and Hofhuis et al ${ }^{11}$ reported that HROLL before the ICU stay was similar to that of an age-matched group taken from the general population. Hofhuis et a ${ }^{11}$ included proxies to report HROOL, which may account for these differences. Although the severity of illness of our patients was similar to other studies, patients reported relatively high HROoL compared to other studies., ${ }^{9,11}$ One explanation for these findings may be that our patients reported low levels of pain that may have eased their psychological burdens. Another possible reason for the relatively high HROoL scores may be that the majority of the participants had elective cardiac surgery. It is known that these patients have better prognoses than patients with acute medical intensive care treatment or unplanned surgeries. ${ }^{13} \mathrm{Cau}$ tion is necessary, however, when comparing studies on HROoL. Follow-up periods and HRQoL assessment instruments vary ${ }^{12,13}$ and baseline measurements are often unavailable. ${ }^{2,5}$ 
Furthermore, some studies include patient reported HROoL, ${ }^{9,13}$ whereas others utilize proxy reports. ${ }^{2,11}$ No proxies were used in our study because patients who could not express themselves verbally or who were cognitively impaired were excluded. In general, there is no uniformly accepted standard procedure to measure HROOL in ICU patients. Our study showed no changes in HRQOL in the ICU group during the follow-up year. The fact that one year after hospital discharge, HROLL is comparable to HROoL before the ICU stay, leads us to conclude that older patients with a good pre-ICU HROOL have adequate physiological or psychological reserves necessary to tolerate an ICU stay. Determining a clinically meaningful degree of change in HROoL is challenging due in part to the different instruments and items measured, the rarity of using the instruments in the clinical setting, the lack of understanding of the importance of the items, and the different perspectives such as those of the patients, family members, and healthcare professionals. ${ }^{35,36}$

Defining which ICU characteristics have the strongest association with long-term HRQOL is important but complex. ${ }^{4}$ Our study shows that patients with acute rena failure, cardiac surgery, and a high severity of illness had significantly lower physical health scores. Wehler et $\mathrm{al}^{33}$ confirmed that patients with renal or respiratory failure had the greatest deterioration in physical health scores. As we did not focus on patients in a particular diagnostic category and therefore had small numbers of patients in the various diagnostic categories, further conclusions concerning the impact of specific illnesses on $\mathrm{HROOL}$ are limited and require further investigation.

An interesting finding in our study is that patients who had both cardiac surgery and a high severity of illness had significantly higher physical health scores. A possible explanation for these positive results can be due to the fact that we included patients with severe cardiac illnesses who were already living with physical restrictions prior to ICU stay. Perhaps these patients gained the most from the surgical procedures and|or the treatments received in the ICU resulting in stronger improvement in their HRQOL. Further influences on HRQoL due to pre-ICU conditions were not examined in this study, but merit further study.

Patients treated in ICUs experience nonsurgical procedures such as chest tube removal, intratracheal suctioning, and turning or wound care as painful interventions. ${ }^{18}$ We found intratracheal suctioning to be associated with a lower mental health score. Most of the ICU group $(n=131)$ had been mechanically ventilated, which often necessitated intratracheal suctioning. Although the association between intratracheal suctioning and a lower mental health score must be viewed with caution, intratracheal suctioning or turning has been reported as an unpleasant and painful experience for ICU patients, ${ }^{18,19}$ is remembered even months after the ICU stay, ${ }^{37}$ and can lead to a lower HROoL. ${ }^{15}$

\section{Limitations}

Some limitations need to be acknowledged. First, pre-ICU HROLL was measured retrospectively and therefore may have had a recall bias. Nevertheless, retrospective reporting within a time frame of 1 to 4 weeks prior to an ICU stay ${ }^{9}$ is widely accepted in research in acute care settings. Because older patients are particularly susceptible to recall bias, the choice of a 1-week retrospective report was intended to enable older patients to remember their situation as accurately as possible. Second, our study focuses on a selective sample and excluded patients who were unable to verbally communicate, had psychotic illnesses or were receiving palliative care due to a terminal illness. These patients are normally treated in an ICU and are very fragile. Therefore, exclusion of these very frail older patients could have influenced our findings and the generalizability of the results. In addition, some of the patients who refused to participate stated they did not want to remember their time in the ICU. They may also have had more traumatic memories that might have influenced their HROLL. Finally, the data in our study were obtained from one university hospital ICU; this influences the external validity of the results.

\section{Conclusion}

This study demonstrates that older patients who are treated in an ICU have a lower HRQOL over one year as compared to a community-based aged-matched group, and that these differences were present before the ICU stay. However, we demonstrated that, overall, older patients have a good HROoL one year after an ICU stay and that HROoL remains relatively stable. Unpleasant experiences such as painful interventions during the ICU stay were associated with lower mental health scores in the older patients. These disagreeable experiences from interventions that often belong to routine ICU procedures should be carried out with as little pain and distress as possible. 


\section{Relevance to Clinical Practice}

Older patients have a relatively stable HRQoL one year following an ICU stay. Our results should help patients, their families, and healthcare professionals understand that an ICU stay does not necessarily result in a poorer HROoL for older patients. These positive results should encourage the nursing staff caring for older patients in the ICU. The study also identifies patients at risk of a reduced HROoL, such as patients with acute renal failure, cardiac illnesses|surgery, and a high severity of illness. Discharge planning should ensure that these patients receive support for their functional needs. Special attention should be given to develop and utilize methods to reduce distress during routine intensive care interventions such as intratracheal suctioning or turning.

Since differences between groups were present before the start of the study, studies aiming to improve long-term outcomes for older ICU patients need to determine the reasons and factors influencing a reduced HROoL before admission to an ICU. Future studies should also examine the specific needs of older patients who have reduced HROOL and routinely assess HROOL, particularly in vulnerable older patients.

\section{References}

1 Vosylius S, Sipylaite J, Ivaskevicius J. Determinants of outcome in elderly patients admitted to the intensive care unit. Age Ageing. 2005;34(2):157-62.

2 Kaarlola A, Tallgren M, Pettilä V. Long-term survival, quality of life, and quality-adjusted life-years among critically ill elderly patients. Crit Care Med. 2006;34(8):2120-6.

3 Bagshaw SM, Webb SA, Delaney A, George C, Pilcher D, Hart GK, Bellomo R. Very old patients admitted to intensive care in Australia and New Zealand: a multi-centre cohort analysis. Crit Care. 2009;13(2):R45

4 Oeyen SG, Vandijck DM, Benoit DD, Annemans L, Decruyenaere JM. Quality of life after intensive care: a systematic review of the literature. Crit Care Med. 2010;38(12):2386-400

5 Vest MT, Murphy TE, Araujo KL, Pisani MA. Disability in activities of daily living, depression, and quality of life among older medical ICU survivors: a prospective cohort study. Health Qual Life Outcomes. 2011;9:9.

6 Azoulay E, Kentish-Barnes N, Pochard F. Health-related quality of life: an outcome variable in critical care survivors. Chest. 2008;133(2):339-41.

7 Fried TR, Bradley EH, Towle VR, Allore H. Understanding the treatment preferences of seriously ill patients. N Engl J Med. 2002;346(14):1061-6.

8 Bullinger M. Erfassung der gesundheitsbezogenen Lebensqualität mit dem SF-36-Health Survey. "Measuring health-related quality of life with the SF-36 Health Survey". Bundesgesundheitsbl - Gesundheitsforsch - Gesundheitsschutz. 2000:43:190-97.

9 Merlani P.Chenaud C, Mariotti N, Ricou B. Long-term outcome of elderly patients requiring intensive care admission for abdominal pathologies: survival and quality of life. Acta Anaesthesio Scand. 2007;51(5):530-7.

10 Roch A, Wiramus S, Pauly V, Forel JM, Guervilly C, Gainnier M, Papazian L. Long-term outcome in medical patients aged 80 or over following admission to an intensive care unit. Crit Care. 2011;15(1):R36.

11 Hofhuis JG, van Stel HF, Schrijvers AJ, Rommes JH, Spronk PE. Changes of health-related quality of life in critically ill octogenarians: a follow-up study. Chest. 2011;140(6):1473-83.

12 Montuclard L, Garrouste-Orgeas M, Timsit JF, Misset B, De Jonghe B, Carlet J. Outcome, functional autonomy, and quality of life of elderly patients with a long-term intensive care unit stay. Crit Care Med. 2000;28(10):3389-95.

13 de Rooij SE, Govers AC, Korevaar JC, Giesbers AW, Levi M, de Jonge E. Cognitive, functional, an quality-of-life outcomes of patients aged 80 and older who survived at least 1 year after planned or unplanned surgery or medical intensive care treatment. J Am Geriatr Soc. 2008:56(5):816-22.

14 Graf J, Koch M, Dujardin R, Kersten A, Janssens U. Health-related quality of life before, 1 month af ter, and 9 months after intensive care in medical cardiovascular and pulmonary patients. Crit Care Med. 2003;31(8):2163-9.

15 Schelling G, Stoll C, Haller M, Briegel J, Manert W, Hummel T, Lenhart A, Heyduck M, Polasek Meier M, Preuss $U$, Bullinger M, Schüffel W, Peter K. Health-related quality of life and posttraumatic stress disorder in survivors of the acute respiratory distress syndrome. Crit Care Med. 1998;26(4):651-9. 
16 Taylor MD, Tracy JK, Meyer W, Pasquale M, Napolitano LM. Trauma in the elderly: intensive care unit resource use and outcome. J Trauma. 2002;53(3):407-14.

17 Boumendil A, Somme D, Garrouste-Orgeas M, Guidet B. Should elderly patients be admitted to the intensive care unit? Intensive Care Med. 2007;33(7):1252-62.

18 Puntillo KA, Morris AB, Thompson CL, Stanik-Hutt J, White CA, Wild LR. Pain behaviors observed during six common procedures: results from Thunder Project II. Crit Care Med. 2004;32(2):421-7.

19 Arroyo-Novoa CM, Figueroa-Ramos MI, Puntillo KA, Stanik-Hutt J, Thompson CL, White C, Wild LR Pain related to tracheal suctioning in awake acutely and critically ill adults: a descriptive study. Intensive Crit Care Nurs. 2008;24(1):20-7.

20 Jeitziner MM, Hantikainen V, Conca A, Hamers JP. Long-term consequences of an intensive care unit stay in older critically ill patients: design of a longitudinal study. BMC Geriatr. 2011;11:52.

21 Hulley SB, Cummings SR, Browner WS, Grady D, Hearst N, Newman TB. Designing clinical research: an epidemiologic approach. Philadelphia: Lippincott Williams \& Wilkins; 2001

22 Bullinger M, Kirchberger I, Ware J. Der deutsche SF-36 Health Survey. Übersetzung und psychometrische Testung eines krankheitsübergreifenden Instruments zur Erfassung der gesundheitsbezogenen Lebensqualität. "The German version of the SF-36 Health Survey. Translation and psychometric testing of a generic instrument to measure health-related quality of life." Z Gesundheitswiss. 1995;3(1):21-36.

23 Perneger TV, Leplège A, Etter JF, Rougemont A. Validation of a French-language version of the MOS 36-Item Short Form Health Survey (SF-36) in young healthy adults. J Clin Epidemiol. 1995;48(8):1051-60

24 Bullinger M, Kirchberger I. SF-36 Fragebogen zum Gesundheitszustand. Handanweisung. SF-36. "Health status questionnaire. Handbook for it's administration. SF-36." Göttingen: Hogrefe Verlag; 1998.

25 Heyland DK, Hopman W, Coo H, Tranmer J, McColl MA. Long-term health-related quality of life in survivors of sepsis. Short Form 36: a valid and reliable measure of health-related quality of life. Crit Care Med. 2000;28(11):3599-605.

26 Li DT, Puntillo K. A pilot study on coexisting symptoms in intensive care patients. Appl Nurs Res. 2006;19(4):216-9.

27 Knaus WA, Draper EA, Wagner DP, Zimmerman JE. APACHE II: a severity of disease classification system. Crit Care Med. 1985;13(10):818-29.

28 Jeitziner MM, Schwendimann R, Hamers JP, Rohrer O, Hantikainen V, Jakob SM. Assessment of pain in sedated and mechanically ventilated patients: an observational study. Acta Anaesthesio Scand. 2012;56(5):645-54

29 Ely EW, Truman B, Shintani A, Thomason JW, Wheeler AP, Gordon S, Francis J, Speroff T, Gautam S, Margolin R, Sessler CN, Dittus RS, Bernard GR. Monitoring sedation status over time in ICU patients: reliability and validity of the Richmond Agitation-Sedation Scale (RASS). JAMA. 2003;289(22):2983-91.

30 Takala J, Dellinger RP, Koskinen K, St Andre A, Read M, Levy M, Jakob SM, Mello PV, Friolet R, Ruokonen E. Development and simultaneous application of multiple care protocols in critical care: a multicenter feasibility study. Intensive Care Med. 2008;34(8):1401-10.

31 R Development Core Team. R: A language and environment for statistical computing. R Foundation for Statistical Computing [Internet]. 2011 [cited 2014 Mar 10]. Available from: http://www.r-project.org.
32 Mosteller F, Turkey JW. Data analysis and regression: a second course in statistics. Reading, MA: Addison Wesley; 1977.

33 Wehler M, Geise A, Hadzionerovic D, Aljukic E, Reulbach U, Hahn EG, Strauss R. Health-related quality of life of patients with multiple organ dysfunction: individual changes and comparison with normative population. Crit Care Med. 2003;31(4):1094-101.

34 Khouli H, Astua A, Dombrowski W, Ahmad F, Homel P, Shapiro J, Singh J, Nallamothu R, Mahbub $H$, Eden E, Delfiner J. Changes in health-related quality of life and factors predicting long-term outcomes in older adults admitted to intensive care units. Crit Care Med. 2011;39(4):731-7.

35 Gill TM, Feinstein AR. A critical appraisal of the quality of quality-of-life measurements. JAMA. 1994;272(8):619-26.

36 Crosby RD, Kolotkin RL, Williams GR. Defining clinically meaningful change in health-related quality of life. J Clin Epidemiol. 2003;56(5):395-407.

37 Granja C, Lopes A, Moreira S, Dias C, Costa-Pereira A, Carneiro A. Patients' recollections of experiences in the intensive care unit may affect their quality of life. Crit Care. 2005;9(2):R96-109. 


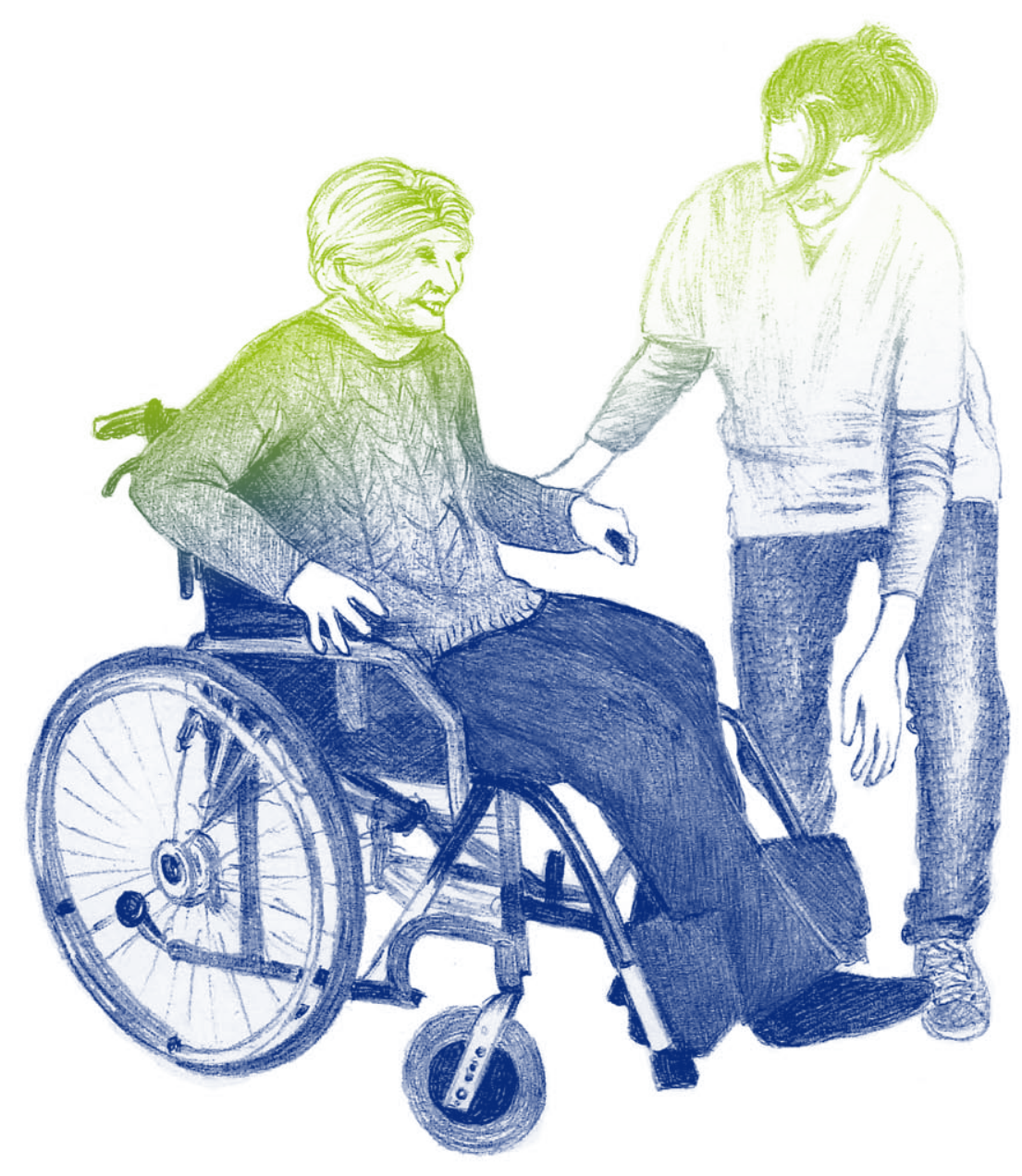


Chapter 6
Healthcare Resource Utilization by Critically Ill Older Patients Following an Intensive Care Unit Stay 


\section{Abstract}

Aims and Objectives

This study examines the utilization of healthcare resources by critically ill older patients over one year following an intensive care unit (ICU) stay.

\section{Background}

Information on healthcare resource utilization following ICU treatment is essentia during times of limited financial resources.

\section{Design}

Prospective longitudinal non-randomized study.

Methods

Healthcare resource utilization by critically ill older patients ( $\geq 65$ years) was recorded during one year following treatment in a medical-surgical ICU. Age-matched community-based participants served as a comparison group. Data were collected at oneweek following ICU discharge|study recruitment and after 6 and 12 months. Recorded were length of stay, (re)admission to hospital or ICU, general practitioner and medical specialist visits, rehabilitation program participation, medication use, discharge destination, home healthcare service use, and level of dependence for activities of daily living.

\section{Results}

145 critically ill older patients and 146 age-matched participants were recruited into the study. Overall, critically ill older patients utilized more healthcare resources. After 6 and 12 months, they visited general practitioners 6 times more frequently, twice as many older patients took medications and only the ICU group patients participated in rehabilitation programs $(n=99,76 \%)$. The older patients were less likely to be hospitalized, very few transferred to nursing homes $(n=3,2 \%)$, and only $7(6 \%)$ continued to use home healthcare services 12 months following the ICU stay.

Conclusions

Critically ill older patients utilize more healthcare resources following an ICU stay, however, most are able to live at home with no or minimal assistance after one year.
Relevance to Clinical Practice

Adequate healthcare resources, such as facilitated access to medical follow-up care, rehabilitation programs, and home healthcare services, must be easily accessible for older patients following hospital discharge. Nurses need to be aware of the healthcare services available and advise patients accordingly.

\section{Summary Box}

What does this paper contribute to the global clinical community?

- Following discharge from ICU, critically ill older patients will require further support from various healthcare resources such as general practitioners, rehabilitation programs, and home healthcare services. With this support, the majority are able to live at home without outside assistance one year after an ICU stay.

- Information on available healthcare resources and how to access them is necessary for effective discharge planning for critically ill older patients. Nurses have an important role in ensuring that patients and their families are aware of and know how to access the needed healthcare resources. Nurses must be sure that their knowledge of the healthcare services available for older patients following an ICU stay remains up-to-date. 


\section{Introduction}

Social and economic pressure to reduce healthcare costs and resource utilization increases in times of economic crises. Outcomes following treatment in intensive care units (ICUs) are being examined to estimate the ultimate cost of treating patients in ICUs, and include post-discharge use of resources within the healthcare system..$^{1-3}$ Previous studies have found that patients who have survived ICU treatment often have significant health problems and continue to have complex healthcare needs, ncreased morbidity, residual disability, activity limitations, and technology dependence, in the months post-ICU stay. ${ }^{4,5}$ These patients need close medical follow-up and are prescribed more medications.

\section{Background}

Owing to advances in medicine, nursing, and healthcare technology, an increasing number of critically ill older patients survive life-threatening illnesses that require ICU treatment. ${ }^{7-9}$ Questions have been raised concerning utilization of healthcare resources post-ICU stay by these older patients. An understanding of the patterns of healthcare resource utilization following critical illness is necessary to identify the services needed and ensure their availability. Nurses are in an ideal position to provide patients and families with information regarding available services and to ensure that patients can access and manage the appropriate healthcare resources following an ICU stay.

Previous studies of older patients treated in ICUs have examined length of stay, rehospitalization, and discharge destinations. ${ }^{10-13}$ Data on length of stay have been inconclusive. Some studies have reported longer hospital stays, ${ }^{10,11}$ whereas other authors reported stays similar to those of younger patients. ${ }^{14}$ Older patients are at a high risk of rehospitalization (ICU or hospital) with prevalence rates between $8 \%$ and $36 \% .7,12,13$ In terms of discharge destination, studies have shown that between $52 \%$ and $97 \%$ of older patients are able to return home after an ICU stay and live independently or with some outside assistance. ${ }^{15,16}$ However, many will require admission to nursing homes, small regional hospitals for long-term care, or rehabilitation programs. ${ }^{9,17,18}$ The mortality rate of critically ill older patients varies, and depending on the diagnosis, could range from $7 \%$ to $69 \%$ in the months following ICU discharge. ${ }^{15,19,20}$

Although previous studies have reported on the resources used by critically ill older patients during an ICU stay, ${ }^{10}$ long-term healthcare resource utilization following discharge from the ICU has been poorly described and inadequately researched.

\section{Methods}

Aims and Objectives

The aims of this study were to identify healthcare resource utilization by critically ill older patients during one year following an ICU stay, and to determine how their healthcare resource utilization differs from older persons selected from the general population. Healthcare resources include length of ICU and hospital stay, (re)admission to hospital or ICU, general practitioner/medical specialist visits, participation in rehabilitation programs, medication use, discharge destination, home healthcare service utilization, and care dependence for activities of daily living.

The research question is:

What is the association between an ICU stay and the subsequent use of the following healthcare resources: length of stay, (re)admission to hospital or ICU, genera practitioner (GP) visits, participation in rehabilitation programs, medication use, living situation and survival, in critically ill older patients 6 and 12 months after hospital discharge?

Design

A prospective longitudinal study was conducted. The present study reports on one aspect of a larger longitudinal non-randomized study focusing on long-term consequences of an ICU stay for critically ill older patients. ${ }^{21}$

\section{Sample and Setting}

Critically ill older patients hospitalized in a medical-surgical ICU of a university hos pital were eligible for the study (ICU group). Patients were included if they stayed in the ICU longer than 48 hours, were able to speak and read German or French, were at least 65 years old, and resided in Switzerland. Patients unable to express themselves verbally due to temporary tracheostomies or chronic mechanical ventilation, cognitive impairment (head trauma, dementia), acute psychotic illnesses, receiving palliative care due to terminal illness, and those transferred directly from the ICU to a smaller acute care hospital, were excluded from the study. In order to aid in the interpretation of the outcome indicators, a comparison group was prospectively recruited via newspaper articles, flyers, organizations, and word-of-mouth. This group received a small financial remuneration to encourage participation for the entire length of the study. The participants of the comparison group had to speak and read German or French, be 65 years or older, and reside in Switzerland. 
Exclusion criteria for the comparison group included medical procedures or surgeries within two weeks of entry into the study. It was planned to recruit 150 subjects per group. Recruitment of the comparison group closely followed recruitment of the ICU group with the following pattern: after 20 patients were recruited to the ICU group 20 age-matched participants were recruited to the comparison group, continuing until each group had 150 participants.

\section{Data Collection}

Demographic and health-related information were collected from the ICU group during the ICU stay and from the comparison group at study recruitment. Healthcare resource utilization was collected from both groups at 6 and 12 months following hospital discharge|recruitment, reflecting the period from discharge|recruitment to 6 months, and the period from 6 to 12 months. A baseline measurement of activities of daily living was made one week post-ICU stay for the ICU group and at study begin for the comparison group.

Demographic information included age, sex, and living situation. ICU data included admission diagnosis, severity of illness as measured by the Acute Physiology, Age and Chronic Health Evaluation II (APACHE II), ${ }^{22}$ length of primary hospital stay, and ICU readmission. Mortality within one year of study recruitment was recorded for both groups

Utilization of the following healthcare resources was recorded for both groups: number and reasons for hospital admissions; number and reasons for visits to GPs and 1 or medical specialists; participation and duration of rehabilitation programs (in and out patient) and type and dosage of medications (antihypertensives, antiarrhythmics, diuretics, analgesics, sedatives, antipsychotics, psychotropics, steroids, antidiabetics, and anticoagulants). Data on discharge destination such as home, acute care hospital, nursing home or other, and the frequency and type of home healthcare services utilized, such as home meal delivery, home nursing care, and care provided by family members (informal care), were collected.

A checklist was developed for the study to assess the need for assistance with activities of daily living, because care dependence may influence the type and frequency of healthcare resource utilization. The goal was to have a clear, simple, and easy to use checklist to evaluate the abilities and needs of critically ill older patients following an ICU stay. The checklist was pilot tested with eleven older persons to determine comprehensibility (i.e., meaning of the words) and applicability (e.g., readability, time necessary to complete it) and was found to be adequate. A 5-point Likert scale was used for the evaluation (1=agree totally to $5=$ totally reject it). The following activities of daily living were assessed: bathing, dressing, food intake and meal preparation, continence|elimination, physical movement|mobility (in-side and outside the home), activities (shopping, etc.) and social contacts.

Care dependence for daily activities was classified as: completely dependent; needs support by caregivers and specialized medical equipment; independent with medi cal equipment; completely independent.

\section{Procedure}

Background data were collected from the medical records (ICU group) and via a questionnaire developed for the study (comparison group) by four specially trained critical care nurse specialists (ICU-nurse specialists). ICU-specific variables, such as ICU admission diagnosis, severity of illness, length of primary hospital stay, and readmission to the ICU, were obtained using the electronic Patient Data Management System. One week following ICU discharge, all eligible patients were contacted by one of the ICU-nurse specialists and invited to participate in the study. The study procedures were explained and the patients signed the informed consent form. Information on activities of daily living prior to the ICU stay was assessed at this time. The comparison group was initially contacted by telephone. The study was explained and a verbal informed consent to participate was obtained. The written informed consent form and a form to collect demographic information were then sent to the participants along with a stamped self-addressed envelope to return the forms. Al participants consented to permit the study ICU-nurse specialists to contact their GPs to obtain information on hospitalizations, medication use, and death over the 12 month period. A questionnaire to collect healthcare resource utilization was created for this study. The study questionnaire and checklist to assess the need for assistance with activities of daily living were administered to the ICU group one week after ICU discharge and via telephone at 6 and 12 months. The questionnaire and checklist were administered by telephone to the comparison group at study recruitment and after 6 and 12 months.

\section{Ethical Considerations}

The regional Ethics Commission approved the study (File Number: 128|08). All study participants were informed about the study and signed a written Informed Consent Form. The critically ill older patients were contacted one week following ICU discharge and in addition to giving informed consent for study participation, gave their permission to access and use their medical records before, during, and after their ICU stay. 


\section{Data Analysis}

Descriptive analyses were used to describe the sample characteristics (mean, median, standard deviation, range).

Chi-squared tests were used for categorical outcome variables. The Mann-Whitney-U Test was used for continuous outcome variables that were not normally distributed. The Bonferroni correction was used as an adjustment for multiple comparisons (level of significance: $p<0.005)$. All statistical analyses were performed with IBM SPSS Statistics version 22 software.

\section{Results}

\section{Patient Characteristics}

A total of 1660 persons were considered for study eligibility: 1214 critically ill older patients were screened upon admission to the ICU and 446 age-matched individuals were screened from the community. The final sample consisted of 291 persons: 145 critically ill older patients (ICU group) and 146 participants from the comparison group. Figure 1 shows the flow diagram for recruitment. Demographic data and specific characteristics of all study participants are shown in Table 1. The ICU group included significantly fewer women than the comparison group $\left(X^{2} 19.34, p<0.001\right)$ and reported more co-morbidities ( $\left.X^{2} 25.03, p<0.001\right)$. Five patients $(4 \%)$ from the ICU group died during the study period. No participants from the comparison group died during the 12 months study period.

\section{Figure 1 Flow diagram of sample recruitment}

\begin{tabular}{|c|c|}
\hline $\begin{array}{l}\text { ICU Group } \\
\text { Assessed for eligibility } \\
(n=1214)\end{array}$ & $\begin{array}{l}\text { Comparison Group } \\
\text { Assessed for eligibility } \\
(n=446)\end{array}$ \\
\hline $\begin{array}{l}\text { Excluded } \\
\text { Did not meet inclusion criteria }(n=536) \\
\text { Declined to participate }(n=19) \\
\text { Other reasons (external transfer } n=387 \text {, } \\
\text { died in ICU } n=126)\end{array}$ & $\begin{array}{l}\text { Excluded } \\
\text { Did not meet inclusion criteria }(n=300)\end{array}$ \\
\hline $\begin{array}{l}\text { Eligible during ICU stay } \\
(n=146)\end{array}$ & \\
\hline $\begin{array}{l}\qquad \\
\text { Recruitment, one week after ICU } \\
(\mathrm{n}=145) \\
\text { Incomplete data }(\mathrm{n}=1)\end{array}$ & $\begin{array}{l}\text { Recruitment to study } \\
(\mathrm{n}=146)\end{array}$ \\
\hline $\begin{array}{l}\qquad \\
6 \text { month follow-up } \\
(\mathrm{n}=130) \\
2 \text { died, } 4 \text { refusals, } 9 \text { lost to follow-up }\end{array}$ & $\begin{array}{l}6 \text { month follow-up } \\
(n=141) \\
5 \text { lost to follow-up }\end{array}$ \\
\hline $\begin{array}{l}12 \text { month follow-up } \\
(\mathrm{n}=124) \\
3 \text { died, } 1 \text { new diagnosis of dementia, } \\
2 \text { lost to follow-up }\end{array}$ & $\begin{array}{l}12 \text { month follow-up } \\
(\mathrm{n}=135) \\
1 \text { refusal after cancer diagnosis, } \\
5 \text { lost to follow-up }\end{array}$ \\
\hline
\end{tabular}

Note: Abbreviations: ICU=Intensive Care Unit. $\mathrm{n}=$ number of subjects. 
Table 1 Demographic characteristics, ICU specific variables

\begin{tabular}{|c|c|c|c|}
\hline Variables & ICU Group & Comparison Group & p-Value \\
\hline Age, mean (SD) & $68.72(5.39)$ & $69.40(5.51)$ & \\
\hline $\begin{array}{l}\text { Sex, } n(\%) \\
\text { Women } \\
\text { Men }\end{array}$ & $\begin{array}{l}39(27 \%) \\
106(73 \%)\end{array}$ & $\begin{array}{l}75(51 \%) \\
71(49 \%)\end{array}$ & $p<0.001^{2}$ \\
\hline $\begin{array}{l}\text { Co-morbidities, n (\%) } \\
\text { With co-morbidities } \\
\text { Without co-morbidities } \\
\text { INA }\end{array}$ & $\begin{array}{l}83(57 \%) \\
41(28 \%) \\
21(15 \%)\end{array}$ & $\begin{array}{l}55(38 \%) \\
83(57 \%) \\
8(5 \%)\end{array}$ & $p<0.001^{2}$ \\
\hline $\begin{array}{l}\text { Living situation, } n(\%) \\
\text { With family member } \\
\text { Alone } \\
\text { Other (nursing home, assisted living) }\end{array}$ & $\begin{array}{l}98(68 \%) \\
45(31 \%) \\
2(1 \%)\end{array}$ & INA & \\
\hline $\begin{array}{l}\text { ICU Admission Diagnosis }{ }^{1}, \mathrm{n}(\%) \\
\text { Cardiac disease (coronary and/or valvular } \\
\text { disease, aortic disease, chronic heart }\end{array}$ & $80(55 \%)$ & & \\
\hline $\begin{array}{l}\text { Pulmonary disease (pneumonia, pulmo- } \\
\text { nary embolism, COPD) } \\
\text { Sepsis } \\
\text { Neurological disease } \\
\text { Trauma } \\
\text { Other (Gastrointestinal disease, burns, } \\
\text { overdose) }\end{array}$ & $\begin{array}{l}20(14 \%) \\
12(8 \%) \\
13(9 \%) \\
11(8 \%) \\
9(6 \%)\end{array}$ & & \\
\hline $\begin{array}{l}\text { Length (days) of ICU hospital stay, } \\
\text { mean (SD) }\end{array}$ & $4.57(5.81)$ & & \\
\hline $\begin{array}{l}\text { Length (days) primary hospital stay, } \\
\text { mean (SD) }\end{array}$ & $22.34(24.81)$ & & \\
\hline $\begin{array}{l}\text { Mortality over } 12 \text { months, n (\%) } \\
\text { INA due to loss to follow-up }\end{array}$ & $\begin{array}{l}5(4 \%) \\
16(13 \%)\end{array}$ & $\begin{array}{l}0 \\
11(8 \%)\end{array}$ & \\
\hline
\end{tabular}

Note: ${ }^{1}$ Only recorded for the ICU group. ${ }^{2}$ Chi-Squared-Test. Abbreviations: ICU=Intensive Care Unit. $\mathrm{n}=$ number of subjects. $\mathrm{COPD}=$ Chronic Obstructive Pulmonary Disease. $\mathrm{SD}=$ Standard Deviation. INA=Information Not Available.
Healthcare Resource Utilization After 6 and 12 Months

As shown in Tables 2 and 3, the ICU group utilized various healthcare resources following their ICU stay, such as rehabilitation programs, home nursing care, meal delivery services, informal care, or a combination of services. Three ICU group patients (2\%) were readmitted to the ICU during the initial hospitalization and 12 were hospitalized during the year.

Reasons recorded for these hospitalizations were coronary angiography $(n=1)$, gallbladder operation $(n=2)$, leg or foot amputation $(n=2)$, uncontrolled diabetes mellitus type II $(n=5)$, and pneumonia $(n=2)$. One hundred twenty-seven ICU group patients (98\%) saw their GPs in the first 6 months following hospital discharge and 114 (92\%) had GP visits during the second 6 months of the study. Reasons for these doctor visits were: medication adjustments, blood work, general examinations, and dressing changes. Eighty-nine (63\%) comparison group participants saw their GPs in the first 6 months of the study and 87 (65\%) had GP visits during the second 6 months of the study. More than two thirds of the ICU group patients $(n=99,76 \%)$ attended rehabilitation programs. The median length of stay in a rehabilitation program was three weeks with a range of 1-24 weeks. No participants from the comparison group attended rehabilitation programs. One ICU group patient was newly admitted to a nursing home following the ICU stay and one ICU group patient was transferred to a long-term acute care hospital.

\section{Differences in Healthcare Resource Utilization}

The ICU group used significantly more healthcare resources than the comparison group (see Tables 2 and 3). The ICU group had six times more GP visits $(p<0.001)$, only ICU group patients attended rehabilitation programs, and 50\% more patients in the ICU group took medications than participants in the comparison group $(p<0.001)$. However, the ICU group had a significantly lower rate of hospitalization during the study period where 12 (10\%) patients from the ICU group and 19 (14\%) participants from the comparison group were hospitalized ( $p<0.001)$. Almost all study participants (ICU group) ( $n=120,97 \%)$ and comparison group $(n=131,97 \%)$ lived at home by the end of the study period. At the end of one year, 7 (6\%) ICU group patients were still dependent for some help at home such as bathing, dressing, feeding themselves, meal preparation, mobility and |or activities outside the home such as shopping. The same percentage, $6 \%(n=8)$ of participants from the comparison group required assistance such as home nursing care and meal delivery services. 


\section{Table 2 Healthcare resource utilization}

\begin{tabular}{|c|c|c|c|}
\hline Variables & ICU Group & Comparison Group & p-Value \\
\hline ICU readmission ${ }^{1}, \mathrm{n}(\%)$ & $3(2 \%)$ patients & & \\
\hline $\begin{array}{l}\text { Hospital admissions, } n(\%) \\
6 \text { months } \\
12 \text { months }\end{array}$ & $\begin{array}{l}7(5 \%) \text { patients } \\
5(4 \%) \text { patients }\end{array}$ & $\begin{array}{l}1(0.5 \%) \text { participant } \\
18(13 \%) \text { participants }\end{array}$ & $\begin{array}{l}p=0.032^{5} \\
p<0.001^{5}\end{array}$ \\
\hline $\begin{array}{l}\text { General practitioner visits } \\
6 \text { months } \\
12 \text { months }\end{array}$ & $\begin{array}{l}6(0-38)^{3} \text { visits }(6)^{4} \\
6(0-72)^{3} \text { visits }(6)^{4}\end{array}$ & $\begin{array}{l}1(0-18)^{3} \text { visits }(0)^{4} \\
1(0-30)^{3} \text { visits }(0)^{4}\end{array}$ & $\begin{array}{l}p<0.001^{5} \\
p<0.001^{5}\end{array}$ \\
\hline $\begin{array}{l}\text { Medical specialist visits } \\
6 \text { months } \\
12 \text { months }\end{array}$ & $\begin{array}{l}1(0-73)^{3} \text { visits }(0)^{4} \\
1(0-24)^{3} \text { visits }(1)^{4}\end{array}$ & $\begin{array}{l}0(0-6)^{3} \text { visits }(0)^{4} \\
0(0-8)^{3} \text { visits }(0)^{4}\end{array}$ & $\begin{array}{l}p<0.001^{5} \\
p<0.001^{5}\end{array}$ \\
\hline $\begin{array}{l}\text { Rehabilitation programs, } n(\%) \\
6 \text { months } \\
12 \text { months }\end{array}$ & $\begin{array}{l}99(76 \%) \text { patients } \\
17(14 \%) \text { patients }\end{array}$ & $\begin{array}{l}\text { no participants } \\
\text { no participants }\end{array}$ & \\
\hline $\begin{array}{l}\text { Use of medications }{ }^{2}, \mathrm{n}(\%) \\
6 \text { months } \\
\text { INA } \\
12 \text { months } \\
\text { INA }\end{array}$ & $\begin{array}{l}72(55 \%) \text { patients } \\
5(4 \%) \text { patients } \\
72(56 \%) \text { patients } \\
17(14 \%) \text { patients }\end{array}$ & $\begin{array}{l}41(29 \%) \text { participants } \\
1(1 \%) \text { participants } \\
34(25 \%) \text { participants }\end{array}$ & $\begin{array}{l}p<0.001^{6} \\
p<0.001^{6}\end{array}$ \\
\hline
\end{tabular}

Note: ${ }^{1}$ Only ICU group. ${ }^{2}$ Use of one or more types of medication. ${ }^{3}$ Median|Range. ${ }^{4}$ Mode. ${ }^{5}$ MannWhitney-U Test. ${ }^{6}$ Chi-Squared-Test. Abbreviations: ICU=Intensive Care Unit. $\mathrm{n}=$ number of subjects. INA=Information Not Available.

\section{Table 1 Discharge destination, care dependence, and home healthcare services}

\begin{tabular}{|c|c|c|}
\hline Variables & ICU Group & Comparison Group \\
\hline \multicolumn{3}{|c|}{ Discharge destination | living situation, n (\%) } \\
\hline $\begin{array}{l}\text { Home } \\
6 \text { months } \\
12 \text { months }\end{array}$ & $\begin{array}{l}127(98 \%) \\
120(97 \%)\end{array}$ & $\begin{array}{l}137(97 \%) \\
131(97 \%)\end{array}$ \\
\hline $\begin{array}{l}\text { Acute care hospital } \\
6 \text { months } \\
12 \text { months }\end{array}$ & $\begin{array}{l}1(1 \%) \\
1(1 \%)\end{array}$ & $\begin{array}{l}0 \\
0\end{array}$ \\
\hline $\begin{array}{l}\text { Nursing home } \\
6 \text { months } \\
12 \text { months }\end{array}$ & $\begin{array}{l}2(1.5 \%) \\
3(2 \%)\end{array}$ & $\begin{array}{l}1(1 \%) \\
1(1 \%)\end{array}$ \\
\hline $\begin{array}{l}\text { Other (living with family or frienc } \\
6 \text { months } \\
12 \text { months }\end{array}$ & $\begin{array}{l}0 \\
0\end{array}$ & $\begin{array}{l}3(2 \%) \\
3(2 \%)\end{array}$ \\
\hline \multicolumn{3}{|c|}{ Care dependence for daily activities', n (\%) } \\
\hline $\begin{array}{l}\text { Independent before }{ }^{2} \text { : } \\
1 \text { week before }\end{array}$ & $129(89 \%)$ & $141(97 \%)$ \\
\hline $\begin{array}{l}\text { Dependent before }{ }^{2} \text { : } \\
1 \text { week before }\end{array}$ & $16(11 \%)$ & $4(3 \%)$ \\
\hline $\begin{array}{l}\text { Independent after: } \\
6 \text { months } \\
12 \text { months }\end{array}$ & $\begin{array}{l}96(74 \%) \\
113(91 \%)\end{array}$ & $\begin{array}{l}131(93 \%) \\
128(95 \%)\end{array}$ \\
\hline $\begin{array}{l}\text { Dependent after: } \\
6 \text { months } \\
12 \text { months }\end{array}$ & $\begin{array}{l}34(26 \%) \\
11(9 \%)\end{array}$ & $\begin{array}{l}10(7 \%) \\
7(5 \%)\end{array}$ \\
\hline \multicolumn{3}{|c|}{ Home healthcare services utilized at } \\
\hline $\begin{array}{l}6 \text { months, } n(\%) \\
\text { Home nursing care } \\
\text { Meal delivery services } \\
\text { Care by relatives (informal care) } \\
\text { Combination of services }\end{array}$ & $\begin{array}{l}6(5 \%) \\
7(5 \%) \\
10(8 \%) \\
8(6 \%)\end{array}$ & $\begin{array}{l}2(1 \%) \\
3(2 \%) \\
4(3 \%) \\
0\end{array}$ \\
\hline $\begin{array}{l}12 \text { months, } n(\%) \\
\text { Home nursing care } \\
\text { Combination of services }\end{array}$ & $\begin{array}{l}2(2 \%) \\
5(4 \%)\end{array}$ & $\begin{array}{l}4(3 \%) \\
4(3 \%)\end{array}$ \\
\hline
\end{tabular}

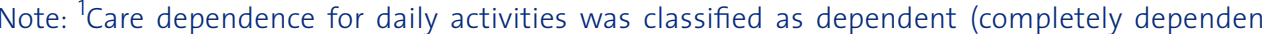
or needs support by caregivers and specialized medical equipment) and independent (independent with and without medical equipment). ${ }^{2}$ One week prior to the ICU staylat study recruitment. Abbreviations: ICU=Intensive Care Unit. $n=$ number of subjects. 


\section{Discussion}

Use of healthcare resources, in general, was not excessive. However, the ICU group did use more healthcare resources over 12 months than the comparison group. Very positive outcomes of the study were that almost no ICU group patients were readmitted to the ICU, hospital, nursing homes or acute care hospitals, which are very cost-intensive institutions. In addition, almost all ICU group patients were able to live independently at home after one year.

The type of healthcare resources used by the ICU group is in line with some of the previously published studies, ${ }^{6,15,23}$ although other studies have shown that the critically ill older patients require significant healthcare resources for months and even years following discharge from ICUs. ${ }^{15}$ The ICU group patients in our study were rarely readmitted to either the ICU or the hospital, and the length of stay in rehabilitation programs was within the average duration of these programs. ${ }^{12,13,24}$ In addition, as compared to previous reports, very few ICU group patients were transferred to nursing homes. ${ }^{13,25}$ Sage et $a I^{6}$ found that after an ICU stay, the critically ill older patients required an intensive amount of post-hospitalization care including (re)hospitalization, surgical procedures, and doctor visits, compared to volunteers from two residential centers. It would seem that increased healthcare resource utilization following an ICU stay is not necessarily due to advanced age. Williams et a ${ }^{23}$ found that $1 / 3$ of their younger patients used more medications and saw their GPs more often than they had prior to hospitalization. The relatively low utilization of healthcare resources found in our study may be explained by the high level of independence of the ICU group patients both prior to their ICU stay and one year following discharge. Most of the ICU group lived with family, attended rehabilitation programs with self-care education and preventive interventions, and were closely monitored by their GPs, primarily because of their ICU stay and|or their co-morbidities. The influence that the higher number of women in the comparison group or the higher number of patients with co-morbidities in the ICU group had on the results is not known.

Interestingly, the ICU group in our study was hospitalized less often than the comparison group during the year of the study, which is similar to the study by Keenan et $\mathrm{al}^{26}$ showing that ICU survivors in British Columbia had fewer readmissions over 3-year period than survivors of a hospitalization without ICU stay. These results are in contrast to Wunsch et $\mathrm{al}^{13}$ who found that older ICU survivors in the USA had more (re)admissions 6 months after an ICU stay when compared to the general population. A possible explanation for these findings is that the ICU groups' frequent visits to GPs allowed early recognition and proactive treatment of health problems that prevented further hospitalizations. In support of this explanation, the comparison group visited their GPs less frequently and tended to go directly to the hospital for acute health problems.
The home healthcare services utilized by the ICU group were similar to reports from previous studies, such as meal delivery services and care by relatives. ${ }^{4,15}$ Interestingly, very few of the ICU group patients needed home healthcare services after one year, which is in contrast to what has been previously reported. ${ }^{4,15}$ We suspect that the patients in the ICU group had returned to a relatively good state of health and had sufficient support to enable them to stay at home. Perrig-Chiello et $\mathrm{al}^{27}$ confirmed that many older persons in Switzerland enjoy a relatively long unencumbered life expectancy and thus are able to remain "independent" at home. The extent to which this "independence" is supported by informal care from relatives and the available social network has neither been examined in our study nor in previously published studies. ${ }^{15,27}$

The mortality rate of the ICU group patients was lower than the mortality rate of 7\%$69 \%$ previously reported for critically ill older patients over a similar time period af ter ICU discharge. ${ }^{15,19,20}$ There are various explanations for this lower mortality rate. Case-mix could be one reason as Vest et al ${ }^{20}$ included only medical ICU patients in their study who tend to have a higher mortality rate after an ICU stay than do elective surgical ICU patients. ${ }^{8}$ In addition, we excluded patients with known cognitive impairment or who were receiving palliative care due to terminal illnesses. These patients may have had a higher mortality rate ${ }^{28}$ than the ICU group patients who were included. The lower mortality rate may have been influenced by the ICU group patients remaining in hospital or rehabilitation until they were stable, and |or receiving close monitoring by their GPs after hospitalization. The study by Kaarlola et al ${ }^{15}$ showed that critically ill older patients who had had coronary bypass surgery had the lowest mortality (7\%). Most of the ICU group patients in our study had cardia surgery, and this may also contribute to the positive outcomes found in this study. Information is also missing on $9 \%(n=11)$ of the study participants who were lost to follow-up. 


\section{Limitations}

This study has some limitations that need to be addressed. First, critically ill older patients were excluded if they were unable to express themselves verbally, had cognitive impairment or acute psychotic illnesses, were receiving palliative care, or were transferred directly from the ICU to a smaller acute care hospital. Critically ill older patients with these characteristics often require specific long-term resources (for example psychological support or long-term institutional care). Second, the use of healthcare resources, such as visits to GPs and medication use before the ICU stay, was not recorded, so that a baseline measurement was not available. Third, it was not possible to ascertain if and how the patients' financial situation influenced their use of healthcare resources. This will need further study especially concerning services that are not covered by health insurance. Fourth, the study used a convenience sample from a heterogeneous population and had significant group differences in sex and co-morbidities. Finally, the study was conducted in one university hospital, all of which restrict the generalizability of the results.

\section{Conclusion}

Critically ill older patients need various healthcare resources following an ICU stay. Utilization of these resources enables them to live at home and contributes to longterm positive outcomes. Provision of adequate healthcare resources can reduce the need for more expensive healthcare such as hospitalization or long-term care institutions.

\section{Relevance to Clinical Practice}

Adequate healthcare resources must be available for older patients after an ICU stay. These include easy access to GPs, rehabilitation facilities, and home healthcare services. Nurses have the responsibility to assist patients to access and manage healthcare resources after hospitalization. In coordination with the entire healthcare team, the critically ill older patient and their family will benefit from identifying the appropriate healthcare services. Creating a printed brochure that explains available services can help to guide the use of healthcare services after an ICU stay. Coordinating follow-up services such as physician visits will provide the patient and family with a significant start. Regular evaluation of healthcare resources enables planning for effective follow-up care. In addition, nurses teach critically ill older patients and their families how to use new techniques and interventions. Given that the family members of critically ill older patients are often older themselves, this must also be taken into consideration when planning for follow-up care. For example, long distances to various programs and appointments can present a burden for the older relative. Further studies are needed to analyze healthcare resource utilization by those critically ill older patients who were excluded from this study. In addition, the social and psychological resources used by critically ill older patients after an ICU stay have not been sufficiently studied. Studies on long-term outcomes such as quality of life may be relevant and are indirect measures of healthcare resource utilization. 


\section{References}

1 Cox CE, Carson SS. Medical and economic implications of prolonged mechanical ventilation and expedited post-acute care. Semin Respir Crit Care Med. 2012;33(4):357-61.

2 Lone NI, Seretny M, Wild SH, Rowan KM, Murray GD, Walsh TS. Surviving intensive care: a systematic review of healthcare resource use after hospital discharge. Crit Care Med. 2013;41(8):1832-43.

3 Ruhl AP, Lord RK, Needham DM. Healthcare resource utilization and costs after critical illness: current knowledge and a plan for moving forward. Crit Care Med. 2013;41(8):2030-1.

4 Montuclard L, Garrouste-Orgeas M, Timsit JF, Misset B, De Jonghe B, Carlet J. Outcome, functional autonomy, and quality of life of elderly patients with a long-term intensive care unit stay. Crit Care Med. 2000;28(10):3389-95.

5 Cuthbertson BH, Roughton S, Jenkinson D, Maclennan G, Vale L. Quality of life in the five years after intensive care: a cohort study. Crit Care. 2010;14(1):R6.

6 Sage WM, Hurst CR, Silverman JF, Bortz WM. Intensive care for the elderly: outcome of elective and nonelective admissions. J Am Geriatr Soc. 1987;35(4):312-8.

7 Boumendil A, Maury E, Reinhard I, Luquel L, Offenstadt G, Guidet B. Prognosis of patients aged 80 years and over admitted in medical intensive care unit. Intensive Care Med. 2004:30(4):647-54.

8 de Rooij SE, Govers AC, Korevaar JC, Giesbers AW, Levi M, de Jonge E. Cognitive, functional, and quality-of-life outcomes of patients aged 80 and older who survived at least 1 year after planned or unplanned surgery or medical intensive care treatment. J Am Geriatr Soc. 2008;56(5):816-22.

9 Aitken LM, Burmeister E, Lang J, Chaboyer W, Richmond TS. Characteristics and outcomes of injured older adults after hospital admission. J Am Geriatr Soc. 2010;58(3):442-9.

10 Taylor MD, Tracy JK, Meyer W, Pasquale M, Napolitano LM. Trauma in the elderly: intensive care unit resource use and outcome. J Trauma. 2002;53(3):407-14.

11 Martin CM, Hill AD, Burns K, Chen LM. Characteristics and outcomes for critically ill patients with prolonged intensive care unit stays. Crit Care Med. 2005;33(9):1922-7.

12 Kaben A, Corrêa F, Reinhart K, Settmacher U, Gummert J, Kalff R, Sakr Y. Readmission to a surgical intensive care unit: incidence, outcome and risk factors. Crit Care. 2008;12(5):R123.

13 Wunsch H, Guerra C, Barnato AE, Angus DC, Li G, Linde-Zwirble WT. Three-year outcomes for Medicare beneficiaries who survive intensive care. JAMA. 2010;303(9):849-56.

14 Rady MY, Johnson DJ. Hospital discharge to care facility: a patient-centered outcome for the evaluation of intensive care for octogenarians. Chest. 2004;126(5):1583-91.

15 Kaarlola A, Tallgren M, Pettilä V. Long-term survival, quality of life, and quality-adjusted life-years among critically ill elderly patients. Crit Care Med. 2006;34(8):2120-6.

16 Merlani P, Chenaud C, Mariotti N, Ricou B. Long-term outcome of elderly patients requiring intensive care admission for abdominal pathologies: survival and quality of life. Acta Anaesthesio Scand. 2007;51(5):530-7.

17 Richmond TS, Kauder D, Strumpf N, Meredith T. Characteristics and outcomes of serious traumatic injury in older adults.J Am Geriatr Soc. 2002;50(2):215-22.
18 Conti M, Friolet R, Eckert P, Merlani P. Home return 6 months after an intensive care unit admission for elderly patients. Acta Anaesthesiol Scand. 2011;55(4):387-93.

19 de Rooij SE, Govers A, Korevaar JC, Abu-Hanna A, Levi M, de Jonge E. Short-term and long term mortality in very elderly patients admitted to an intensive care unit. Intensive Care Med. 2006;32(7):1039-44.

20 Vest MT, Murphy TE, Araujo KL, Pisani MA. Disability in activities of daily living, depression, and quality of life among older medical ICU survivors: a prospective cohort study. Health Qual Life Outcomes. 2011;9:9.

21 Jeitziner MM, Hantikainen V, Conca A, Hamers JP. Long-term consequences of an intensive care unit stay in older critically ill patients: design of a longitudinal study. BMC Geriatr. 2011;11:52.

22 Knaus WA, Draper EA, Wagner DP, Zimmerman JE. APACHE II: a severity of disease classification system. Crit Care Med. 1985;13(10):818-29.

23 Williams TA, Leslie GD, Brearley L, Dobb GJ. Healthcare utilisation among patients discharged from hospital after intensive care. Anaesth Intensive Care. 2010:38(4):732-9.

24 Bundesamt für Statistik. Medizinische Statistik der Krankenhäuser [Internet]. 2011 "Federa Office of Statistics. Medical statistics from hospitals." [cited 2014 Mar 3]. Available from: http://www.bfs.admin.ch/bfs/portal/de/index/news/publikationen.html?publicationlD=5103.

25 Gehlbach BK, Salamanca VR, Levitt JE, Sachs GA, Sweeney MK, Pohlman AS, Charbeneau J, Krishnan JA, Hall JB. Patient-related factors associated with hospital discharge to a care facility after critical illness. Am J Crit Care. 2011;20(5):378-86.

26 Keenan SP, Dodek P, Chan K, Simon M, Hogg RS, Anis AH, Spinelli JJ, Tilley J, Norena M, Wong H. Intensive care unit survivors have fewer hospital readmissions and readmission days than other hospitalized patients in British Columbia. Crit Care Med. 2004;32(2):391-8.

27 Perrig-Chiello P, Hutchison S, Höpflinger F. AgeCare-Suisse Latine: Pflegende Angehörige in der lateinischen und deutschsprachigen Schweiz. Forschungsbericht Spitex-Schweiz. Internet).2011 "Family caregivers in the French-, Italian- and German-speaking regions of Switzerland. Research report from Spitex-Switzerland." [cited 2014 Mar 3]. Available from: http://upload.sitesystem.ch/ B2DBB48B7E/OCDC636B60/FDAB600C70.pdf.

28 Puntillo KA, Arai S, Cohen NH, Gropper MA, Neuhaus J, Paul SM, Miaskowski C. Symptoms experienced by intensive care unit patients at high risk of dying. Crit Care Med. 2010;38(11):2155-60. 


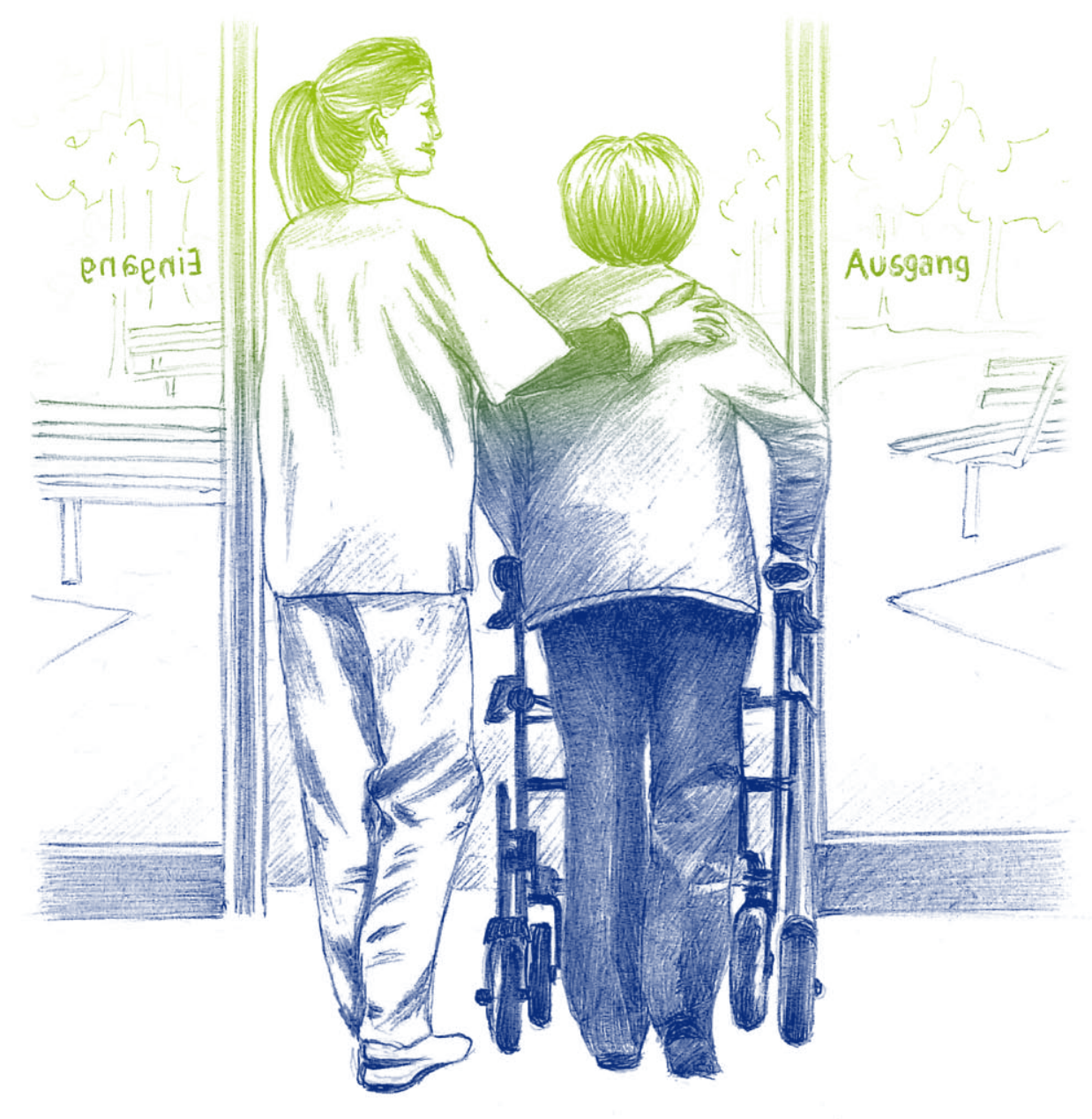




\section{Introduction}

The final chapter of this thesis summarizes the main study findings and discusses methodological issues in conducting the study. It also examines theoretical considerations regarding the interpretation of the results, presents suggestions for implementation in clinical practice and implications for future research, and ends with a summary of the findings of this study.

\section{Main Findings}

Main study findings highlight that the long-term negative consequences of an ICU stay for critically ill older patients are minimal, and that the patients are, in general, in good health one year following the ICU stay.

Specific key conclusions based on the study results are:

- Older patients do not experience increased pain, anxiety, or agitation 12 months following an ICU stay. However, for those patients who report pain at 12 months, an association was found with various factors present prior to ICU admission and during the ICU stay. For example, pain prior to the ICU admission and pain during the ICU stay were associated with longer-term pain.

- Older patients reported low pain levels during their ICU stay. The pain patterns of critically ill older patients are distinctive because of the low levels of reported pain and the substantial individual variability in pain levels.

- Health-related quality of life (HROoL) of the crically ill older patients was good 12 months following the ICU stay and remained stable over the 12-month period. Nev ertheless, HROoL of the critically ill older patients was lower than that of the participants in the comparison group throughout the study. This lower HROLL was documented in the critically ill patients prior to their hospitalization. Factors associated with reduced HROoL were an increased severity of illness, specific diagnoses, and having had surgical procedures. Routine ICU interventions, such as turning and intratracheal suctioning, were also asso ated with a reduction in HROoL after 12 months.

- Older patients did utilize more healthcare resources during the 12 months after hospital discharge than the participants in the comparison group. Despite higher use of healthcare resources in terms of general practitioner and medical specialist visits, rehabilitation program participation and medication use, cost-intensive healthcare resources such as hospital or nursing home admissions were rarely required by the critically ill older patients.

\section{Methodological Considerations}

This section addresses the most important methodological strengths and limitations. Issues discussed include: 1) study design, 2) recruitment of subjects, and 3) outcome measures.

\section{Study Design}

The study utilized a longitudinal design that allowed the examination of long-term outcomes. The main advantage of longitudinal studies lies in the ability to analyze changes in variables over time. ${ }^{1}$ Longitudinal studies identify and determine intraindividual and inter-individual changes. ${ }^{2}$ However, longitudinal studies have common methodological issues in terms of data collection, measurement, and analysis. This study had additional challenges inherent in doing research with older and seriously ill research participants. ${ }^{3-5}$

\section{Adequate Length of Follow-Up}

How long is "long" for critically ill older patients? Based on previous longitudinal studies, ${ }^{6,7}$ a follow-up period of one year with three measurement times was chosen for our study. It is generally accepted that the real burden of an ICU stay is evident up to 6 months after ICU discharge. ${ }^{8}$ Although still minimal, we found the greatest changes in long-term consequences between the first week after ICU discharge and 6 months later. Previous studies with older patients had follow-up periods of 3 months to 8 years. ${ }^{3,9,10}$ To date, no conclusive findings are available to identify the specific time period during which the ICU stay no longer has a significant impact on everyday life. An adequate length of follow-up to detect potential adverse consequences of an ICU stay cannot be defined solely as a dimension of time. Changes in long-term consequences, physical and psychological reserves and the context in which older patients live must be considered in estimating the most appropriate follow-up period. For critically ill older patients, it is not only the quantity (duration) of life that should be evaluated, but also the quality of life. ${ }^{11}$ Based on the relatively stable pattern we found in long-term consequences (Chapters 4, 5, 6), we can expect that a follow-up period of one year is adequate for critically ill older patients after an ICU stay within the Swiss healthcare system. The Swiss healthcare system is known for its high quality and availability to the entire population. ${ }^{12}$ In addition, our study found that early follow-up data collection (within one week after an ICU stay) could reveal relevant health changes in critically ill older patients (Chapter 4). 
Retrospective Baseline Assessment

Our study design called for a retrospective baseline assessment, which introduce the possibility of recall bias. Baseline assessments are necessary when investigating the influence of a critical illness, prognosis, and decision-making in the ICU. ${ }^{8,13}$ Given that most ICU admissions take place under emergency situations and thus are unex pected, baseline measurements cannot always be obtained. In this case, a retrospective baseline assessment presents the only possibility to obtain information from patients themselves. Asking the relatives to fill out the HROoL (SF-36) for the patient would have been an alternative. ${ }^{14}$ However, interviewing relatives when a family member is critically ill can be problematic. ${ }^{15,16}$ Existing studies demonstrate variable results for agreement between patients and relatives, and relatives tend to overestimate or underestimate the HROOL of their family member. ${ }^{17,18}$ In particular, relatives of the older patients have been found to be less capable of describing symptoms and the living situation than patients themselves. ${ }^{19}$ Given these conflicting findings in terms of patient-relative agreement, we decided to ask the patients themselves to answer questions referring to one week prior to ICU admission.

Loss to Follow-Up

One important risk of longitudinal studies is that patients will be lost to follow-up, ${ }^{8}$ which could lead to a significant attrition bias in the results. Since a loss to follow-up of $20 \%$ is an expected attrition rate in studies of ICU patients, ${ }^{8}$ the high follow-up rate of $86 \%$ for the ICU group and $92 \%$ for the comparison group can be regarded as a major strength of this study. Reasons for loss to follow-up were comparable to other long-term ICU studies, for example, reluctance to recall unpleasant memories and personal reasons not related to health. ${ }^{8}$ Very few subjects left the study due to age-related impairments. Additionally, only five patients in the ICU group died, and no one died in the comparison group during the 12-month follow-up period. The one-year mortality for older patients who have survived an ICU stay varies between 7\%-69\%. ${ }^{3,20}$ The low mortality in our study can be explained by the case-mix (e.g., diagnoses, ratio of medical and surgical patients) or the starting point for the follow-up. Recruitment, or study begin for our study was one week following ICU discharge. Had we started recruitment at the time of ICU admission, we could have expected a much higher mortality rate because, given the older age of the patients, some of the patients who subsequently died during the ICU stay would have also been included..$^{21,22}$ Most of the ICU group patients in our study had cardiac surgery. Kaarlola et al ${ }^{3}$ confirms that critically ill older patients who have had coronary artery bypass surgery have the lowest mortality (7\%).
Recruitment of Subjects

Inclusion Criteria

One of the biggest challenges in this study was the recruitment of appropriate subjects. We screened 1214 ICU patients of whom 145 critically ill older patients (12\%) met the inclusion criteria and agreed to participate. Very few patients refused to participate in the study.

Cognitive impairment in ICU patients is a special problem. Previous studies confirm that impaired cognitive functioning is common for critically ill older patients. ${ }^{23,24}$ Memory, attention and concentration problems, as well as neuropsychological deficits comparable to the impact of low-level dementia, affect a majority of these olde patients. ${ }^{25}$ Because we excluded patients with cognitive impairment, the study used a selective sample. It is possible that we included patients in our study who had better health, because these patients were capable of taking part in the study one week after ICU discharge, and this may have created a selection bias. We excluded patients with clinically significant cognitive impairment because it can take months to years for critically ill older patients to recover from ICU-induced cognitive impairment. ${ }^{24}$

Prospective Comparison Group and Matching

Utilizing a community-based comparison group matched to the ICU group on age was one of the strengths of the study design. The comparison group was selected to provide an example of the "normal" age-related signs and symptoms older individuals may experience. Most longitudinal studies have matched critically ill older patients with individuals selected to represent a healthy population, ${ }^{3,8}$ individuals reflecting the population norms, ${ }^{8,26}$ or even with younger ICU patients..$^{27}$ Although patients who are critically ill may not reflect the population norm or be comparable to younger ICU patients before an illness, ${ }^{28}$ a comparison group does allow a more realistic interpretation of the results and may possibly account for confounding, extraneous variables that may impact the outcome variables. ${ }^{8}$ One limitation of our study was that the groups were only matched for age, and not for sex or comorbidities. This was a design decision taken in order to recruit the planned 150 subjects per group, realizing that recruitment of older patients may be challenging as older patients tend to be less likely than younger patients to agree to participate in research studies. ${ }^{29,30}$ Our study had an unequal distribution of women and men in the two groups. Because more men than women were hospitalized in the ICU, more men were eligible for the study. This unequal distribution of men and women reflects national and international data where men, especially older men, are more frequently hospitalized in ICUs. ${ }^{31-34}$ Significantly more women volunteered to be in the study for the comparison group, which resulted in the imbalance of men and women between 
the two groups. Previous studies that compared patients by sex found that older women are more dependent on institutionalized care, and more frequently suffer due to restrictions in their daily functioning. ${ }^{35,36}$ Men, however, can usually rely on informal help and care, as the men in Switzerland tend to live with a partner and the older women tend to live alone. ${ }^{37}$ The degree to which the imbalance in the distribution of men and women in the two groups of our study affected the good long-term consequences remains unknown.

\section{Outcome Measures}

Validity, Reliability, and Feasibility

Several strategies were employed to increase the validity, reliability, and feasibility of the outcome measurements. First, we used instruments and questionnaires with good psychometric properties and in the native language of the participants. For example validated translations into German and French of the numeric rating scale (NRS), verbal rating scale (VRS), behavioral scale, and Short Form Health Survey 36 (SF-36) were used. Critically ill older patients often have difficulty using various instruments or following the instructions for using the instruments. The Confusion Assessment Method ICU (CAM-ICU) is one example where difficulties for patients arise due to fatigue or limited energy. ${ }^{30,38}$ We chose easily applicable instruments, such as the numeric rating scale for pain, and the survey methods were adjusted to the cognitive and physical abilities of the patients. Further research is needed in this area, including ways in which data can be collected while causing the least amount of stress for the critically ill older patient. Second, all critical care nurses had special training in assessing pain, anxiety, and agitation. The training included: 1) assessing and managing pain, anxiety, and agitation during the ICU stay; 2) determining the peak duration of analgesia and sedation; 3) and advanced understanding of the pharmacological mechanisms of analgo-sedation. The training of the critical care nurses may have influenced the results of our study. A better knowledge of analgo-sedation allowed the critical care nurses to administer and optimize selected analgo-sedation. Given that the study was carried out in an ICU that already had a defined analgo-sedation management program, treatment of pain, anxiety, and agitation followed standard procedure. Third, to increase consistency of data collection, the same 4 critical care nurse specialists carried out the data collection for the entire year after the ICU discharge. The fourth key strength of the study was compiling a complete database over 12 months on the 124 critically il older patients and the 135 age-matched community-based participants. The data collection process was continuously monitored for quality assurance purposes. Missing values were minimized by using telephone interviews and mailed questionnaires to determine the outcome measures. To minimize missing data, participants who had not responded to the mailed questionnaires were contacted a second time by telephone and, if necessary, questionnaires were sent again by mail.

\section{Theoretical Considerations}

This section provides some theoretical considerations regarding the interpretation of the results. The following issues are discussed: 1) target population; 2) pain, anxiety, and agitation after the ICU stay; and 3) good health-related quality of life without excessive healthcare resource use.

\section{The Target Population}

Good Physical and Psychological Reserve

Noteworthy are the good long-term consequences for this particular sample of critically ill older patients (Chapters 4, 5, 6). One explanation is that the critically ill older patients who survived the ICU stay exhibited good physiological reserve that supports their ability to cope with the ICU stay and the subsequent recovery period. The physical and psychological reserves of critically ill older patients are often limited by pre-existing diseases or diminished as a result of the acute illness. ${ }^{39}$ Currently, there are no valid and reliable methods to estimate physiological reserves in ICU patients. ${ }^{40}$ It is possible, though, that some components of the HROOL reflect physiological reserves. ${ }^{13}$ This would coincide with our results showing that a good mental and functional HROoL before the ICU stay (Chapter 5) will probably have a positive influence on the long-term consequences of the stay. A further explanation can be found in previous studies demonstrating that the critically ill older patients who are hospitalized most frequently in the ICU are in relatively good health, ${ }^{41}$ and therefore this may favorably influence the long-term consequences. Frailty, characterized by loss of physical and cognitive reserve, ${ }^{40}$ has been shown to closely correlate with the aging process and the development of critical illness. ${ }^{40,42}$ Thus frailty may, in the future, be used as a measure for physical and psychological reserves and as an aid to identify vulnerable patients. This may be important because the amount of physical and psychological reserves may or may not relate to the ability to tolerate an ICU stay. ${ }^{42}$ 
Pain, Anxiety, and Agitation After the ICU Stay

Low Level of Pain, Anxiety, and Agitation

We found that levels of pain, anxiety, and agitation were low in general throughout the ICU stay and the follow-up period. Interestingly, critically ill older patients normally have a heightened risk of persistent pain due to the normal physiologic aging processes affecting the musculoskeletal system and increased number of co-morbidities. ${ }^{29,43}$ Our results correspond with previous HRQoL studies showing that persistent pain in critically ill older patients does not differ from that in a matched normal population. ${ }^{7,31}$ However, other HROoL studies show that persistent pain is common among critically ill older patients. ${ }^{3,44}$ Growing evidence suggests that management of pain and agitation during the ICU stay will improve the long-term consequences for ICU patients; ${ }^{45}$ this corresponds to our find ings (Chapters 2, 4, 5, 6). Previous studies report that patients with sepsis and trauma tend to have persistent pain. ${ }^{46-48}$ Most of the critically ill older patients in our study had cardiac illnesses or surgery that may explain the low levels of pain reported at 6 and 12 months. Persistent pain after surgery is primarily associated with younger patients. The reduction in the peripheral nociceptive function with increased age is the explanation commonly given for this phenomenon of decreased pain perception in older patients. ${ }^{29,43,46}$

Anxiety after the ICU stay was also low in the critically ill older patients. Previous studies found anxiety present in younger patients in relation to depression, post-traumatic stress disorders (PTSD), or when viewed as a psychiatric complication. ${ }^{28,49,50}$ Most of our critically ill older patients had accurate memories of their ICU stays (Chapter 4), as opposed to delusional memories which are most often related to long-term anxiety disorders or other psychiatric conditions. ${ }^{51,52}$ Studies also show that light sedation or daily interruption of sedation may be protective for PTSD and anxiety. ${ }^{53,54}$ This corresponds to our findings that the older patients had light sedation (Chapter 2) and daily sedation interruption (Chapters 4, 5).

Not only were pain and anxiety levels found to be low after the ICU stay, levels of agitation were also low. Agitation without delirium has been reported during the ICU stay. ${ }^{45,55}$ However, agitation following an ICU stay has primarily been investigated in the context of PTSD, post-ICU syndrome, or as a psychiatric complication. ${ }^{28,49,50}$ Our results are supported by previous publications indicating that the frequency of psychiatric complications decreases with increasing age. ${ }^{50}$ Agitation during and after an ICU stay is an area in need of further research. Ouestions arise in terms of exact definitions and limitations of the psychiatric complications, as several of the symptoms overlap. ${ }^{28}$ For example, there is significant overlap in some behavioral symptoms for pain, agitation, and anxiety. Further research is needed to determine the extent to which agitation can be analyzed as a symptom isolated from other issues with which it shares symptom overlap, such as pain or anxiety.
Good Health-related Ouality of Life Without Excessive Healthcare Resource Use

Acute and Chronic Critically III

An important finding from our study is, that the critically ill older patients had a good HROoL, and did utilize healthcare resources, but at a much lower level than the cost intensive services such as admission to a nursing home or hospital (Chapters 5, 6). These findings are consistent with the results of some studies. ${ }^{3,8}$ However, other studies have reported worsening HROOL and increases in institutionalization. ${ }^{31,20,56}$ One important explanation for our results concerns the nature of our ICU patient population with regard to specific illnesses. ${ }^{7,8,31}$ Many of our patients had cardiac surgery and this patient population has a higher probability of good long-term consequences ${ }^{3}$ due to the possibility of an operative cure for severe coronary artery disease or valvular disease. Patients with severe acute respiratory distress syndrome, prolonged mechanical ventilation, severe trauma, and severe sepsis, appear to have the worst HROoL and highest pain levels. ${ }^{8,46}$ The mean ICU length of stay in our study was 4.57 days and only a few of the patients in our study developed a chronic critical illness with an ICU stay longer than 7 days. ${ }^{57}$ Older patients hospitalized in ICUs are at increased risk of developing a chronic critical illness. ${ }^{58}$ Chronic critical illnesses are associated with profound debilitation, months of hospitalization, permanent dependence on mechanica ventilation and |or other life-sustaining technology, thus requiring long-term medical and nursing care..$^{56,58}$

A Good Population State of Health

One other possible explanation for the good HRQoL and the adequate healthcare resource use in our study can be related to the generally good state of health of the older population in Switzerland. Studies show that the great majority of older persons living in Switzerland, including those who have previously been treated in an ICU, esti mate their own state of health to be "good" to "very good" and have a long disabilityfree life expectancy. ${ }^{35-37}$ These reports confirm the results of our study, which showed that after a year, most of the critically ill older patients were living at home with little outside support.

\section{Adaptation Process}

Alternative explanations for the good long-term outcomes in our study include the adaptation process. Interestingly, critically ill older patients generally adapt well to their limitations and perceive their HROOL as good. ${ }^{8}$ The literature describes the adaptation process as a response shift and defines it as changes in internal standards, values, and conceptualization. ${ }^{59}$ Experts note that any conclusions regarding response 
shift should be based on careful investigation and documentation. ${ }^{59}$ We have not performed an investigation of the response shift in our study. It is also important to note that the self-assessment of health by older patients only moderately correlated with their objective health, because the perception of health changes with age. Patients felt they were healthy in spite of their complaints, because they compared themselves to peers who were sicker than they were. ${ }^{60}$ However, considering the concept of response shift, issues such as adaptation, coping, expectations or self-control in the measurement of long-term consequences become significant. Further studies are needed to explore these mechanisms in critically ill older patients after an ICU stay.

Our study, albeit with a selected sample, shows that critically ill older patients have good long-term consequences following an ICU stay. These patients profited both from treatment in the ICU as well as the healthcare resources available to them following hospital discharge. A caveat is that management of older patients during and after an ICU stay is a complex issue and not all older patients will experience the hoped for return to good health. Future developments in medicine, nursing, and technology will continue to influence the long-term consequences of an ICU stay. These long-term consequences must continuously be evaluated to the benefit of critically ill older patients.

\section{Implications}

Implications for Practice

The results of this study have several implications for the clinical practice with critically ill older patients during and after an intensive care unit (ICU) stay.

- Critically ill older patients undergo many painful interventions during an ICU stay. It is crucial that nurses recognize and treat pain prior to, during, and following the stay. Prevention of long-term pain requires special attention to patients with pain before and during the ICU stay, after surgery, and in situations where high doses of sedation have been used. Lower levels of sedation allow critically ill older patients to express the presence of pain, anxiety, and agitation. Nurses should also use validated assessment instruments to recognize pain and anxiety. Assessment and treatment of pain should start from the onset of the ICU stay, since the most intensive pain usually occurs on day 1 of the stay.

- Our study shows that critically ill older patients with severe illnesses, acute renal failure, and following cardiac surgery, may have restricted functioning following an ICU stay. Therefore, when preparing for discharge, nurses need to carefully explain to the patients and their relatives the various rehabilitation and supportive services available for the patient. During the ICU stay, intratracheal suctioning and turning were associated with lower mental health scores, therefore it is advisable that nurses plan and execute these interventions according to individual needs, and not as standard components of "routine care."

- Critically ill older patients will need a broad range of healthcare resources such as rehabilitation, home care services, etc. following an ICU stay. According to our findings, it is important that older patients have access to a wide-range of healthcare resources. Nurses play a key role in structuring and managing care by an interdisciplinary team dedicated to the special needs of these patients. Nurses have major responsibilities in decision-making, coordination, planning, and evaluation of the available resources. Therefore, they must have up-to-date knowledge of current healthcare resources in order to competently advise patients, their relatives and other healthcare professionals. 


\section{Implications for Future Research}

Our study identifies areas for future research. We highlight a few in the following section.

- Subsets of critically ill older patients have long-term cognitive limitations, serious illnesses such as severe sepsis, acute respiratory distress syndrome, chronic critical illnesses, or a terminal illness. These vulnerable and often older patients receive long-term treatment, such as mechanical ventilation and care across a range of venues. In addition, these patients often have substantial health-related burdens, for example cognitive impairment or polyneuropathy, and need special care (e.g., ICU follow-up clinics, palliative care). Previously, long-term consequences such as pain, anxiety, agitation, and health-related quality of life (HROLL) or the use of healthcare resources by these patients have seldom been studied, even though they present specific medical and nursing challenges.

- Future studies are needed to identify factors that have a positive influence on long-term consequences for critically ill older patients. Factors such as physical and psychological reserves, the ability to cope in extreme situations, and specific ICU interventions, such as early mobilization, adequate analgesia and sedation, targeted delirium management, standardized ICU protocols, and early rehabilitation may be able to positively influence the long-term consequences for the older patients. Specific ICU interventions such as early mobilization, etc. have a positive influence on long-term consequences for critically ill patients. Very few studies have examined the physical and psychological reserves and ICU interventions that specifically focus on critically ill older patients. Randomized controlled studies for older patients are important, because age is associated with decreased cardiac, pulmonary, rena and cognitive function, which contribute to a reduction in physical reserves. This physical reserve influences specific ICU interventions, for example early rehabilitation during the ICU stay and also interventions during the recovery period after discharge.

- Finally, many methodological concerns remain about the research on long-term consequences for critically ill older patients, such as the choice of measurement tools, measurement time points, length of follow-up, comparison groups and baseline assessment. No consensus has been reached on which measurement tools are optimal for measuring different long-term consequences, such as the HROOL. A consensus of experts on measurement tools would be a valuable asset in planning research designs and methodology. Baseline assessments prior to the ICU stay, when measuring long-term consequences such as pain, anxiety, agitation or HROOL, are necessary, because conditions present before the ICU stay, may influence the long-term consequences. One way to improve patient care is by promoting HROoL.
Although little is known about $\mathrm{HROoL}$ during the ICU stay, it may substantially contribute to the ICU outcome for critically ill older patients. Measurement tools need to be developed that can be used with critically ill older patients during the ICU stay Additionally, research needs to determine whether long-term consequences such as pain, HROoL, etc. belong to the standardized examinations by general practitioners or other healthcare providers, and therefore be used on a long-term basis. 


\section{References}

1 Goldstein H. Longitudinal studies and the measurement of change. Statistician. 1968;18:93-117.

2 Schaie KW, Hofer SM. Longitudinal studies in aging research. In: Birren JE, Schaie KW, editors. Hand-book of the psychology of aging. San Diego: Academic Press; 2001; p. 53-77.

3 Kaarlola A, Tallgren M, Pettilä V. Long-term survival, quality of life, and quality-adjusted life-years among critically ill elderly patients. Crit Care Med. 2006;34(8):2120-6.

4 Bagshaw SM, Webb SA, Delaney A, George C, Pilcher D, Hart GK, Bellomo R. Very old patients admitted to intensive care in Australia and New Zealand: a multi-centre cohort analysis. Crit Care. 2009;13(2):R45.

5 Ihra GC, Lehberger J, Hochrieser H, Bauer P, Schmutz R, Metnitz B, Metnitz PG. Development of demographics and outcome of very old critically ill patients admitted to intensive care units. Intensive Care Med. 2012;38(4):620-6.

6 Eddleston JM, White P, Guthrie E. Survival, morbidity, and quality of life after discharge from intensive care. Crit Care Med. 2000;28(7):2293-9.

7 Dowdy DW, Eid MP, Sedrakyan A, Mendez-Tellez PA, Pronovost PJ, Herridge MS, Needham DM. Quality of life in adult survivors of critical illness: a systematic review of the literature. Intensive Care Med. 2005;31(5):611-20.

8 Oeyen SG, Vandijck DM, Benoit DD, Annemans L, Decruyenaere JM. Quality of life after intensive care: a systematic review of the literature. Crit Care Med. 2010;38(12):2386-400.

9 Daubin C, Chevalier S, Séguin A, Gaillard C, Valette X, Prévost F, Terzi N, Ramakers M, Parienti JJ, du Cheyron D, Charbonneau P. Predictors of mortality and short-term physical and cognitive dependence in critically ill persons 75 years and older: a prospective cohort study. Health Oual Life pendence in critically
Outcomes. 2011;9:35.

10 Iwashyna TJ, Ely EW, Smith DM, Langa KM. Long-term cognitive impairment and functional disability among survivors of severe sepsis. JAMA. 2010;304(16):1787-94.

11 Azoulay E, Kentish-Barnes N, Pochard F. Health-related quality of life: an outcome variable in critical care survivors. Chest. 2008;133(2):339-41.

12 Bundesamt für Gesundheit [Internet]. 2014 “Federal Department of Health.” [cited 2014 Oст 14]. Available from: http://www.bag.admin.ch/themen/medizin/index.html?lang=de.

13 Hofhuis JG, Spronk PE, van Stel HF, Schrijvers AJ, Bakker J. Quality of life before intensive care unit admission is a predictor of survival. Crit Care. 2007;11(4):R78.

14 Hofhuis J, Hautvast JL, Schrijvers AJ, Bakker J. Quality of life on admission to the intensive care: can we query the relatives? Intensive Care Med. 2003;29(6):974-9.

15 Gutierrez KM. Experiences and needs of families regarding prognostic communication in an in tensive care unit: supporting families at the end of life. Crit Care Nurs Q. 2012;35(3):299-313.

16 Adams JA, Anderson RA, Docherty SL, Tulsky JA, Steinhauser KE, Bailey DE Jr. Nursing strategies to support family members of ICU patients at high risk of dying. Heart Lung. 2014;43(5):406-15.

17 Gifford JM, Husain N, Dinglas VD, Colantuoni E, Needham DM. Baseline quality of life before intensive care: a comparison of patient versus proxy responses. Crit Care Med. 2010;38(3):855-60.
18 Dinglas VD, Gifford JM, Husain N, Colantuoni E, Needham DM. Quality of life before intensive care using EQ-5D: patient versus proxy responses. Crit Care Med. 2013;4(1):9-14.

19 Tamim H, McCusker J, Dendukuri N. Proxy reporting of quality of life using the EQ-5D. Med Care. 2002;40(12):1186-95.

20 de Rooij SE, Govers A, Korevaar JC, Abu-Hanna A, Levi M, de Jonge E. Short-term and long term mortality in very elderly patients admitted to an intensive care unit. Intensive Care Med. 2006;32(7):1039-44.

21 Kaukonen KM, Bailey M, Suzuki S, Pilcher D, Bellomo R. Mortality related to severe sepsis and septic shock among critically ill patients in Australia and New Zealand, 2000-2012. JAMA. 2014;311(13):1308-16.

22 Andersen FH, Kvåle R. Do elderly intensive care unit patients receive less intensive care treatment and have higher mortality? Acta Anaesthesiol Scand. 2012;56(10):1298-305.

23 Jackson JC, Pandharipande PP, Girard TD, Brummel NE, Thompson JL, Hughes CG, Pun BT, Vasilevskis EE, Morandi A, Shintani AK, Hopkins RO, Bernard GR, Dittus RS, Ely EW. Depression, post-traumatic stress disorder, and functional disability in survivors of critical illness in the BRAIN-ICU study: a longitudinal cohort study. Lancet Respir Med. 2014;2(5):369-79.

24 Pandharipande PP, Girard TD, Jackson JC, Morandi A, Thompson JL, Pun BT, Brummel NE, Hughes CG, Vasilevskis EE, Shintani AK, Moons KG, Geevarghese SK, Canonico A, Hopkins RO, Bernard GR, Dittus RS, Ely EW. Long-term cognitive impairment after critical illness. N Engl J Med. 2013;369(14):1306-16.

25 Wehler M. Langzeitprognose alter Patienten nach intensiv-medizinischer Behandlung. "Long term prognosis for older patients following intensive care medical treatment." Med Klin Intensivmed. 2011;106:29-33.

26 Hofhuis JG, van Stel HF, Schrijvers AJ, Rommes JH, Spronk PE. Changes of health-related quality of life in critically ill octogenarians: a follow-up study. Chest. 2011;140(6):1473-83.

27 Kleinpell RM, Ferrans CE. Factors influencing intensive care unit survival for critically ill elderly patients. Heart Lung. 1998;27(5):337-43.

28 Desai SV, Law TJ, Needham DM. Long-term complications of critical care. Crit Care Med. 2011;39(2):371-9.

29 Gagliese L. Pain and aging: the emergence of a new subfield of pain research.J Pain. 2009;10(4):343-53.

30 Mody L, Miller DK, McGloin JM, Freeman M, Marcantonio ER, Magaziner J, Studenski S. Recruitment and retention of older adults in aging research. J Am Geriatr Soc. 2008;56(12):2340-8.

31 Merlani P, Chenaud C, Mariotti N, Ricou B. Long-term outcome of elderly patients requiring intensive care admission for abdominal pathologies: survival and quality of life. Acta Anaesthesio Scand. 2007;51(5):530-7.

32 Garland A, Olafson K, Ramsey CD, Yogendran M, Fransoo R. Epidemiology of critically ill patients in intensive care units: a population-based observational study. Crit Care. 2013;17(5):R212.

33 Fowler RA, Sabur N, Li P, Juurlink DN, Pinto R, Hladunewich MA, Adhikari NK, Sibbald WJ, Martin CM. Sex-and age-based differences in the delivery and outcomes of critical care. CMA 2007;177(12):1513-9. 
34 Schweizerische Gesellschaft für Intensivmedizin (SGI). Minimaler Datensatz der SGI [Internet]. 2014 "Swiss Society for Intensive Care Medicine (SGI). Minimal Data Set of the SGI." [cited 2014 May 25]. Available from: http://www.sgi-ssmi.ch/sgi-mdsi-aktuell.html.

35 Perrig-Chiello P, Hutchison S. Health and well-being in old age: the pertinence of a gender mainstreaming approach in research. Gerontology. 2010;56(2):208-13.

36 Bundesamt für Statistik. Die funktionale Gesundheit von ältern Menschen in Privathaushalten [Inter-net]. 2012 "Swiss Federal Office of Statistics. The functional health of oder people (Iiving)in private homes." [cited 2014 Oct 17].Available from:http://www.bfs.admin.ch/bfs/portal/de/index/ dienstleistungen/publikationen statistik/publikationskatalog.html?publicationID=5687

37 Perrig-Chiello P, Hutchison S, Höpflinger F. AgeCare-Suisse Latine: Pflegende Angehörige in de ateinischen und deutschsprachigen Schweiz. Forschungsbericht Spitex-Schweiz. [Internet]. 2011 "Family caregivers in the French-, Italian- and German-speaking regions of Switzerland. Research report from Spitex-Switzerland." [cited 2014 Mar 3]. Available from: http://upload.sitesystem.ch/ B2DBB48B7E/0CDC636B60/FDAB600C70.pdf.

38 Puntillo KA, Arai S, Cohen NH, Gropper MA, Neuhaus J, Paul SM, Miaskowski C. Symptoms experìenced by intensive care unit patients at high risk of dying. Crit Care Med. 2010;38(11):2155-60.

39 Menaker J, Scalea TM. Geriatric care in the surgical intensive care unit. Crit Care Med. 2010;38 (9 Suppl):S452-9.

40 McDermid RC, Stelfox HT, Bagshaw SM. Frailty in the critically ill: a novel concept. Crit Care. 2011;15(1):301.

41 Duke GJ, Barker A, Knott Cl, Santamaria JD. Outcomes of older people receiving intensive care in Victoria. Med J Aust. 2014;200(6):323-6

42 Bagshaw SM, McDermid RC. The role of frailty in outcomes from critical illness. Curr Opin Crit Care. 2013;19(5):496-503.

43 Gerbershagen HJ. Transition from acute to chronic postsurgical pain. Physiology, risk factors and prevention. Schmerz. 2013;27(1):81-93.

44 Montuclard L, Garrouste-Orgeas M, Timsit JF, Misset B, De Jonghe B, Carlet J. Outcome, functional autonomy, and quality of life of elderly patients with a long-term intensive care unit stay. Crit Care Med. 2000;28(10):3389-95.

45 Chanques G, Jaber S, Barbotte E, Violet S, Sebbane M, Perrigault PF, Mann C, Lefrant JY, Eledjam JJ. Impact of systematic evaluation of pain and agitation in an intensive care unit. Crit Care Med. 2006;34(6):1691-9.

46 Battle CE, Lovett S, Hutchings H. Chronic pain in survivors of critical illness: a retrospective analy sis of incidence and risk factors. Crit Care. 2013;17(3):R101.

47 Granja C, Teixeira-Pinto A, Costa-Pereira A. Quality of life after intensive care-evaluation with EQ5D questionnaire. Intensive Care Med. 2002;28(7):898-907.

48 Kyranou M, Puntillo K. The transition from acute to chronic pain: might intensive care unit patients be at risk? Ann Intensive Care. 2012;2(1):36.

49 Hopkins RO, Key CW, Suchyta MR, Weaver LK, Orme JF Jr. Risk factors for depression and anxiety in survivors of acute respiratory distress syndrome. Gen Hosp Psychiatry. 2010;32(2):147-55.
50 Davydow DS, Gifford JM, Desai SV, Needham DM, Bienvenu OJ. Posttraumatic stress disorder in general intensive care unit survivors: a systematic review. Gen Hosp Psychiatry. 2008;30(5):421-34.

51 Rose L, Nonoyama M, Rezaie S, Fraser I. Psychological wellbeing, health-related quality of life and memories of intensive care and a specialised weaning centre reported by survivors of prolonged mechanical ventilation. Intensive Crit Care Nurs. 2014;30(3):145-51.

52 Jones C, Griffiths RD, Humphris G, Skirrow PM. Memory, delusions, and the development of acute posttraumatic stress disorder-related symptoms after intensive care. Crit Care Med. 2001;29(3):573-80

53 Kress JP, Gehlbach B, Lacy M, Pliskin N, PohIman AS, Hall JB. The long-term psychological effects of daily sedative interruption on critically ill patients. Am J Respir Crit Care Med. 2003;168(12) 1457-61.

54 Treggiari MM, Romand JA, Yanez ND, Deem SA, Goldberg J, Hudson L, Heidegger CP, Weiss NS. Randomized trial of light versus deep sedation on mental health after critical illness. Crit Care Med. 2009;37(9):2527-34.

55 Jaber S, Chanques G, Altairac C, Sebbane M, Vergne C, Perrigault PF, Eledjam JJ. A prospective study of agitation in a medical-surgical ICU: incidence, risk factors, and outcomes. Chest. 2005, 128(4):2749-57.

56 Szubski CR, Tellez A, Klika AK, Xu M, Kattan MW, Guzman JA, Barsoum WK. Predicting discharge to a long-term acute care hospital after admission to an intensive care unit. Am J Crit Care. 2014;23(4):e46-53.

57 Jeitziner MM, Massarotto P, Barandun U. Chronically Critical Illness - Symptombelastung und entsprechende Interventionen. "Chronically critical illness - Symptom burden and related interventions." Submitted to the Journal intensiv - Fachzeitschrift für Intensivpflege und Anästhesie.

58 Nelson JE, Cox CE, Hope AA, Carson SS. Chronic critical illness. Am J Respir Crit Care Med. 2010;182(4):446-54

59 Schwartz CE, Sprangers MA. Guidelines for improving the stringency of response shift research using the then test. Oual Life Res. 2010;19(4):455-64.

60 Barandun U. Die individuelle Lebensqualität älterer Menschen nach Aufenthalt auf einer Intensivstation. [Masterarbeit]. "The individual quality of life of older persons following a stay in an intensive care unit. [Master's Thesis]."The Netherlands: University of Maastricht; 2003. 


\section{Summary}

Increasing numbers of critically ill older patients with severe illnesses and injuries are hospitalized in intensive care units (ICUs) and survive to discharge. It has been found that being hospitalized for treatment in an ICU can be burdensome for both the older patients and their relatives. An increasing number of patients who survive the ICU stay will face the hardship of either a long-term critical illness or long-term pain and disability. Treatment of critically ill older patients during and after the ICU stay is complex, challenging, and often embroiled in controversy. Questions arise as to the risk of poor long-term consequences due to the challenges of co-morbidities and reduced physiological reserve. In addition, previous study results are inconclusive and raise the following questions: Do older patients profit from treatment in an ICU; and, if they survive the ICU stay, are they in a relatively good state of health?

The overall aim of this study was to identify how an ICU stay influences the older patients' experiences later in life. The long-term consequences examined were pain, anxiety, agitation, health-related quality of life (HROOL), and healthcare resource utilization. It is evident that there is a need for research on the benefits of intensive care treatment for critically ill older patients. This thesis entitled "Critically ill older patients treated in intensive care units: long-term consequences" is based on a prospective non-randomized longitudinal study of critically ill older patients and a comparison group of age-matched community-based participants. Study subjects were followed for one year and data collection took place at study recruitment, and 6 and 12 months.

Chapter 1 presents an overview of the demographic developments in the ICU, specifically looking at critically ill older patients, and describes the challenges confronting these patients during and after the ICU stay, and includes the main aims and the contents of the study.

Chapter 2 presents the results of the prospective observational study that examines pain patterns in critically ill older patients during the first 3 ICU days, and identifies differences between severely ill and moderately ill patients. One hundred forty-one critically ill older patients with a mean age of 69 years were recruited. This study shows that pain is relatively stable and consistent at a low level of intensity. Although levels of pain decreased steadily over the first 3 days of treatment in the ICU, there was substantial variation in individual pain patterns. More than half of the patients were admitted to the ICU because of cardiac diseases or cardiac surgery. Severely il patients were found to have relatively stable pain patterns, whereas those patients who were moderately ill tended to have fluctuations in pain. Most patients were treated with analgesia (98\%) and sedation (88\%), although most had a low level of sedation, allowing them to report pain.
Chapter 3 describes the design of the prospective non-randomized longitudinal study. Recruitment began in December 2008 and ended in April 2010. Data collection was completed in April 2011. The sample size calculation determined that 96 patients were needed for each group. To account for loss to follow-up, it was planned to recruit 150 subjects for each group. Due to the restrictions of the inclusion and exclusion criteria, 145 critically ill older patients and 146 participants for the comparison group were recruited. The critically ill older patients had medical as well as surgical ICU admission diagnoses and the comparison group had the normal illnesses of aging. Utilizing a comparison group facilitated the interpretation of the results. Baseline data were collected at study recruitment, which, for the critically ill older patients, was one week following ICU discharge. Follow-up data collection took place at 6 and 12 months after hospital discharge. The participants in the comparison group were interviewed at study begin, and data collection continued 6 and 12 months later. Valid and reliable assessment instruments were used to measure the outcomes. Pain and anxiety were assessed with a numerical rating scale (NRS) during the ICU stay and at follow-up. Agitation during the ICU stay was assessed with the Richmond AgitationSedation Scale (RASS) and the NRS was used during the follow-up data collection period. HROoL was measured with the Short Form Health Survey 36 (SF-36). The SF-36 consists of 8 dimensions that are consolidated into two overal dimensions: physical and mental health scores. In addition, the following aspects of healthcare resource utilization were examined: length of stay, (re)admission to hospital or ICU, general practitioner and medical specialist visits, rehabilitation program participation, medication use, discharge destination, home healthcare service use, and level of dependence for activities of daily living. Data collection methods included face-to-face and telephone interviews and questionnaires sent by post. Challenges associated with conducting this longitudinal study are discussed at the end of Chapter 3.

Chapter 4 examines long-term pain, anxiety, and agitation in critically ill older patients up to 12 months after an ICU stay. This is the first part of the prospective nonrandomized longitudinal study of long-term consequences following an ICU stay. This study positively shows that an ICU stay is not associated with persistent pain anxiety, and agitation in critically ill older patients one year after ICU stay. Pain, anxiety, and agitation were found to be low throughout the follow-up period. One week following ICU discharge, pain and anxiety were significantly higher than in the comparison group, but there was no difference in agitation. No differences were found in pain, anxiety or agitation at the 6 and 12 month follow-up. The pre-ICU and ICU related factors associated with persistent pain after 12 months were: pain prior to the ICU and pain during the ICU stay. Surgery during the ICU, pain during the ICU and higher doses of sedatives were associated with pain one week after the ICU stay. No significant associations were found between pain and length of ICU stay or the presence of co-morbidities. 
Chapter 5 discusses the association of an ICU stay and the HROoL of critically ill older patients up to 12 months following an ICU stay. This second part of the non-randomized longitudinal study highlights that critically ill older patients report an overal good and stable HROoL one year following an ICU stay, although the HROoL was significantly lower than the comparison group in both physical and mental health scores throughout all assessment periods. These differences already existed prior to the ICU stay. The critically ill older patients had individual variability in the HROoL scores; but not the participants in the comparison group. Disease-related factors such as renal failure, cardiac surgery and a high illness severity were associated with lower physical health scores, and in addition to the disease-related factors, nursing interventions such as intratracheal suctioning and turning were associated with persistently lower mental health scores. There were no associations found between HRQOL and length of stay, pain, anxiety or agitation during the ICU stay.

Chapter 6 examines the relationship between an ICU stay and healthcare resource utilization one year following discharge from the ICU. This study represents the third part of the non-randomized longitudinal study. We found that the use of healthcare resources by critically ill older patients is not excessive, although they used more resources than the participants in the comparison group. Compared to the community-based participants, critically ill older patients visited their GPs 6 times more frequently, $76 \%$ attended rehabilitation programs whereas no comparison group participants attended rehabilitation programs, and 50\% more took medications. Positive outcomes of the study were that almost no critically ill older patients were readmitted to an ICU, hospital, nursing home or acute care hospital, all of which are very cost-intensive institutions, while $13 \%$ of the community-based participants had hospital admissions. In addition, $97 \%$ of all patients and all participants still lived at home at the end of one year.

Chapter 7 presents the main findings of the study, and focuses on methodological and theoretical considerations, and concludes with recommendations for clinical practice and future research.

In summary, this study shows that critically ill older patients return to a good level of functioning one year following an ICU stay. They do not have long-term pain, anxiety or agitation, report a good HRQoL, and do not require treatment in cost-intensive institutions. However, one caveat remains: The management of older patients during and after an ICU stay is a complex issue that needs to be continuously evaluated due to new developments in medicine, nursing, and healthcare technology. Much of the responsibility and duties in caring for critically ill older patients belongs to nurses who need to be prepared to accept the challenges, including evaluating the treatments and the long-term consequences.

\section{Samenvatting}

Oudere patiënten op de Intensive Care: gevolgen op lange termijn

Steeds meer oudere patiënten met ernstige aandoeningen of letsels worden opgenomen op een Intensive Care (IC) afdeling. Door de goede intensieve zorg zijn de overlevingskansen hoog. Studies tonen aan dat de opname op de IC voor patiënten en hun familie belastend zijn kan en resulteert niet in altijd in een volledig herstel. Een steeds groeiend aantal overlevenden hebben na ontslag te maken met pijn en andere gezondheidsklachten. De behandeling van ernstig zieke oudere patiënten tijdens en na de IC-afdeling is complex, een uitdaging en vaak verbonden met controverse discussies. Vragen zijn bijvoorbeeld het risico op gevolgen op lange termijn door een opname vanwege co-morbiditeiten en gereduceerde lichamelijke reserves. Bovendien zijn resultaten van eerdere studies niet eenduidig en roepen volgende vragen op: profiteren oudere patiënten van een behandeling op een IC; en zijn zij in een relatief goede gezondheidstoestand indien zij deze overleven?

Deze thesis richt zich dan ook op de gevolgen op lange termijn voor oudere patiënten die een opname op de Intensive Care ondergaan. Meer specifiek wordt er gekeken naar de gevolgen van een opname op lange termijn op uitkomsten zoals pijn, angst, agitatie, gezondheidsgerelateerde kwaliteit van leven en gebruik van gezondheidszorgvoorzieningen en middelen. $\mathrm{Er}$ is behoefte aan onderzoek naar de voordelen van een behandeling op de IC voor ernstig zieke oudere patiënten. Deze thesis met als titel "Critically ill older patients treated in intensive care units: long-term consequences” baseert op een prospectieve niet-gerandomiseerde longitudinale studie waarin ernstig zieke oudere deelnemers werden vergeleken met een groep van mensen uit de bevolking met een verglijkbare leeftijd. De deelnemers werden gedurende een jaar gevolgd en de verzameling van data vond op volgende tijdspunten plaats: start van de studie, na 6 en 12 maanden.

In hoofdstuk 1 wordt achtergrondinformatie gegeven over demografische ontwikkelingen in de zorg voor oudere patiënten op de Intensive Care. De uitdagingen waarmee deze patiënten tijdens en na hun verblijf op de IC worden geconfronteerd worden beschreven. Aan het einde van hoofdstuk 1 worden de doelstellingen en de opbouw van de thesis gepresenteerd.

Hoofdstuk 2 beschrijft de uitkomsten van een prospectieve empirische studie. Deze studie richt zich op verloop van pijn (patroon) van oudere patiënten tijdens de eerste $3 \mathrm{da}$ gen van hun verblijf op de IC. Daarnaast worden de verschillen beschreven tussen de patronen van ernstig zieke versus minder ernstig zieke IC patiënten. In totaal werden 141 oudere IC patiënten geïncludeerd met een gemiddelde leeftijd van 69 jaar. Meer dan de helft van de patiënten was vanwege een cardiologische aandoening of voor een cardio- 
chirurgische ingreep op de IC opgenomen. De meeste patiënten kregen analgetica (98\%) en sedatie (88\%) toegediend. De resultaten tonen aan dat de pijnintensiteit relatief stabiel, consistent en laag was gedurende deze eerste 3 dagen. Desalniettemin variëren de pijnpatronen tussen patiënten in sterke mate. Ernstig zieke patiënten toonden relatief stabiele pijnpatronen in vergelijking met minder ernstig zieke patiënten.

Hoofdstuk 3 beschrijft het design van de prospectieve longitudinale studie. De inclusie vond plaats van December 2008 tot April 2011. De berekening van de grootte van de groepen bepaalde dat in elke groep 96 patiënten benodigd werden. Doel was om 150 oudere IC patiënten en 150 deelnemers in de vergelijkingsgroep te includeren om ondanks verlies tijdens follow-up voldoende patiënten te hebben. Vanwege de restricties van inclusie en exclusie criteria werden 145 ernstig zieke oudere patiënten en 146 deelnemers voor de vergelijkingsgroep gerekruteerd. Oudere patiënten konden voor medische of chirurgische problemen op de IC zijn opgenomen. De vergelijkingsgroep bestond uit deelnemers met normale ouderdomsklachten. Data werden verzameld op baseline (bij de oudere IC patiënt een week na het verblijf op de IC). De follow-up gegevens werden 6 en 12 maanden na ontslag uit het ziekenhuis verzameld. Valide en betrouwbare meet instrumenten werden gebruikt. Zo werd pijn en angst met een numerieke schaal (NRS) gemeten tijdens verblijf op de IC afdeling en tijdens de vervolgmetingen. De RichmondAgitation-Sedation-Scale (RASS) werd gebruikt om de mate van agitatie van patiënten tijdens hun verblijf op de IC te beoordeelden. Agitatie tijdens de follow-up werd gemeten met een NRS. Gezondheidsgerelateerde kwaliteit van leven werd bepaald met behulp van de Short Form Health Survey 36 (SF-36). De schaal omvat 8 dimensies van fysieke en psychische gezondheid. Zorggebruik (voorzieningen en middelen) werden in kaart gebracht. Hierbij werd specifiek gekeken naar: verblijfsduur op de IC en verblijfsduur in het ziekenhuis, heropnames, aantal bezoeken aan de huisarts of specialist, deelname aan revalidatieprogramma, medicatiegebruik, woonbestemming na ontslag, aanvullende hulpverlening (wijkverpleging etc.) en de mate van ondersteuning door anderen bij het uitvoeren van dagelijkse activiteiten. De data werden verzameld tijdens interviews waarbij de vragenlijsten werden afgenomen. Hoofdstuk 3 besluit met een discussie over de mogelijke uitdagingen bij het uitvoeren van voorgestelde longitudinale studie.

Hoofdstuk 4 beschrijft de lange termijn consequenties (12 maanden na ontslag) van een IC opname op pijn, angst en agitatie. Dit is het eerste gedeelte van de prospectieve nietgerandomizeerde longitudinale studie over de consequenties na een verblijf op een IC op lange termijn. Bevindingen tonen aan dat een verblijf op de IC afdeling een jaar later niet resulteert in meer pijn, angst en agitatie. De mate van pijn, angst en agitatie waren zee gering tijdens de 12 maanden na ontslag. Patiënten rapporteerden een week na opname wel meer pijn en angst in vergelijking met de deelnemers uit de vergelijkingsgroep. Echter 6 en 12 maanden later was de mate van angst in beide groepen gelijk. Agitatie was in beide groepen vergelijkbaar en slechts in zeer geringe mate aanwezig. Pijn na 12 maanden vertoonde een samenhang met de aanwezigheid van pijn voor en tijdens opname op de IC afdeling. Chirurgische ingrepen, aanwezigheid van pijn tijdens opname en hogere doseringen aan sedativa vertoonde een samenhang met de aanwezigheid van pijn in de eerste week opname. Er werd geen significante correlatie gevonden tussen pijn, de verblijfsduur op de IC of co-morbiditeiten.

Hoofdstuk 5 beschrijft de invloed van opname op de IC op de kwaliteit van leven van de oudere patiënten, 12 maanden na verlijf op de IC. Resulaten van dit tweede gedeelte van de studie tonen aan dat de levenskwaliteit van patiënten na 12 maanden over het algemeen goed en stabiel is. Metingen na 6 en 12 maanden toonden echter wel dat de gerapporteerde kwaliteit van leven van de oudere IC patiënten in vergelijking met de deelnemers uit de vergelijkingsgroep significant lager was. De verschillen waren echter al bij opname aanwezig. Daarnaast waren er sterke individuele verschillen in de gerapporteerde kwaliteit van leven. Nieraandoeningen, cardio-chirurgische ingrepen of een ernstigere ziekte correleerden met een lager gerapporteerde fysische gezondheid na 12 maanden. Daarnaast werd er een samenhang gevonden tussen verpleegkundige interventies (zoals o.a. intratracheal uitzuigen of veranderen van positie) en een verminderde psychische gezondheid na 12 maanden. Er kon geen samenhang tussen de gezondheidsgerelateerde kwaliteit van leven en de verblijfsduur, pijn, angst of agitatie tijdens het verblijf op de IC aangetoond worden.

Hoofdstuk 6 onderzoekt de samenhang tussen opname op de IC en het zorggebruik (middelen of voorzieningen) in de 12 maanden na verblijf op de IC. Resultaten tonen aan dat voormalige IC patiënten niet overmatig veel gebruik maken van zorgvoorzieningen Desondanks maken ze meer gebruik van zorgvoorzieningen. Zo gaan ze 6 keer vaker naar hun huisarts, nemen vaker deel aan revalidatie programma's (76\% van de oudere patiënten tegenover $0 \%$ in de controlegroep) en de helft van hun nemen meer medicatie in. Positief is dat maar weinig oudere patiënten na verloop van tijd worden heropgenomen in het ziekenhuis. De meeste oudere patiënten uit de IC groep (97\%) woonden 12 maanden na opname nog steeds zelfstandig thuis.

De algemene discussie in hoofdstuk 7 beschrijft de meest belangrijke resultaten van dit proefschrift en besluit met een methodologische en theoretische discussie. Er worden aanbevelingen voor de klinische praktijk en toekomstige studies geformuleerd.

Samenvattend kan worden geconcludeerd dat oudere patiënten na opname op de IC geen pijn, angst of agitatie op lange termijn rapporteren. Ze rapporteren een goede kwaliteit van leven en maken geen gebruik van kostbare gezondheidsvoorzieningen na hun verblijf op de Intensive Care afdeling. Desondanks kan worden gesteld dat de behandeling van oudere patiënten op de Intensive Care een complexe aangelegenheid is die continu dient te worden geëvalueerd door de nieuwe ontwikkelingen in de geneeskunde, verpleging en zorgtechnologie. Veel van de zorg voor de ernstig zieke oudere patiënt ligt in de verantwoordelijkheid en plicht van verpleegkundigen. Zij moeten voorbereid zijn op de uitdagingen in de zorg inclusief de evaluatie van de behandeling en de gevolgen op lange termijn 


\section{Acknowledgements}

Without the great support of many individuals, this study could not have been carried out. First of all, I would like to thank the critically ill older patients who shared their experiences of the intensive care unit (ICU) stay. Although their stay was coupled with life-threatening illnesses, serious accidents or major surgical procedures, they showed an enormous willingness to participate in this study. The participants of the comparison group have also earned a heartfelt thanks for sharing information and for their perseverance with this longitudinal study.

My deepest gratitude goes to my supervisor, Prof. Dr. Jan Hamers, who has guided me with competence and helpfulness throughout the years of working on my thesis Through your professional expertise, ability to bring various perspectives, motivating discourses and constructive ideas, I have broadened my knowledge in the area of research. My visits to Maastricht were special "learning" moments that I will never for get. Thank you so much, dear Jan, for this wonderful chance that you have given me.

Dr. Sandra Zwakhalen, my co-supervisor, with your professional, personal and competent support, you have been a wonderful help to me. Your meticulous, dedicated and clear feedback gave me the structure I needed for my thesis. For all of this - a sincere thank you. Jan and Sandra, you have enriched my thesis and accompanied me on a long and not always easy path.

I also wish to express special thanks to Dr. Virpi Hantikainen, my second co-supervisor who gave close support and guidance throughout the thesis study process.

I would also like to thank all of the members of the Department of Intensive Care Medicine of the Bern University Hospital (Inselspital) for their support. Without the permission of Prof. Dr. med Jukka Takala, Director and Chief Medical Director of the Department of Intensive Care Medicine, I would not have had access to the ICU patients. Matthias Theis, Nursing Director of the ICU, thank you for organizing my schedule so that I could work on this thesis. I would also like to thank Prof. Dr. med Stephan Jakob, Medical Director of the Intermediate Care (IMC), for your expert input into this study. Brigitte Hämmerli, Nursing Director of the IMC, provided spontaneous support in so many situations. Prof. Dr. med Hans-Ueli Rothen, thank you for your expertise and advice on literature and information relevant to my research. And last but not least, a sincere thank you to the nursing staff of the ICU department who have enriched this study, and who care for critically ill patients and accompany them on their way to healing. I am impressed by your professionalism, your keen observations in the clinical situation and perceptions of the slightest changes in the patients. After the ICU stay, the patients were transferred to 12 different departments within the Inselspital, where I was permitted to continue the interviews; thank you for this access.
Naturally, I would like to thank the team of ICU clinical nurse specialists: Ottilia Rohrer, I am especially grateful for your involvement in formulating the research proposal, data collection and control, help in organizing the necessary time for the research and in solving all kinds of problems and for your motivation and "perseverance" in good and less good moments. I will always be grateful for your human kindness, professional and social support. Irene Warmuth, thank you for helping with the study, the supportive words and strong coffee in times of stress. Beatrice Jenni Moser, thank you for your support during the final phases of this thesis. All together, you are a great team. In addition, I want to thank Ruth Hartmann, Head of Operations of the ICU: thank for your special assistance during the past years Not only did you always have an open ear and understanding words, but were also able to identify needed resources. Christine Dysli, Head of Operations at the Inselspital ICU, thank you for your support of nursing research and development. Sandra Koch, critical care nurse, your enormous assistance in collecting and organizing the data was essential to my work.

Reto Bürgin was my statistical expert and showed praiseworthy stamina over the years. You helped me understand the statistical analyses and provided insights into the magical world of statistics. I would like to thank you and show my great respect for your work, without which this thesis would not be what it is today. Thank you, too, Sina Rüger, for the help you provided with the statistics.

The Department of Nursing Development and Research of the Bern University Hospital (Inselspital) provided the financial support for this thesis, and therefore I want to thank Luzia Herrmann, head of the department for organizing the financial support. Dr. Elisabeth Spichiger, also from the Department of Nursing Development and Research, provided important feedback on writing the thesis.

Marcia Leventhal provided support, not only with the English but also through her nursing competence and knowledge, and her questions helped me to move forward. A huge thank you for your timely work. Many thanks go to Linda Bolzern for her coaching and encouragement in English over the past years.

A special thank you is also for Prof. Dr. Mary-Beth Happ and Prof. Dr. Celia Wills for organizing and supporting my stay at Ohio State University. You created an environment for me where I could delve totally into my thesis. You provided me with feedback and enabled me to learn so much. It was a wonderful time for me.

Daniela Pfaffen solved the computer problems and helped with formatting. Simone Streit, thank you for your many ideas about the design and layout; our discussions were inspiring. 
I would also like to thank Madeleine Rytz, Elisabeth Ochsner, Andrea Brenner, Antoinette Conca, Eliane Gugler, Monika Fliedner, Yvonne Walker and Antonie Haut. Our innumerable discussions about positive and negative experiences were essential for this study.

My special thanks go to Brigitte Seuser and Oda Machemer, for their unfailing support in the past years. THANK YOU.

And finally a word of thanks to my mother, "Danke für deine Unterstützung in meinem ganzen Leben. Durch dich habe ich gelernt durchzuhalten, ein Ziel im Auge zu haben im Wissen, dass es immer einen Weg gibt. Du weisst, was es heisst alt zu sein und krank - du bist für mich eine Inspiration zu dieser Studie gewesen und kennst die Bedürfnisse älterer Menschen. Danke." Thank you for your support in my ife. Through your guidance I have learned to persevere, and to keep a goal in mind in the knowledge that there will always be a way. You know what it means to be old and sick-you were my inspiration for my studies and you represent the needs of older persons. With my heart, I thank you.

\section{Curriculum vitae}

Marie-Madlen Jeitziner was born in Ferden, Switzerland, on July 11, 1968. She completed her first healthcare training as a caregiver for children in 1988. Following this initial training, she pursued an education in nursing, which she completed in 1991 After one year of work experience in an acute surgical ward, she completed further training to be a Critical Care Nurse. She worked as a Critical Care Nurse in the interdisciplinary intensive care unit (ICU) of the University Hospital of Bern for the next five years. In 2001 she received certification as a clinical nurse specialist and worked in the clinical training of critical care nurses in the ICU. She earned her Master's Degree in Nursing Science in 2006 from the University of Maastricht, Berlin, and the University of Applied Science in Aarau, Switzerland. Since 2006 she has been working as a clinical nurse specialist and in clinical nursing in the interdisciplinary ICU in the University Hospital of Bern. In 2008 she began her PhD studies at the University of Maastricht. In 2014 she had the opportunity to spend a month at Ohio State University in Columbus at the Center of Excellence in Critical Care and Complex Care where she gained insight into research and practice development. She was awarded the fifth Bernese nursing prize for outstanding research for her PhD study.

In her role as clinical nurse specialist, she is responsible for nursing research and development in the ICU of the University Hospital of Bern. Currently she is researching the long-term consequences for critically ill patients who have been treated in an $\mathrm{ICU}$, and the interventions that positively influence the long-term consequences.

Marie-Madlen Jeitziner is a member of the Working Group for Clinical Nursing Development of the Swiss Society of Intensive Care Medicine. 


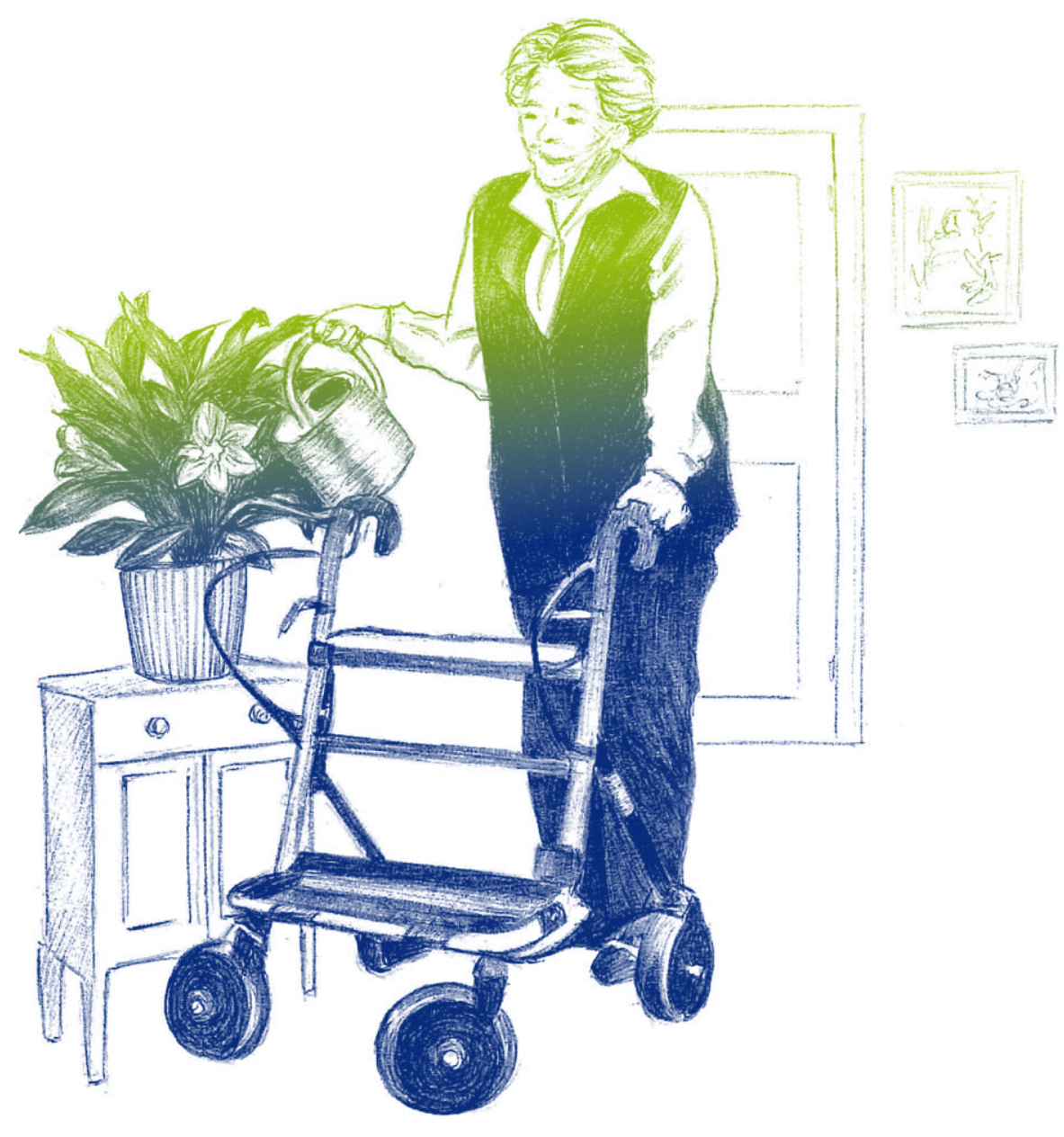




\section{Valorization}

The demographic structure of the industrialized world is shifting towards a higher proportion of older people with longer life expectancies. As a result of this demographic shift, the number of hospitalizations of older patients with acute critical illnesses in intensive care units (ICU) is also predicted to increase. The case-mix of the patients treated in ICUs is also changing toward increasing numbers of patients with cardiogenic shock and acute exacerbations of chronic obstructive pulmonary disease. Advances in medicine, nursing, and new technologies have improved the survival rates for older patients with life-threatening illnesses or accidents, while at the same time presenting new challenges for the healthcare team. The older patients are particularly vulnerable due to their critical illnesses, agerelated physical and mental changes, multiple comorbidities, and the effect of the hospital environment. In addition, therapeutic interventions may be stressful for the critically ill older patients, and distressing for their family members.

The discussions on the skyrocketing costs of healthcare accentuate the challenges in treating critically ill multi-morbid older patients who require complex care. Questions arise such as: How stressful and painful are intensive care therapies? What ong-term complications or consequences might be expected? How is the quality of life affected after an ICU stay?

Results of evaluations of long-term consequences for critically ill older patients following an ICU stay are increasingly significant. The previously accepted narrow focus on mortality data does not provide answers to the current questions arising from patients, family members, healthcare professionals, clinicians, researchers, administrators, health maintenance organizations, and government policy makers. Understanding long-term consequences such as pain, anxiety, agitation, health-related quality of life (HROOL) and healthcare resource utilization will provide a starting point for goal-oriented treatment strategies that commence during the ICU stay. The overall aim of this thesis was to identify how an ICU stay influences the older patients' experiences later in life. The long-term consequences examined were: pain anxiety, agitation, HROoL and healthcare resource utilization. The choice of these ong-term consequences is meaningful because they provide information on the burden from an ICU stay and express the nonclinical qualitative effects of the newest developments in medical, nursing and technology, and reflect the level of care and treatment necessary following an ICU stay.

\section{Population and Patients}

The results of this study show that critically ill older patients have good long-term quality of life following an ICU stay. This is important to help older patients and families cope with the uncertainties, decisions and fear that accompany an ICU stay.

The general population needs to be aware that receiving the appropriate level of care at the right time and at the right place can improve the health of older patients and relieve their suffering. They need to know that the ICU is available and useful for al age groups, even in times of limited economic resources. Given the right situation, intensive care medicine can allow the critically ill older patients the chance to return to a satisfactory life. The goal of intensive care must be that the older patients will be able to live at home as long as possible, if necessary, with formal and or informal care.

\section{Interdisciplinary Care}

The collective expertise of an interdisciplinary healthcare team consisting of nurses, physicians and specific therapists is essential for the survival of critically ill older patients. The teams work under extreme stress und burdens due to the constantly changing situations. Caring for critically ill older patients may raise ethical conflicts and or problems. The autonomy and integrity of the older patients may be at risk. The lack of feedback regarding the recovery process influences the motivation to care for the older patients and raises questions as to the meaning and purpose of intensive care treatment. Healthcare teams can find motivation through an understanding of the long-term consequences of an ICU stay.

Standardized routine interventions during the initial life-threatening phase in intensive care are essential. However, once this initial phase passes, care for the older patient needs further definition. The frequency of interventions such as intratracheal suctioning or positioning must be individually determined according to need rather than routine. Specific services following hospital discharge, such as rehabilitation or follow-up care by the family physician, should be designed to allow patients and their families to live their everyday life as independently as possible. The present study provides evidence that individually coordinated interventions and services are important during the patient's further process of recovery. 


\section{Organizational Support and Hospital Leadership}

Hospital-wide strategies are needed to care for the increasing number of critically ill older patients who are being hospitalized. Hospital management must initiate strategies and processes that offer age-appropriate hospital care in terms of "senior friendly hospitals." This would promote positive attitudes towards older patients and their caregivers; build appropriate communication strategies; ensure respectful treatment of older patients and their families; develop policies and evidence-based guidelines; cooperate with interface institutions; and develop structures, equipment, and facilities to provide an environment that takes the vulnerabilities of older patients into consideration.

CUs in particular are in need of change in order to find a balance between the highly vulnerable older patients and the ICU environment with its technical equipment, noise, stressors and rotating personnel.

A better understanding of the needs of older patients, family members, and the members of the interdisciplinary healthcare team in the ICU is critical. ICUs of the future will be designed with customized rooms with integrated areas for families, specially selected colouring, lighting and noise reduction, and easy accessibility. A workplace for the healthcare team with educational opportunities should be the standard in future ICUs. Innovative treatment models will allow continuity and communication, for example using mobile healthcare teams, and involving consultation with advance practice nurses.

Cooperation and Collaboration with Healthcare Service Providers

The greater complexity of care required for the critically ill older patients complicates hospital discharge. Physical, social and functional stress factors present additional challenges when transferring patients out of the ICU or to other care facilities. Older patients need healthcare services that can be individualized during their recovery period. Healthcare services, rehabilitation institutions and general practitioners must coordinate their services, increase access by informing the public of these services, and assure that the services offered are age-appropriate. To build an optimally balanced program, providers need training and knowledge of the needs of older patients and their families. Furthermore, medical and technical developments such as digitalization, virtualization and automated feedback systems will influence care provision Examples are the tele-medicine and tele-nursing programs. Nursing will assume new responsibilities in coordination and communication among the various healthcare providers, as in case management, thereby reducing further stress for the older patients (i.e., stress resulting from frequent physicians and medical specialist visits).

\section{Educational Challenges}

Well-trained nurses and physicians in the ICU can positively influence the long-term consequences for older patients. It is clear that the traditional distribution of responsibilities between nurses and physicians should be critically and constructively examined and redefined. A need exists for continuing education courses in gerontology including aging, frailty, the rapidly changing societal realities, dealing with the challenges confronting the older patients and their families, and the concrete healthcare resources including legal, technical and financial issues. An important tool will be interdisciplinary case discussions and clinical supervision. These services will not only ensure professionalism but will also enhance the expertise in working with older patients.

\section{Political Aspects}

Governmental and regulatory organizations must recognize their responsibility for the critically ill older patients by providing the necessary resources, monitoring and regulating service contracts with healthcare providers, developing national guidelines for the care of older patients and supporting initiatives for "senior friendly hospitals" and innovative care models. It is important that healthcare policy makers accept their responsibility in the care of the older patients. Sustainable and needsbased health care for older patients should be implemented with binding and comprehensive guidelines, from financial security for long-term care to end of life care. In this respect, concepts can be developed based on research of relevant clinical practices and experiences gained in cooperation with older patients, families, interdisciplinary healthcare teams and politicians. 


\section{CAPHRI}

The Research presented in this thesis was conducted at the School of Public Health and Primary Care; CAPHRI, Departement Health Sciences Research, of Maastricht University. CAPHRI participates in the Netherlands School of Primary Care Research CaRe. CAPHRI was classified as 'ecxellent' by the external evaluation committee of leading international experts that reviewed CAPHRI in December 2010 
